\title{
MICRO ELECTROSTATIC ACTUATION OF A SILICON DIAPHRAGM
}

\author{
A Thesis \\ presented to \\ the Faculty of California Polytechnic State University, \\ San Luis Obispo
}

\author{
In Partial Fulfillment \\ Of the Requirements for the Degree \\ Master of Science in Biomedical Engineering
}

by

Matthew W. Samples

June 2015 
(C) 2015

Matthew W. Samples

ALL RIGHTS RESERVED 


\section{COMMITTEE MEMBERSHIP}

TITLE:

AUTHOR:

DATE SUBMITTED:
Micro Electrostatic Actuation of a Silicon Diaphragm

Matthew W. Samples

June 2015

COMMITTEE CHAIR: Richard Savage, Ph.D.

Biomedical Engineering Department Chair

COMMITTEE MEMBER: David Clague, Ph.D.

Associate Professor of Biomedical Engineering

COMMITTEE MEMBER: Hans Mayer, MS

Lecturer of Biomedical Engineering 


\section{ABSTRACT \\ Micro Electrostatic Actuation of a Silicon Diaphragm \\ Matthew W. Samples}

There are a number of applications, from hearing aids to microfluidic pumps, which utilize micro-scale actuating diaphragms. These MEMS (micro-electromechanical system) devices can be actuated by electrostatic forces, which utilize an induced electric field to pull two charged plates towards one another. Such devices were fabricated and electrostatic actuation of the diaphragms was performed to analyze its viability as a micro-speaker. The long-term performance of such products requires adequate diaphragm deflection to create audible pressure waves with relatively low maximum stresses to ensure a high cycle fatigue life. With these requirements, initial calculations and FEA (finite element analysis) were performed to establish the optimal square diaphragm side length combined with an attainable gap between electrodes to achieve an audible response. Optical and acoustic testing was then performed on 4, 5, and $7 \mathrm{~mm}$ side length square diaphragms with $10 \mu \mathrm{m}$ thickness and a $70 \mu \mathrm{m}$ electrode gap. For the $5 \mathrm{~mm}$ device and a $300 \mathrm{~V}$ applied potential, deflection was calculated to be $4.12 \mu \mathrm{m}$ theoretically and $3.82 \mu \mathrm{m}$ using FEA, although deflections based on optical test data averaged $30.53 \mu \mathrm{m}$ under DC conditions. The DAQ used for optical testing was extremely limiting due to its fastest sampling interval of 89 milliseconds, so this testing was performed at 2 and $5 \mathrm{~Hz}$. Although the $7 \mathrm{~mm}$ device generated audible noise at 300 $\mathrm{V}$ and $2 \mathrm{kHz}$ when the observer was within approximately 6 inches of the device, acoustic testing with a microphone placed 1 inch from the device did not yield any definitive results. 


\section{ACKNOWLEDGMENTS}

A number of individuals contributed insight, prior work, advice, and support throughout the past year of work on this project. I would like to thank my advisor, Dr. Savage, for his guidance throughout the project. I thank Dr. Savage and Hans Mayer for keeping the microfabrication lab and its equipment operational for the duration of the project. Also, I thank Ross Gregoriev for his contribution of the MEMS driver and for assisting with its implementation. Evan Cate has made the valuable contribution of silicon diaphragms of various sizes that enabled this project in the first place. Finally, I would like to thank my parents for their encouragement and financial support throughout the past five years of college. 


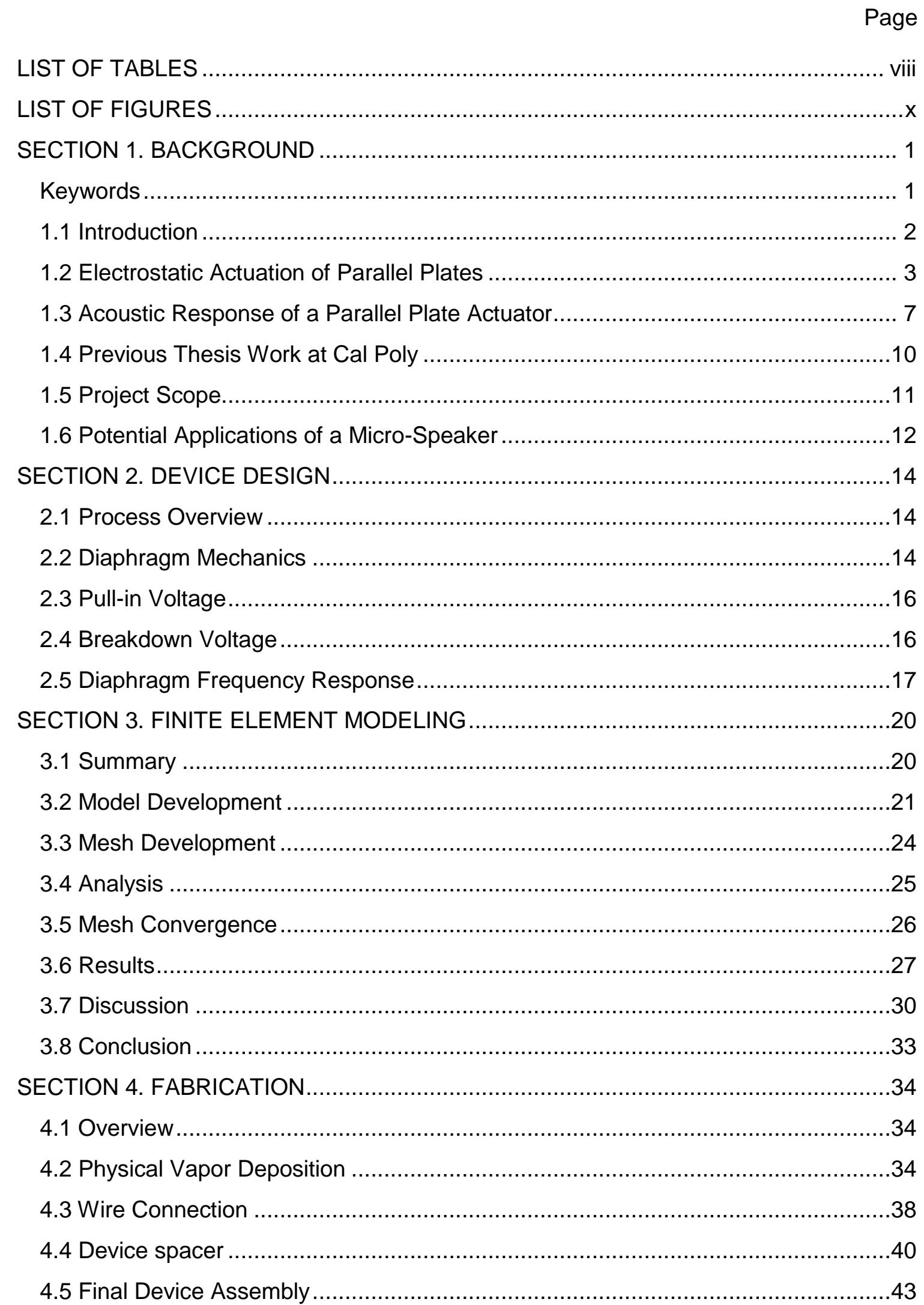




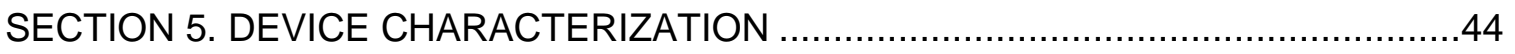

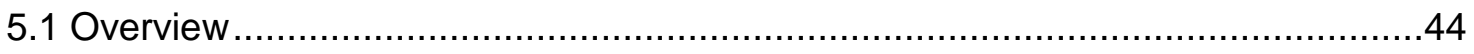







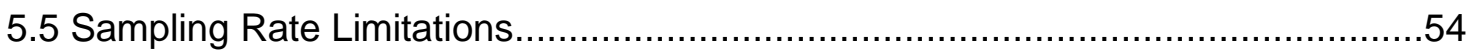

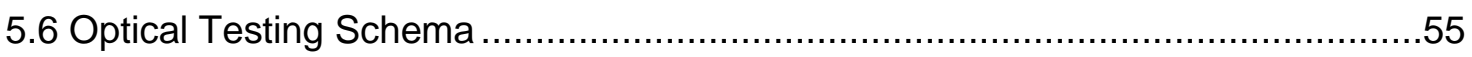



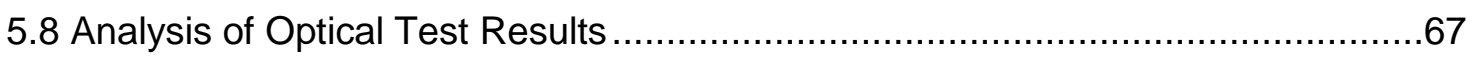

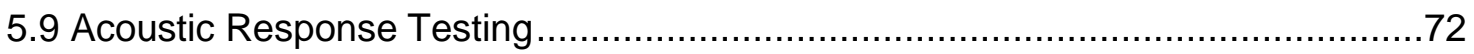

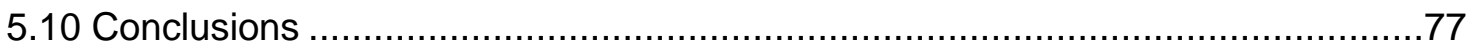

SECTION 6. RECOMMENDATIONS FOR FUTURE WORK ...................................79

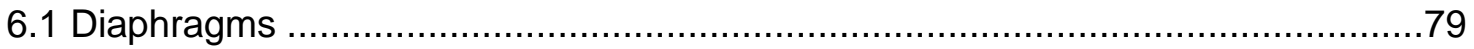

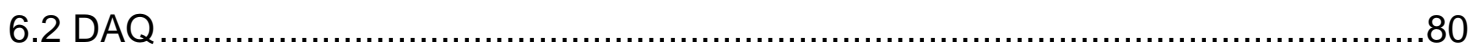

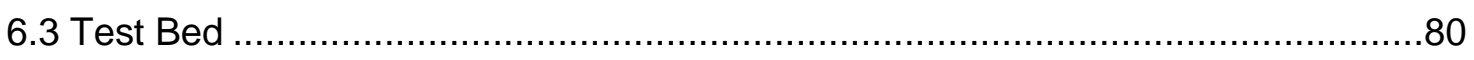



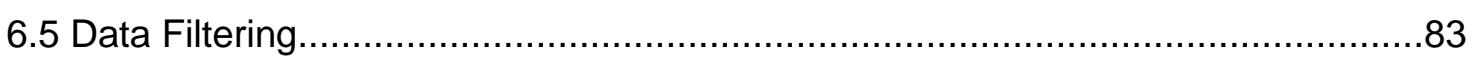

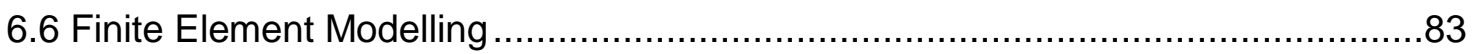

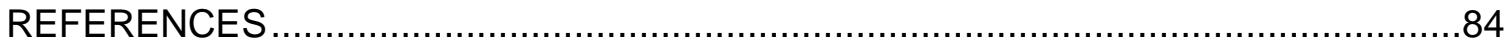

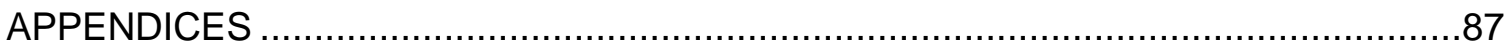

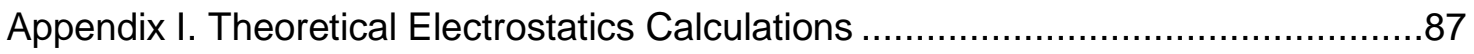

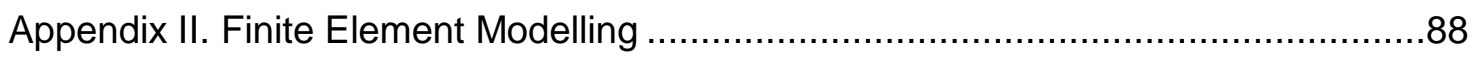

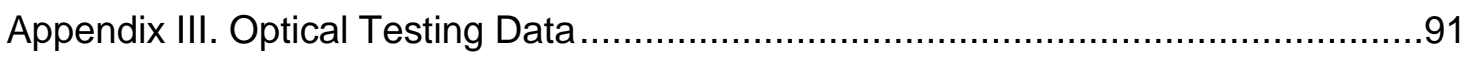




\section{LIST OF TABLES}

Page

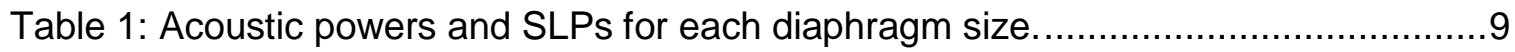

Table 2: List of material parameters used for diaphragm calculations..........................16

Table 3: Theoretical resonant frequencies of each available diaphragm size................19

Table 4: Material properties used for silver and silicon .......................................23

Table 5: Mesh convergence study results for the full $5 \mathrm{~mm} \times 5 \mathrm{~mm}$ model ...................27

Table 6: Stress and displacement summary for abbreviated $5 \mathrm{~mm}$ side length

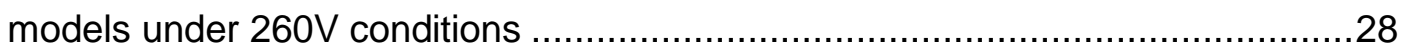

Table 7: Paired resonant frequency modes for the full and quarter model ....................28

Table 8: Results from higher pressure (81.21 Pa) application on a $5 \mathrm{~mm} \times 5 \mathrm{~mm}$ diaphragm quarter-model. ............................................................ 30

Table 9: Direct comparison of applicable FEA and hand calculation results..................30

Table 10: Torr CrC-150 and Denton V physical vapor deposition parameters................36

Table 11: Resistance measurements used for diaphragm RC time constant calculations 40

Table 12: Thickness values for double sided Kapton Tape obtained by 2 part profilometry method.

Table 13: The testing plan for all devices under dynamic loading .............................56

Table 14: The testing plan for all devices under static loading conditions ....................57

Table 15: Oscillation results immediately, 30 seconds, and 60 seconds after powering of $4 \mathrm{~mm}$ devices tested at 2 and $5 \mathrm{~Hz}, 260 \mathrm{~V}$.

Table 16: Oscillation results immediately, 30 seconds, and 60 seconds after powering of $5 \mathrm{~mm}$ devices tested at 2 and $5 \mathrm{~Hz}, 260 \mathrm{~V}$.

Table 17: Oscillation results immediately after powering the $7 \mathrm{~mm}$ devices at 2 and

$5 \mathrm{~Hz}, 260 \mathrm{~V}$ 
Table 18: Calculated initial diaphragm deflection during DC testing at $300 \mathrm{~V} \ldots \ldots \ldots \ldots \ldots . . . . .64$

Table 19: Paired t-tests were performed for both 5 and $7 \mathrm{~mm}$ devices to compare deflections at 260 and $300 \mathrm{~V}$ for each. 


\section{LIST OF FIGURES}

Page

Figure 1: SP80 Pressure sensor diagram

Figure 2: Representation of the balance of mechanical and electrostatic forces on a

parallel plate electrostatic actuator

Figure 3 (a): A family of curves dependent on voltage applied show the

electrostatic force on a parallel plate actuator, while the red line shows the linear relationship between displacement and mechanical restoring force. (b)

Example of the highest applied voltage possible before $\mathrm{V}_{\text {pull-in }}$ is reached, as seen by the tangent relationship between the electrostatic force curve and

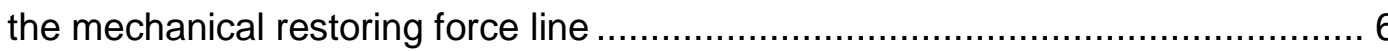

Figure 4: Range of human hearing can be seen as a function of frequency................. 9

Figure 5: A table displaying the sound pressure levels and intensities of various

noises. 10

Figure 6 (a): SOI wafer as received prior to diaphragm fabrication with a $10 \mu \mathrm{m}$ device layer, $6 \mu \mathrm{m}$ buried oxide, and $400 \mu \mathrm{m}$ handle side. (b) Photolithography mask used for diaphragm fabrication with red corresponding to $4 \mathrm{~mm}$ side length, green being $5 \mathrm{~mm}$, and blue being $7 \mathrm{~mm}$.

Figure 7: SolidWorks Exploded view of base electrode, double sided tape, and silicon diaphragm

Figure 8: Magnified view showing the 10 micron thick silicon diaphragm with 3000 angstrom silver layer

Figure 9: A view in Abaqus of the fixed edge boundary conditions and uniform

pressure loading conditions on the diaphragm. .23

Figure 10: Displacement convergence of the $5 \mathrm{~mm} \times 5 \mathrm{~mm}$ diaphragm model. .27 
Figure 11: Static $2.5 \mathrm{~mm} \times 2.5 \mathrm{~mm}$ quarter-model stress results under periodic loading at frequency $261 \mathrm{~Hz}$.

Figure 12: Dynamic quarter-model stress results at frequency $5564 \mathrm{~Hz}$. 32

Figure 13: The sputtering process as it occurs in the Denton V sputtering system in the Cal Poly microfabrication lab .35

Figure 14 (a): Laser cut sputtering masks made from 1/8" ABS and 1/4" acrylic. (b) Pyrex slide with a $\mathrm{Cr}$ then Au layer deposited as an electrode. 37

Figure 15: One gold sputtered and one chromium then gold sputtered Pyrex slide which have both undergone identical peel-off testing. The gold on chromium layer (right) displays good adhesion.

Figure 16: Continuity was established by taking resistance measurements between the base electrode and end of the epoxied wire. 39

Figure 17: Profilometer output when directly measuring thickness of double sided tape



Figure 19: GUI of the LabView program that controls the MEMS driver. .46

Figure 20: PSD Calibration test setup using a laser mounted on a precision linear stage to translate a laser across the PSD surface.

Figure 21: Channel 301 displays Voltage changes associated with horizontal translation of the laser across the PSD surface.

Figure 22: Complete testing setup for collection of PSD output during diaphragm actuation.

Figure 23: SolidWorks assembly of the testing setup with the AOI $\theta$ referring to the angle between the vertical and the HeNe laser beam. .50

Figure 24: Simplified figure used for calculating diaphragm deflection based on AOI and laser translation along PSD surface. 
Figure 25: Idealized plot of the change in PSD voltage from non-actuated baseline values as a function of horizontal distance across the DUT during AC actuation. .52

Figure 26: Diagram showing how the laser responds to device actuation based on the laser's point of incidence along the central horizontal axis of the diaphragm. .53

Figure 27: The HeNe laser is centered on the diaphragm using the horizontal and vertical fine adjustment knobs of the mounting assembly. .53

Figure 28: Demonstration of aliasing where the dashed line is the false lower frequency component being reconstructed from the solid line signal .54

Figure 29 (a): Full minute and 10 seconds of data collected for $7 \mathrm{~mm}$ device 2 at $300 \mathrm{~V} 2 \mathrm{~Hz}$. (b) Expanded view of first 20 seconds of data collection. (c) Expanded view of initial actuation data with a square outlining 4 oscillations in a 2 second period, which validates the $2 \mathrm{~Hz}$ driving frequency was achieved mechanically. .59

Figure 30 (a): $7 \mathrm{~mm}$ device 2 data from testing at $260 \mathrm{~V} \mathrm{AC} 5 \mathrm{~Hz}$. (b) Expanded view of the data from (a) showing 5 peaks and troughs in the first second of actuation, validating that $5 \mathrm{~Hz}$ was achieved mechanically.

Figure 31: Oscillation amplitudes over time for $4 \mathrm{~mm}$ devices tested at $260 \mathrm{~V}$ for 1 minute (device number is denoted by $\mathrm{D \#}$ and replicate by $\mathrm{R \# )}$.

Figure 32: Oscillation amplitudes over time for $5 \mathrm{~mm}$ devices tested at $260 \mathrm{~V}$ for 1 minute (device number is denoted by $\mathrm{D \#}$ and replicate by $\mathrm{R \# )}$.

Figure 33: Boxplot of distances traveled by the laser on the PSD as a result of oscillating diaphragm deflections. Data is broken up by applied voltage and device side length, including $24 \mathrm{~mm}, 25 \mathrm{~mm}$, and $17 \mathrm{~mm}$ devices. 
Figure 34 (a): DC stability testing of $5 \mathrm{~mm}$ device 1 at $300 \mathrm{~V}$ with split lines between each 1 minute test segment, which were each 15 minutes apart. (b) Expanded view of the first 2 seconds of deflection demonstrating a gradual mechanical response.

Figure 35 (a): DC stability testing of $7 \mathrm{~mm}$ device 1 at $300 \mathrm{~V}$. (b) Expanded view of the diaphragm response at the time of actuation. .66

Figure 36: ANOVA readout from Minitab for analysis of AC characterization results......68

Figure 37: Minitab output for a paired t-test comparing laser deflection from $4 \mathrm{~mm}$ diaphragms operated at both 260 and $300 \mathrm{~V}$.

Figure 38: DC testing results plotted and shown with the figure demonstrating laser redirection based on point of incidence on a deflected diaphragm. .72

Figure 39: The inside of the acoustic foam fixture with the Vernier microphone inserted.

Figure 40: Acoustic testing setup including the DUT connected to the MEMS driver and the acoustic foam fixture lifted from where it sits over the DUT. .74

Figure 41: Plot of ambient noise in the acoustic foam fixture. .75

Figure 42: Offset pressure generated by PZT disc operating at 1 VPP and $2 \mathrm{kHz}$ with a $10 \mathrm{kHz}$ sampling rate. .75

Figure 43: Plot of $7 \mathrm{~mm}$ device 2 actuating at $2000 \mathrm{~Hz}$ with $300 \mathrm{~V}$ applied. .76

Figure 44: An example setup that can be used in laser-Doppler vibrometry .82 


\section{SECTION 1. BACKGROUND \\ Keywords}

Abaqus FEA: A finite element analysis program that provides the capability of performing theoretically accurate mechanical analysis of specified loading conditions on a components or system.

Data Acquisition Unit (DAQ): A device or system set up to measure electrical or physical phenomenon.

Diaphragm: A thin film component of a MEMS device, typically composed of silicon, designed to deform under induced stresses

Electrostatic Force: An effect in which a force is generated between two electrically charged surfaces. Two oppositely charged surfaces in close proximity with one another experience an attractive force, while two surfaces with the same charge experiences a repulsive force.

MEMS: A micro-electromechanical system is the name given to a broad category of devices with electrical and mechanical components that have micron-scale $\left(10^{-6}\right.$ meters $)$ dimensions.

PSD: A position sensitive detector uses a voltage differential across its surface both horizontally and vertically to precisely track in both axes the location of incident light on its surface.

Sound Pressure Level (SPL): The difference between a local pressure wave and atmospheric pressure. This is used in assessing the loudness of an acoustic output. 


\subsection{Introduction}

MEMS technology has revolutionized a wide range of products in the past few decades thanks to the advances made in microfabrication methods. The benefits of microfabrication have been seen in devices like transistors. The number of transistors capable of being fabricated per square inch, in accordance with Moore's Law, has successfully been on track for doubling every $1-2$ years since the invention of the integrated circuit in $1965 .{ }^{1}$ Transducers, many of which are now MEMS devices, have seen the same breakthroughs in the form of miniaturization while maintaining accuracy thanks to microfabrication. Microfabrication techniques provide the ability to fabricate millions of identical components on a single chip with the same effort as is required to create a single component. The capability of fabricating these devices en masse on a micro-scale has opened up a range of possible applications for them as products like strain gauges, pressure sensors, and accelerometers.

Within the field of transducers, devices which convert energy of one form to another (e.g. electrical to mechanical), there are two categories- sensors and actuators. A sensor is a transducer which typically converts forms of energy into electrical signals, such as a microphone that translates the mechanical vibrations created by sound pressure waves into an electrical response. An actuator is a transducer that typically does the opposite, such as a speaker to which electrical signals are input and audio output is produced through mechanical vibrations. In a traditional speaker, electrical input is converted to mechanical vibrations using electromagnetic actuation, whereas in the field of MEMS the same actuation results can be achieved on a smaller scale with high accuracy by a number of different means. Electromagnetic, electrostatic,

piezoelectric, and thermo-pneumatic actuation can be achieved on the micro scale due to the unique thin film surface effects present at that scale. 


\subsection{Electrostatic Actuation of Parallel Plates}

The structure of an electrostatically actuated MEMS speaker typically involves a parallel plate capacitor setup in which a conductive thin film is fixed a small distance, typically 10 to $100 \mu \mathrm{m}$,- from a base electrode. When a capacitor is placed in a circuit with a voltage source, charge buildup occurs between the two electrodes until the point of discharge. This charge buildup can be utilized in MEMS devices to perform work in the form of electrostatic actuation so long as at least one of the parallel plates is a thin film with weak enough mechanical restoring force to be overcome by the electrostatic force.

Coulomb's law provides the basis of mathematically determining electrostatic interactions between charged particles, which can then be applied to the electrostatic interactions between plates. Coulomb's law is stated in Equation 1.1, which relates particle charge and distance between them to the electrostatic force created:

$F_{\text {electrostatic }}=\frac{k * q_{1} * q_{2}}{r^{2}}$

where $\mathrm{k}$ is Coulomb's constant $\left(8.988 \times 10^{9} \mathrm{Nm}^{2} \mathrm{C}^{-2}\right), \mathrm{q}_{1}$ and $\mathrm{q}_{2}$ are charge magnitudes, and $r$ is a scalar distance between the charged points. When moving from point to planar surface electrostatic effects, there are three factors which influence the electric field. These including electrode gap, voltage, and electrode area. Equations 1.2 through 1.5 show the development of the governing equation of electrostatics as applied to charged plates.

$\mathrm{F}_{\text {electrostatic }}=E_{\text {field }} * \rho$

$E_{\text {field }}=\frac{V}{z}$ 
$\rho=C * V=\frac{\varepsilon * \varepsilon_{0} * A * V}{z}$

$\mathrm{F}_{\text {electrostatic }}=\frac{\varepsilon * \varepsilon_{0} * A * V^{2}}{z^{2}}$

where $\rho$ is charge, $E_{\text {field }}$ is the strength of the electric field, $V$ is the applied potential, $A$ is the area of plate overlap, $z$ is the distance between the plates, and $\varepsilon_{0}$ is the permittivity of free space $\left(\varepsilon_{0}=8.85^{\star} 10^{-12} \mathrm{~F} / \mathrm{m}\right)$. $\varepsilon$ can be neglected when solving for most MEMS devices as it is the dielectric constant of the material (air) between capacitor plates, and $\varepsilon_{\text {air }}=1$. As can be seen from this equation, a larger overlapping plate area will increase electrostatic effects, but not as significantly as applied voltage and electrode gap.

The desired magnitude of electrode displacement due to electrostatic forces varies greatly based on the application of the MEMS device. A pressure sensor (essentially a microphone) can typically have a smaller deflection than a micro-speaker to achieve the desired output due to the high accuracy of piezoresistive strain gauges in MEMS devices. One such device can is the SP80 Pressure Sensor, seen in Figure 1, which utilizes doped regions of the silicon diaphragm at high strain points to generate an accurate reading. ${ }^{2}$



Figure 1: SP80 Pressure sensor diagram. ${ }^{2}$ 
A micro-speaker, on the other hand, must translate electrical input into mechanical actuation on a magnitude that generates an audible sound pressure level. This corresponds to an electrostatic force that triggers a physical response capable of overcoming the mechanical restoring force of the parallel plate attachment points to its bulk supporting structure. This is diagramed in Figure 2, which sums up the relationship between mechanical restoring force and electrostatic force on a given parallel plate. Note that the mechanical restoring force of the parallel plate support structure is essentially a spring force and therefore elicits a linear elastomechanical response, while the electrostatic force versus displacement relationship is exponential.

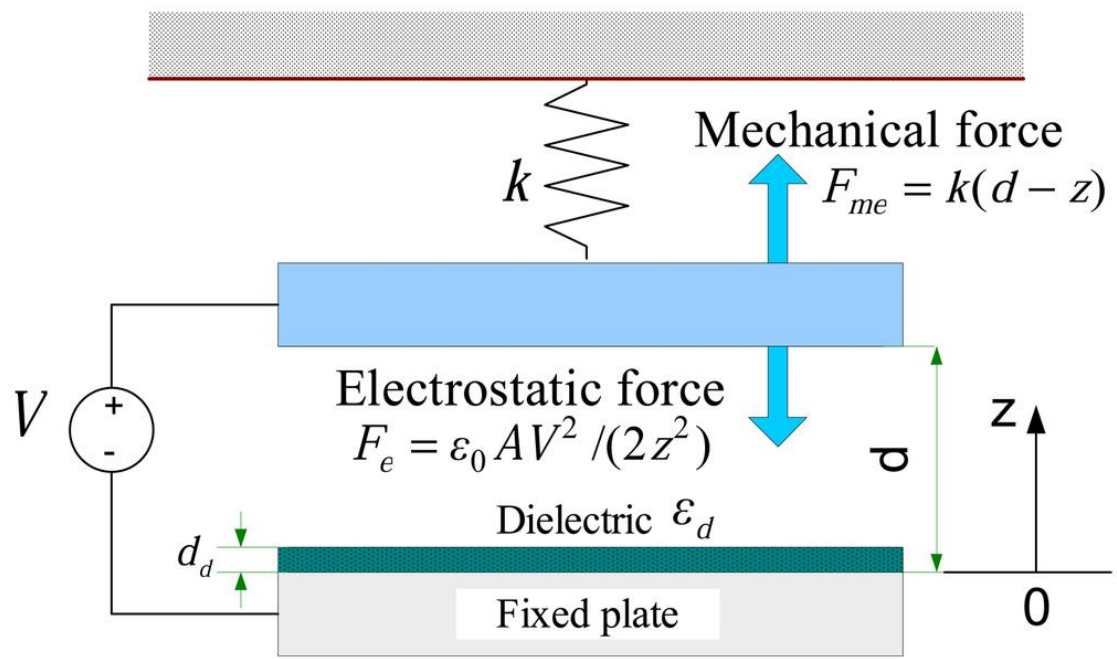

Figure 2: Representation of the balance of mechanical and electrostatic forces on a parallel plate electrostatic actuator. ${ }^{3}$

The non-linear relationship of electrostatic force versus parallel plate displacement stems from the redistribution of charge on the surface of the actuating electrode as it moves closer to the fixed electrode. This can potentially lead to an issue of snap-down in the instance of the electrodes becoming overly-charged and flexing too close towards each other. An example of being on the edge of such an occurrence can be seen in Figure 3 (b), wherein the linear mechanical restoring force lies tangential to 
the electrostatic force curve. The intersection point of the two curves marks the equilibrium displacement of the plate. As can be seen in Figure 3(a), increasing voltage moves the electrostatic force curve to the right, meaning that at any voltage greater than that seen in Figure 3(b) snap-down will occur. The minimum potential required to achieve this phenomenon is referred to as the pull-in voltage $\left(\mathrm{V}_{\text {pull-in }}\right)$, and while certain applications such as electrostatic switches do utilize $\mathrm{V}_{\text {pull-in }}$, a micro-speaker typically does not.

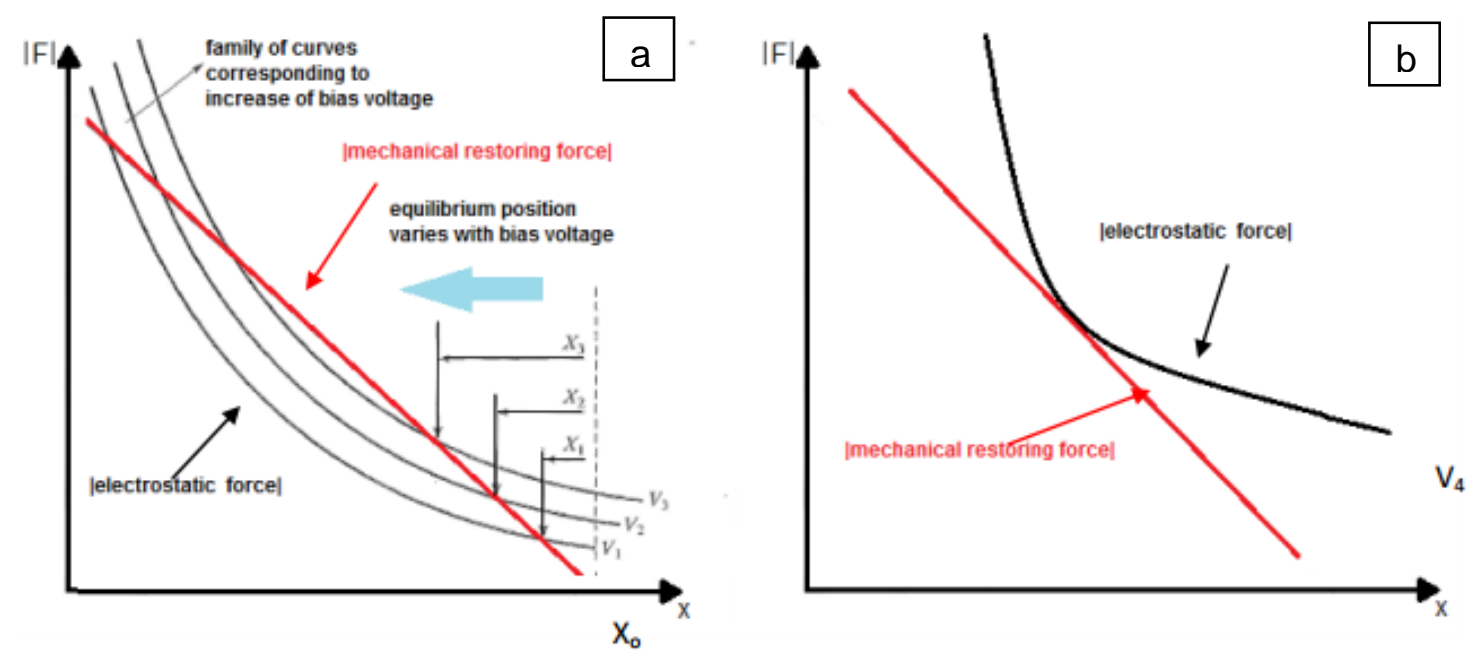

Figure 3 (a): A family of curves dependent on voltage applied show the electrostatic force on a parallel plate actuator, while the red line shows the linear relationship between displacement and mechanical restoring force. (b) Example of the highest applied voltage possible before $\mathrm{V}_{\text {pull-in }}$ is reached, as seen by the tangent relationship between the electrostatic force curve and the mechanical restoring force line. ${ }^{4}$

Equation 1.5 sums the potential energy in a parallel plate electrostatic actuator, which can be used to establish the deflection distance and $V_{\text {pull-in }}$ at which snap-down is triggered.

$\mathrm{PE}=\frac{\mathrm{kz}^{2}}{2}-\frac{\varepsilon_{0} * \mathrm{~A} * \mathrm{~V}^{2}}{2 * \mathrm{Z}}$ 
The second derivative of this equation is set to 0 to establish the required condition for mechanical equilibrium:

$$
\begin{aligned}
& \frac{\delta^{2}(\mathrm{PE})}{\delta \mathrm{z}^{2}}=\mathrm{k}-\varepsilon_{0} * \mathrm{~A} * \frac{\mathrm{V}^{2}}{(\mathrm{~d}-\mathrm{z})^{3}}=0 \\
& \mathrm{~V}^{2}=\mathrm{k} * \frac{(\mathrm{d}-\mathrm{z})^{3}}{\varepsilon_{0} * \mathrm{~A}} \\
& \mathrm{~V}_{\text {pull-in }}=\sqrt{8 * \mathrm{k} * \frac{\mathrm{d}^{3}}{27 * \varepsilon_{0} * \mathrm{~A}}}
\end{aligned}
$$

where $d$ is the original distance between the parallel plates and $k$ is the spring constant of the diaphragm. Equation 1.7 can also be substituted into the first derivative of Equation 1.5, seen in Equation 1.9 below, to determine that the maximum deflection before snap-down occurs is one third of the initial electrode gap, $\mathrm{d}$.

$\mathrm{kz}=\frac{1}{2} * \varepsilon_{0} * \mathrm{~A} * \frac{\mathrm{V}^{2}}{(\mathrm{~d}-\mathrm{z})^{2}}=\frac{\mathrm{k}(\mathrm{d}-\mathrm{z})}{2}$

$\mathrm{z}_{\text {pull-in }}=\frac{\mathrm{d}}{3}$

Equations 1.8 and 1.10 provide critical stability criteria for effective electrostatic

operation. ${ }^{5}$ It is therefore important to avoid these values with a factor of safety to avoid snap-down, which limits the work (force ${ }^{\star}$ displacement) capacity of an electrostatic actuator.

\subsection{Acoustic Response of a Parallel Plate Actuator}

In order to assess the acoustic response of a micro-speaker, the basic principles of what makes a sound must be explored. The human body perceives pitch, which is a means of differentiating sound frequencies. A sound frequency is the rate at which compression waves arrive at a fixed location. Another key measure of sound is the intensity, which is commonly expressed as a measure of decibels. The sound pressure level is a deviation from atmospheric pressure caused by the sound waves as they 
propagate through a material. Sound pressure level can be calculated as 10 times the logarithm of the ratio of two sound intensities, or using the ambient pressure $\left(P_{\text {ref }}\right)$ and generated pressure $(P)$ as seen in Equation $1.11 .^{6}$

$L_{p}=20 * \log _{10} \frac{P}{P_{\text {ref }}}$

Alternatively, an acoustic power approach can be taken. The power that a square parallel plate capacitor can generate can be approximated using Equation 1.12, which was developed for a disc-shaped radiator. ${ }^{7}$

$P_{\text {acoustic }}=0.25 * d^{4} * f^{4} * x_{\text {peak }}^{2}$

In this equation, $d$ is the radiator diameter (on in this case, diaphragm side length), $f$ is the actuation frequency, and $x_{\text {peak }}$ is the maximum radiator displacement at that frequency. The displaced portion of a square diaphragm takes on roughly the same discshape as the radiator that Equation 1.12 was developed for, so the results should provide a reasonably accurate value for acoustic power. This power can then be applied to Equation 1.13 to find the sound pressure level $\mathrm{L}_{\mathrm{db}}$ achieved by an actuator:

$P_{\text {acoustic }}=10^{\frac{L_{d b}}{10}} * 10^{-12} * 4 * \pi * x_{\text {peak }}^{2}$

where $y$ is the distance from the sound radiator. Applying the maximum MEMS driver potential of $300 \mathrm{~V} \mathrm{AC}$ at $2000 \mathrm{~Hz}$, the acoustic power and sound intensity can be calculated for 4,5 , and $7 \mathrm{~mm}$ side length diaphragms at a distance of 1 inch (length of the ear canal) from the actuator. These results can be seen in Table 1. $2000 \mathrm{~Hz}$ was used as the driving signal because as seen in Figure 4, this is approximately the largest hearing threshold range and $200 \mathrm{~Hz}$ was used as the other end of the spectrum because this is a common frequency of the human voice. ${ }^{7}$ 
Table 1: Acoustic powers and SLPs for each diaphragm size.

\begin{tabular}{|c|c|c|c|c|}
\hline Diaphragm Size & $\begin{array}{c}\mathrm{P}_{\text {acoustic }}\left(\mathrm{m}^{6} / \mathrm{s}^{4}\right) \\
\text { at } \mathrm{f}=200 \mathrm{~Hz}\end{array}$ & $\begin{array}{c}\mathrm{P}_{\text {acoustic }}\left(\mathrm{m}^{6} / \mathrm{s}^{4}\right) \\
\text { at } \mathrm{f}=200 \mathrm{~Hz}\end{array}$ & $\begin{array}{c}\mathrm{L}_{\mathrm{db}}(\mathrm{dB}) \\
\text { at } \mathrm{f}=200 \mathrm{~Hz}\end{array}$ & $\begin{array}{c}\mathrm{L}_{\mathrm{db}}(\mathrm{dB}) \\
\text { At } \mathrm{f}=2000 \mathrm{~Hz}\end{array}$ \\
\hline $4 \mathrm{~mm}$ & $2.92 \mathrm{E}-13$ & $2.92 \mathrm{E}-9$ & 15.57 & 55.57 \\
\hline $5 \mathrm{~mm}$ & $4.25 \mathrm{E}-12$ & $4.25 \mathrm{E}-8$ & 27.20 & 67.20 \\
\hline $7 \mathrm{~mm}$ & $6.27 \mathrm{E}-11$ & $6.27 \mathrm{E}-7$ & 38.88 & 78.88 \\
\hline
\end{tabular}

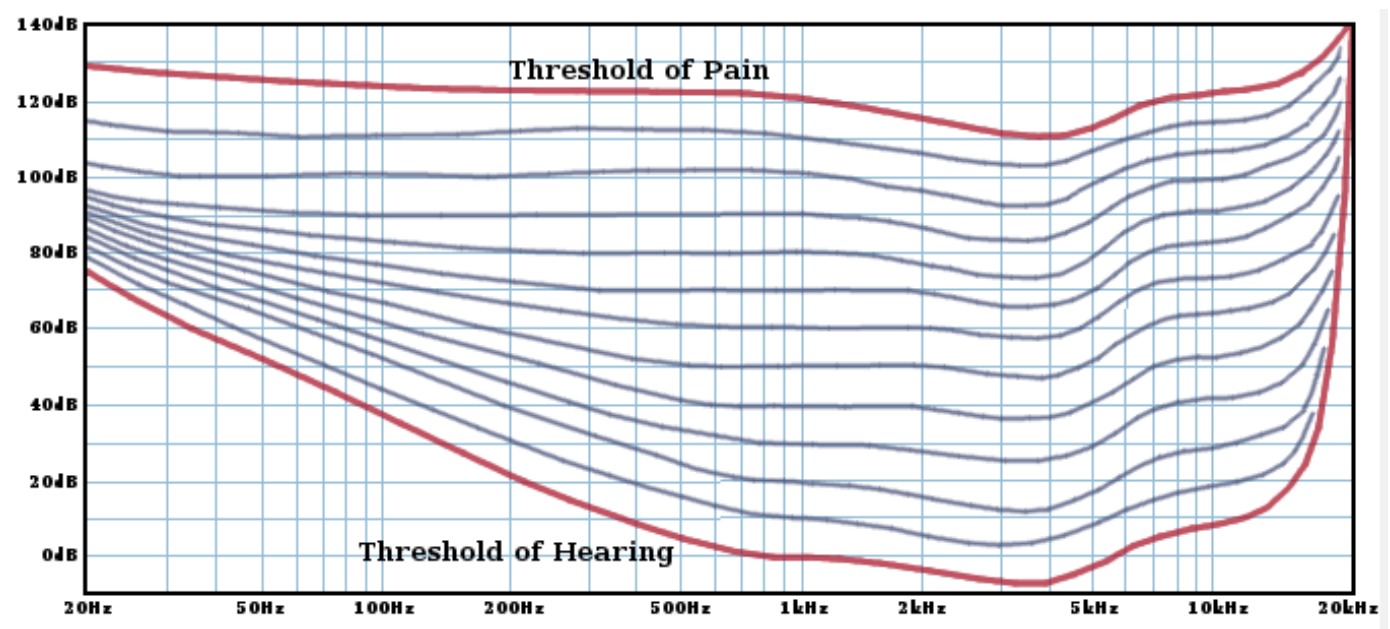

Figure 4: Range of human hearing can be seen as a function of frequency. ${ }^{7}$

One can compare the expected sound pressure levels calculated in the previous table to the table seen in Figure 5 and find that only at high frequencies can any of the diaphragms generate a sound pressure level comparable to that of conversational speech. Despite the setback of a limited frequency range at which the devices are potentially audible, they are capable of being tested at lower frequencies with sensitive microphones. 


\begin{tabular}{|c|c|c|c|}
\hline \multicolumn{4}{|c|}{$\begin{array}{l}\text { Table of sound levels } L \text { and corresponding } \\
\text { sound pressure and sound intensity }\end{array}$} \\
\hline \multirow{2}{*}{ Examples } & \multicolumn{3}{|c|}{ Sound Pressure Sound Pressure $p$ Sound Intensity I } \\
\hline & Level $L_{p}$ dBSPL & $\mathrm{N} / \mathrm{m}^{2}=\mathrm{Pa}$ & $W / m^{2}$ \\
\hline Jet aircraft, $50 \mathrm{~m}$ away & 140 & 200 & 100 \\
\hline Threshold of pain & 180 & 63.2 & 10 \\
\hline Threshold of discomfort & 120 & 20 & 1 \\
\hline Chainsaw, $1 \mathrm{~m}$ distance & 110 & 6.3 & 0.1 \\
\hline Disco, $1 \mathrm{~m}$ from speaker & 100 & 2 & 0.01 \\
\hline Diesel truck, $10 \mathrm{~m}$ away & 90 & 0.63 & 0.001 \\
\hline Kerbside of busy road, $5 \mathrm{~m}$ & 80 & 0.2 & 0.0001 \\
\hline Vacuum cleaner, distance $1 \mathrm{~m}$ & 70 & 0.063 & 0.00001 \\
\hline Conversational speech, $1 \mathrm{~m}$ & 60 & 0.02 & 0.000001 \\
\hline Average home & 50 & 0.0063 & 0.0000001 \\
\hline Quiet library & 40 & 0.002 & 0.00000001 \\
\hline Quiet bedroom at night & 30 & 0.00063 & 0.000000001 \\
\hline Background in TV studio & 20 & 0.0002 & 0.0000000001 \\
\hline Rustling leaf & 10 & 0.000063 & 0.00000000001 \\
\hline Threshold of hearing & 0 & 0.00002 & 0.000000000001 \\
\hline
\end{tabular}

Figure 5: A table displaying the sound pressure levels and intensities of various noises. ${ }^{9}$

\subsection{Previous Thesis Work at Cal Poly}

A range of diaphragm sizes have been fabricated using multiple methods in past Cal Poly thesis projects. Most recently, success has been seen by Evan Cate in fabrication of square silicon diaphragms of $10 \mu \mathrm{m}$ thickness with side lengths of $4 \mathrm{~mm}$, $5 \mathrm{~mm}$, and $7 \mathrm{~mm}$ in the Cal Poly Microfabrication Lab. This fabrication was performed using a silicon-on-insulator (SOI) wafer of the dimensions seen in Figure 6 (a) and a photolithography mask seen in Figure 6 (b). SOI wafers have been the preferred means of diaphragm fabrication in most recent attempts due to the built-in etch stop that mitigates the warping issues that were inherent with the previously attempted boron doped silicon etch stops. 

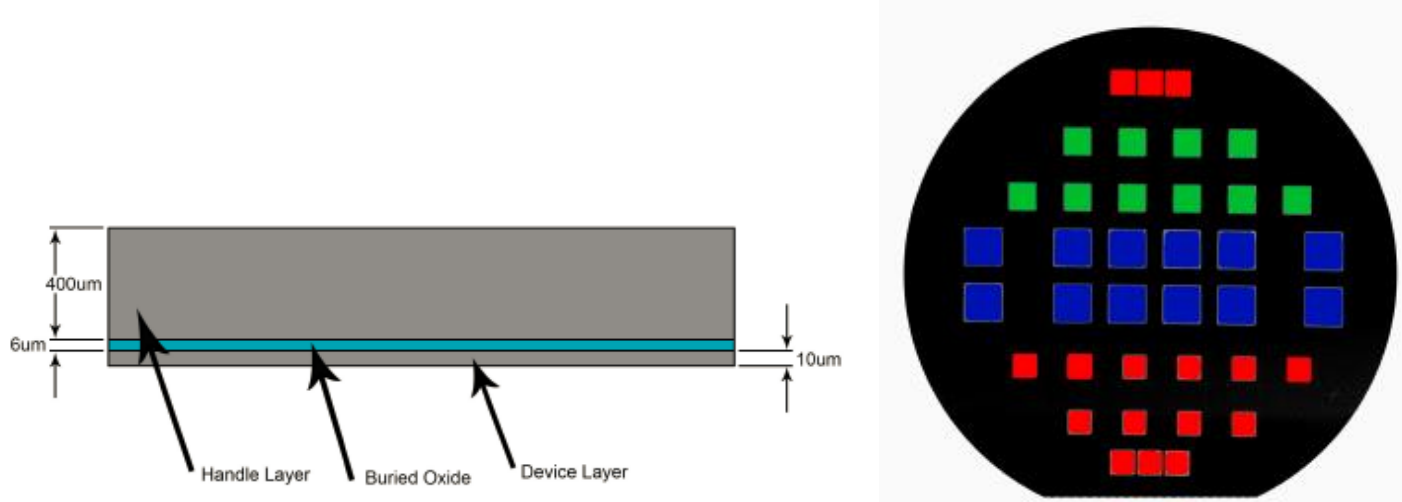

Figure 6 (a): SOI wafer as received prior to diaphragm fabrication with a $10 \mu \mathrm{m}$ device layer, $6 \mu \mathrm{m}$ buried oxide, and $400 \mu \mathrm{m}$ handle side. (b) Photolithography mask used for diaphragm fabrication with red corresponding to $4 \mathrm{~mm}$ side length, green being $5 \mathrm{~mm}$, and blue being $7 \mathrm{~mm} .{ }^{10}$

Characterization of the diaphragms fabricated in past projects was performed, although this has typically been done using a micro-force displacement system (MFDS) both with and without a DC voltage applied across the electrodes. The MFDS, while fairly reliable at measuring the mechanical response of a diaphragm on the nanometer scale, has its limits. Once a diaphragm is actuated by electrostatic means, the mechanical force that the MFDS prober tip must apply to locate the new surface location further deflects the diaphragm. This leaves the exact deflection distance from electrostatic forces indeterminate. It has been concluded that electrostatic actuation has occurred on the larger $(5+\mathrm{mm})$ devices charged at 300 VDC based on lower MFDS force readings at a constant displacement, but no quantification of displacement was performed. $^{11}$

\subsection{Project Scope}

The goal of this project is to design, fabricate, and assess the actuation capabilities of an electrostatically actuated MEMS diaphragm. Silicon diaphragms were fabricated in numerous past thesis projects at Cal Poly, which most recently resulted in Evan Cate creating $10 \mu \mathrm{m}$ thick square diaphragms with side lengths of $4 \mathrm{~mm}, 5 \mathrm{~mm}$, and 
$7 \mathrm{~mm} .{ }^{10}$ While square diaphragm microfabrication methods have been developed in the Cal Poly Microfabrication Lab, electrostatic actuation of these diaphragms has been a point of questionable success. Characterization of an electrostatically actuated parallel plate device that has been fabricated in the on-campus Microfabrication Lab is the end goal of this project. The scope has been limited to characterizing actuation of an already fabricated diaphragm (therefore $4 \mathrm{~mm}, 5 \mathrm{~mm}$, or $7 \mathrm{~mm}$ side length square diaphragm) that, as calculated, has the potential to be applied as a micro-speaker. This means the diaphragm should be capable of producing an audible sound pressure level through electrostatic actuation. Device characterization criteria include definitive identification of diaphragm actuation, determination of the capacitive time response, dynamic cycling response, estimation of device actuation, and sound pressure level achieved during device actuation. Characterization is to be carried out for all available diaphragm sizes, including devices of $4 \mathrm{~mm}, 5 \mathrm{~mm}$, and $7 \mathrm{~mm}$ side length.

\subsection{Potential Applications of a Micro-Speaker}

Micro-speakers have existed for years, but an omnipresent challenge associated with them is finding new ways to shrink their size further, achieve better sound quality, and package them in a more compact form all at a lower cost. In the US alone, nearly 314 in 1000 people over 65 suffer from hearing loss, and $80 \%$ of those would benefit from using hearing aids but choose not to use them. ${ }^{12} \mathrm{~A}$ major factor in refusing treatment with hearing aids is the social stigma associated with wearing them and reluctance to treat presbycusis, the loss of hearing with age. While hearing aids have been undergoing steady improvements since the introduction of digital hearing aids in 1996, patients continue to seek out longer-lasting battery life, better directionality, and lower costs, background noise, and acoustic feedback. ${ }^{12}$ 
Of the two forms of hearing loss, conductive and sensorineural, hearing aids of the microphone-amplifier-loudspeaker variety can be beneficial to those with conductive hearing loss. In order to overcome the stigma of wearing hearing aids, completely-in-thecanal $(\mathrm{CIC})$ hearing aids are a necessity, but these provide many challenges for improving quality due to the 0.7 inch diameter and 1 inch length size constraints in order to fit in the ear canal. Under such constraints, electromagnetically actuated MEMS loudspeakers have been seen to exhibit the most effective operating conditions ( $7 \mu \mathrm{m}$ displacements, equivalent to $120-\mathrm{dB} S P L$ at $1 \mathrm{kHz}$ ) due to the relatively low power consumption compared to electrostatic actuation. ${ }^{12}$ 


\section{SECTION 2. DEVICE DESIGN}

\subsection{Process Overview}

The design process for creation of a capacitive micro-speaker began with the establishment of design requirements. It was known that diaphragm deflections must be maximized in order to achieve adequate pressure waves from the device for potential application as a micro-speaker. Constraining factors such as $\mathrm{V}_{\text {pull-inn }}$, diaphragm side length, electrode spacing, and material selection were considered during the design process. Knowing the available diaphragm side lengths fabricated by Evan Cate, the mechanics of a diaphragm undergoing electrostatic actuation could be analyzed to assess device viability in a high frequency actuation application.

\subsection{Diaphragm Mechanics}

The mechanics of a square diaphragm were analyzed to ensure adequate deflections could be achieved, stresses were within a safe operating range, and pull-in voltages were not reached. A square film of a given side length is preferable because under identical operating conditions it can achieve greater deflection than a circular film with a diameter equal to the square's side length, meaning that the footprint to deflection ratio of a square diaphragm is more favorable than that of a circle. Square diaphragms also have the greatest pressure induced stresses compared to rectangular and circular diaphragms, which leads to greater precision in its deflections. ${ }^{13}$ Some assumptions were made to simplify the calculations associated with electrostatically actuated diaphragm mechanics. These include the square shape being clamped on all four edges to a rigid support structure, the diaphragm thickness being significantly smaller than the side length ( $\mathrm{t}=\mathrm{a} / 10$, a being side length) so the structure is considered to be loaded in full bending, and the forces present are tangential to the surface of the diaphragm. 
Additionally, the material was considered homogeneous and isotropic, and the inherent membrane stresses from fabrication were neglected.

As can be noted from Equation 1.4, the electrostatic force exerted on a parallel plate actuator is primarily dependent on the device side length and electrode gap. Assuming uniform loading, the electrostatic force can be divided by the area of the actuator to find an equivalent electrostatic pressure on the diaphragm.

$\mathrm{P}_{\text {electrostatic }}=\frac{\varepsilon * \varepsilon_{0} * V^{2}}{z^{2}}$

This pressure can then be applied to the mathematical models which approximate a square diaphragm's maximum deflection $Z_{\text {center }}$ and maximum stress $\sigma_{\max }$.

$\mathrm{Z}_{\text {center }}=\frac{0.0138 * a^{4} * P}{E * t^{3}}$

$\sigma_{\max }=\frac{0.308 * a^{2} * P}{t^{2}}$

In Equations 2.2 and 2.3, $a$ refers to diaphragm side length and $t$ to its thickness. As intuition suggests, the maximum displacement of a uniformly loaded square diaphragm is at its center, hence $z_{\text {center }}$ is the critical deflection used in device characterization. The maximum stress $\sigma_{\max }$, on the other hand, is located at the center of the edges on a square diaphragm. The material constants used in the previously mentioned calculations can be seen in Table 2 below. Single crystal silicon, the material used to fabricate the diaphragms being tested, is highly anisotropic due to its face-centered cubic diamond unit cell structure. This means the Young's Modulus E for the (110) plane must be used for calculations because that is the plane perpendicular to the applied electrostatic load. 
Table 2: List of material parameters used for diaphragm calculations

\begin{tabular}{|c|c|c|c|}
\hline Material & $\begin{array}{c}\text { Young's Modulus } \\
\mathrm{E}_{(110)}(\mathrm{Pa})\end{array}$ & Poisson's Ratio & $\begin{array}{c}\text { Yield Strength } \\
\sigma_{\mathrm{y}}(\mathrm{Pa})\end{array}$ \\
\hline Silicon & $170 \mathrm{E} 9^{14}$ & 0.23 & $7 \mathrm{E} 9$ \\
\hline
\end{tabular}

The calculated electrostatic force and resultant deflection values for multiple electrode gaps, applied voltages, and diaphragm side lengths are tabulated in Appendix I. Calculations were performed for electrode gaps between 70 and $100 \mu \mathrm{m}$ due to ease of fabrication and voltages between 260 and $300 \mathrm{~V}$ due to the limitations of the MEMS driver. Key results were then used based on a $70 \mu \mathrm{m}$ electrode gap, 260 and $300 \mathrm{~V}$, and $5 \mathrm{~mm}$ side length to move forward with finite element modelling of the device with the most likelihood of successfully producing an acoustic output.

\subsection{Pull-in Voltage}

Equation 1.10 from Section 1.2 states that snap down is likely to occur when the device is actuated to one third of the initial electrode gap distance. This constraint was considered after deflection calculations were run to establish that within the $300 \mathrm{~V}$ operating range capability in the microfabrication lab, a $5 \mathrm{~mm}$ by $5 \mathrm{~mm}$ diaphragm with a $70 \mu \mathrm{m}$ electrode gap does not achieve its pull-in voltage. The theoretical deflection of said device at $300 \mathrm{~V}$ is $4.12 \mu \mathrm{m}$ with a maximum stress of $6.26 \mathrm{MPa}$. Pull-in is predicted at approximately $23 \mu \mathrm{m}$ and the yield strength of single crystal silicon is $7 \mathrm{GPa}$, therefore the diaphragm is clear to operate with a factor of safety of 5.58 with regard to pull-in. ${ }^{14}$ Due to the extreme resilience of silicon undergoing cyclic loading, there is little concern with material fatigue effects under these conditions.

\subsection{Breakdown Voltage}

When working with the high voltages inherent in performing electrostatic operations, the breakdown voltage must be avoided. According to Paschen's law, pressure and gap length are the determining factors of breakdown voltage, which is the 
voltage required to create an electric arc between two electrodes. ${ }^{15}$ The lower the density of atoms in an electrode gap, the higher the voltage required to trigger an avalanche breakdown. This relationship can be seen below in Equation 2.4, in which A and $B$ are experimentally determined values dependent on the gas medium, $p$ is the operating pressure, and $d$ is the electrode gap distance. In the case of air, $A$ is $15 \mathrm{~cm}^{-1 *}$ Torr $^{-1}$ and $\mathrm{B}$ is $365 \mathrm{~V}^{\star}$ Torr $^{*} \mathrm{~cm}^{-1}$.

$V_{b}=\frac{A * p * d}{\ln (p * d)+B}$

\subsection{Diaphragm Frequency Response}

Multiple factors contribute to maximum operating frequency of an electrostatically actuated device. When designing a parallel plate actuator, the capacitive charging and mechanical response must be considered as potential operating frequency limiters. The actuator operates like a capacitor in that a surface charge is established over time, the properties of which can be characterized by the parameters seen in Equations 2.5-2.6.

$\tau=R * C$

$C=\varepsilon_{r} * \varepsilon_{0} * \frac{A}{d}$

$f_{c}=\frac{1}{2 * \pi * \tau}$

In Equations 2.4 and 2.5, $\mathrm{R}$ is resistance, $\mathrm{C}$ is capacitance, $\varepsilon_{\mathrm{r}}$ is the dielectric constant of air $(\sim 1), \varepsilon_{0}$ is the electric constant $\left(8.854 \times 10^{-12} \mathrm{~F} / \mathrm{m}\right), \mathrm{A}$ is the overlapping plate area, and $d$ is the distance between plates. These parameters establish the capacitive time constant $\mathrm{T}$ at which point the capacitor has charged to $63.2 \%$ or discharged to $36.8 \%$ of its full capacity. If a device is operated at its cutoff frequency, defined by Equation 2.7, and losses from the mechanical response are neglected, it can only achieve a small fraction of its total deflection due to the small portion of the full charge capacity that is 
reached. In order to achieve deflections consistent with theoretical calculations for a capacitive actuator, the transient response of the $\mathrm{RC}$ circuit must be reached. This is approximately $5 \mathrm{r}$, at which point $95 \%$ of the source voltage is seen across the capacitor. For this reason, it is of critical importance to minimize resistance and capacitance values of the actuator in order to achieve high frequency response rates. Calculation of the device capacitances could be done before fabrication, but the resistance in the circuit leading up to the capacitor could only be determined after key fabrication steps had been performed. The cutoff frequency was therefore not determined until the devices were ready for testing.

The mechanical response of the capacitor is another issue that is only partially dependent on its time dependent charging. The time delay of an actuators mechanical response is considerably larger than its capacitive time response for an efficient electrostatic device. ${ }^{16}$ Inherent stresses in the actuating material play a large role in its mechanical response to stimulus, so on a device-by-device basis this could be quite variable depending on the consistency of the fabrication procedure. What can be predetermined mathematically is the resonant frequency of a square diaphragm based on the Young's modulus $E(170 \mathrm{GPa})$, side length a, thickness $t(10 \mu \mathrm{m})$, material density $\rho$ $\left(2330 \mathrm{~kg} / \mathrm{m}^{3}\right)$, and Poisson's ratio $v(0.23) .{ }^{14}$ Equation 2.8 can be used to calculate the resonant angular velocity $\omega_{r}$, while Equation 2.9 can convert that to the resonant frequency. Table 3 displays the resonant frequencies calculated for the 3 sizes of diaphragms characterized in this project.

$$
\begin{aligned}
& \omega_{r}=35.16 * \sqrt{\frac{E}{12 * \rho *\left(1-v^{2}\right)}} *\left(\frac{t}{4 * a^{2}}\right) \\
& f_{r}=\frac{w_{r}}{2 * \pi}
\end{aligned}
$$


Table 3: Theoretical resonant frequencies of each available diaphragm size

\begin{tabular}{|c|c|c|}
\hline $\begin{array}{c}\text { Diaphragm Side } \\
\text { Length }(\mathrm{mm})\end{array}$ & $\omega_{\mathrm{r}}(\mathrm{rad} / \mathrm{s})$ & $f_{\mathrm{r}}(\mathrm{Hz})$ \\
\hline 4 & 13919 & 2215 \\
\hline 5 & 8909 & 1417 \\
\hline 7 & 4545 & 723 \\
\hline
\end{tabular}

Whether or not these resonant frequencies can be realized is a factor of the cutoff frequency from capacitive charging and the subsequent mechanical response times for each device. In the case of a micro-speaker for use in a hearing aid, the resonant frequency should be avoided to mitigate sound distortion and maintain consistent functionality. For characterization purposes and attempting to generate acoustic output from such a device, being able to drive it at its resonant frequency is a desirable capability. 


\section{SECTION 3. FINITE ELEMENT MODELING}

\subsection{Summary}

A finite element model was developed to characterize the physical response of electrostatically actuated MEMS diaphragms. This analysis was performed in Abaqus/CAE 6.11 on a $5 \mathrm{~mm}$ by $5 \mathrm{~mm}$ silicon diaphragm with a uniform thickness of 10 $\mu \mathrm{m}$ and a 3000 angstrom silver layer deposited on top, as seen in the SolidWorks model in Figure 7. A two part model was created for each analysis in which a silver layer composed of shell elements was fixed to the surface of the solid hexagonal silicon elements and a pressure mimicking the corresponding theoretical electrostatic response was applied. The deflection and maximum principle stress of a $5 \mathrm{~mm} \times 5 \mathrm{~mm}$ diaphragm under static loads were determined to be $2.86 \mu \mathrm{m}$ and $4.04 \mathrm{MPa}$, respectively. These static results, which are slightly below the calculated values for an electrostatically actuated silicon diaphragm without an attached electrode, are supportive of further development of this sized diaphragm. The dynamic FEA results support the operation of a $5 \mathrm{~mm} \times 5 \mathrm{~mm}$ MEMS diaphragm below the $5283.3 \mathrm{~Hz}$ resonant frequency for maximum efficiency and predictable acoustic output. 




Figure 7: SolidWorks exploded view of base electrode, double sided tape, and silicon diaphragm

\subsection{Model Development}

A $5 \mathrm{~mm} \times 5 \mathrm{~mm} \times 10 \mu \mathrm{m}$ square, silicon MEMS diaphragm was modeled and analyzed with a 3000 angstrom layer of silver attached to it (which acts as an electrode). The diaphragm loading is characteristic of the conditions that can be imparted on it in the Cal Poly Microfabrication Lab (i.e. maximum 300 V output from MEMS driver). Static and dynamic analyses were run with the electrostatically generated forces for $260 \mathrm{~V}$ and $300 \mathrm{~V}$ signals with a $70 \mu \mathrm{m}$ gap between the charged plates, and a linear perturbation step was run to find the resonant frequencies.

As seen below in Figure 8, the assembly was modeled in SolidWorks, but it was determined that the models would have to be created in Abaqus to overcome the zero volume elements inherent in a meshed solid material as thin as the silver layer. The entire diaphragm and electrode were modeled first to generate a solution reasonably close to the calculations performed in the project proposal. The boundary conditions 
consisted of 0 displacements on all axes, which were applied along all edges of the silicon diaphragm. This corresponds to where the diaphragm connects to the main block of silicon it is fabricated from. The silver layer is its own part in Abaqus, so it was positioned on top of the silicon diaphragm. A tie boundary condition was then applied between the bottom face of the silver electrode and the top face of the silicon so the two would react together when the load is applied. This mimics the constraint of the silver electrode that is sputtered onto the silicon diaphragm. Finally, a pressure of magnitude 61.04 Pa was applied to the top face of the electrode. A view of the boundary conditions in Abaqus can be seen in Figure 9. The pressure used was calculated using Equation 3.1, seen below, by substituting in the force seen on the diaphragm under the conditions of a $260 \mathrm{~V}$ signal applied and a 70 micron distance between electrodes (see table in Appendix I). All material properties were applied to their corresponding parts as they are defined in Table 4 below.

$P=\frac{F}{A}$



Figure 8: Magnified view showing the 10 micron thick silicon diaphragm with 3000 angstrom silver layer 
Table 4: Material properties used for silver and silicon

\begin{tabular}{|c|c|c|c|}
\hline Material & Density $\left(\mathrm{kg} / \mathrm{m}^{3}\right)$ & Young's Modulus (Pa) & Poisson's Ratio \\
\hline Silicon & 2330 & $170 \mathrm{E} 9$ & 0.23 \\
\hline Silver & 10490 & $83 \mathrm{E} 9$ & 0.37 \\
\hline
\end{tabular}

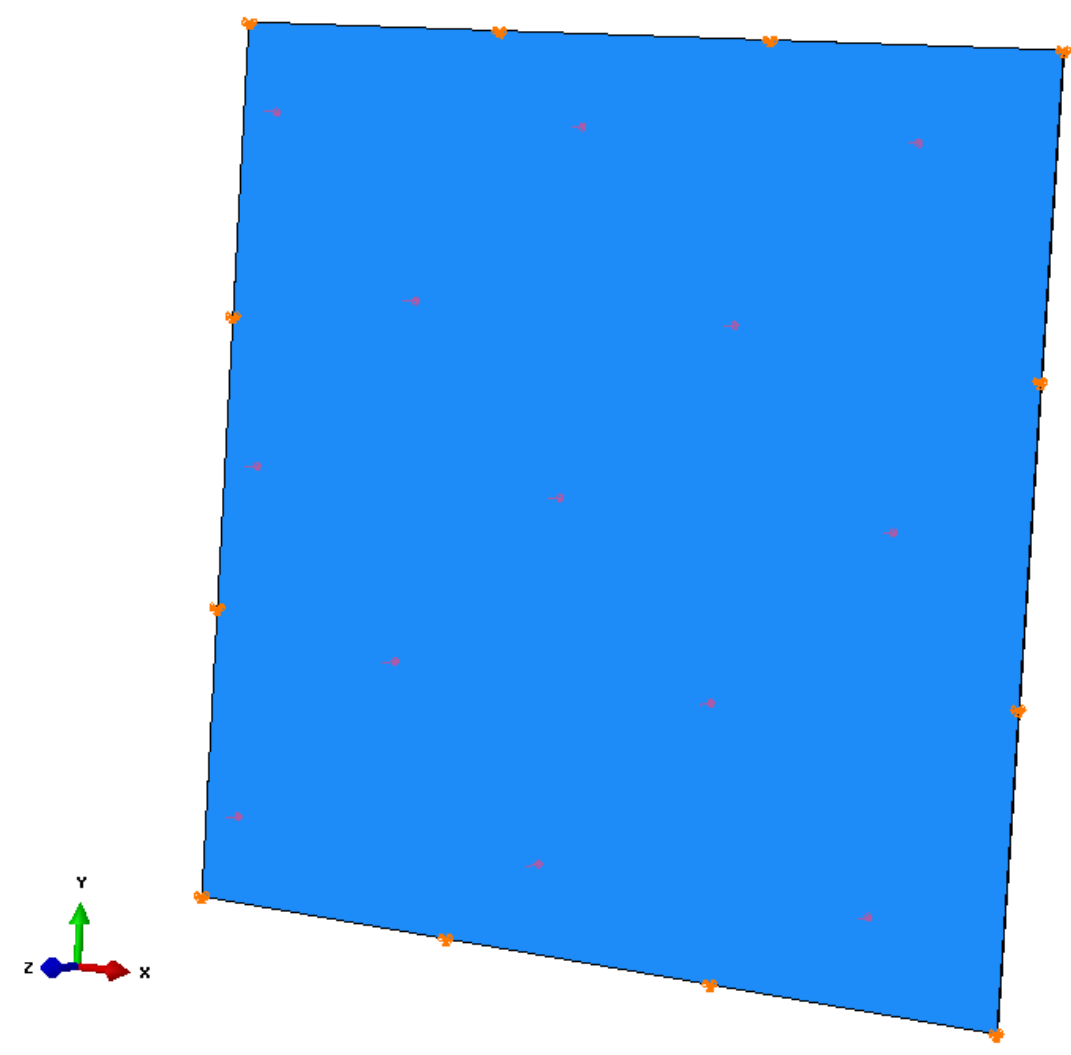

Figure 9: A view in Abaqus of the fixed edge boundary conditions and uniform pressure loading conditions on the diaphragm.

Once the full model was verified based on its maximum stress and displacement values by comparing them to the preliminary calculations, the model was simplified using its symmetry to cut down memory requirements and calculation time. The quarter-model had the same zero displacement boundary conditions applied to the two outer edges 
and was fixed in the direction perpendicular to the other remaining "inside" edges (see Appendix II). Once the quarter-model was verified by comparing its results to those of the full model, the analysis progressed to using a dynamic step on the simplified model.

\subsection{Mesh Development}

A number of different meshing attempts were made before the final convergent mesh was decided upon. Initially, two shell sectioned parts were constructed with 100 shell elements each due to the thickness of the parts being significantly smaller than the length or width of the parts. Complications were encountered when applying the tie boundary conditions to faces of each part because each one is displayed as a zero thickness plane, causing the two to deform incorrectly and seemingly overlap. Next, two solid parts were imported from SolidWorks. A coarse mesh was attempted using both quadratic hexagonal (brick) and tetrahedral (pyramid) elements. Errors regarding zero volume elements prevented this job from running- every element comprising the silver layer was too thin for accurate use in the matrix calculations. This necessitated the switch to shell elements for the silver part, while the silicon part maintained a solid section constructed in Abaqus. Quadratic elements were used to capture the bending of the elements more accurately since the strains present in the model are relatively high in the direction of the thickness.

Throughout the trial and error of the meshing process the quality of the elements being used improved steadily in terms of minimizing the aspect ratio and avoiding

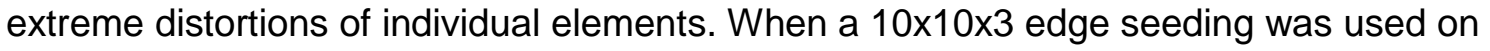
the silicon part, the aspect ratio for 300 elements exceeded 100 to 1 . This explains the inaccurate results seen later as the first data point in the mesh convergence process. Once the mesh became more refined, all minimum/maximum angles and aspect ratio criteria were met. 


\subsection{Analysis}

In the Model Development section, the static analysis was introduced. In this static analysis, both a constant and periodic load was analyzed. The periodic load was characterized by a circular frequency $\omega=2^{*} \pi^{*}$, with $f=261$ (a middle- $C$ frequency that was first arbitrarily attempted in this project), initial amplitude of 1 at time 0 , and constants $A$ and $B$ defined as 0 and 1 . These constants were determined from the Fourier series of the amplitude a, seen in Equation 3.2.

$$
a=A_{0}+\sum_{n=1}^{N}\left[A_{n} \operatorname{cosn} \omega\left(t-t_{0}\right)+B_{n} \operatorname{sinn} \omega\left(t-t_{0}\right)\right] \text { for } t \geq t_{0}
$$

The next model development step was using a steady state dynamics, directstep analysis rather than static. The importance of the dynamic step is to examine the effects of a range of frequencies on diaphragm actuation. During characterization, the diaphragms can be subjected to a wide range of frequencies to evaluate their peak performance range, thus knowing their response at a range of frequencies is beneficial. The frequency response was analyzed on the simplified model between $20 \mathrm{~Hz}$ and $10,000 \mathrm{~Hz}$ to cover the lower half of the range of human hearing, which is more frequently utilized during normal activity.

Finally, a linear perturbation-frequency step was used to evaluate the resonant frequencies of the device. The input for this analysis supports boundary conditions only for its calculations (as opposed to previous analyses using applied load as well). The quarter-model with the minimum convergent mesh parameters was again used to run this job.

Throughout the stepwise analysis of this model a number of warnings were present. To summarize, the following warnings were consistent in each step:

- Adjustment was specified for tie pairs but no major adjustments were made 
- There is a zero moment everywhere in the model based on default criterion

- Multiple Tie dependent nodes have specified boundary conditions. These conditions will be transferred to associated tie independent nodes

- Boundary conditions are specified on inactive dof of $x$ nodes.

These warnings were not a concern because most of them are stating that the desired effects of the tie condition were placed on the part, and the zero moment is acceptable because the edges do not have a zero rotation boundary condition on them. This means there are no reaction moments nor were any moment loads on it, therefore the warning is not a concern. These analysis results, which are very close to the predicted values, verify that these warnings are inconsequential.

\subsection{Mesh Convergence}

Once it was established that the elements would be quadratic, quadrilateral shell elements for the silver part and quadratic, hexagonal 3D stress elements for the silicon, a mesh convergence study was performed on the full model. Seeding was performed by edge on both parts of the model, resulting in a mesh with 1 element along the thickness of the silver part and 4 on the silicon part. A high stress node at the mid-point on the left edge of the silicon part was selected for checking convergence (Appendix II), while the node at the very center of the top plane of the silicon part was used for the displacement mesh convergence check (Appendix II). The mesh convergence study outlined in Table 5 shows the number of elements, degrees of freedom, max principle stress and displacement for each mesh attempt on the model. Figure 10 displays the convergence plot of the displacement results from the study, while the stress based mesh convergence can be found in Appendix II. 
Table 5: Mesh convergence study results for the full $5 \mathrm{~mm} \times 5 \mathrm{~mm}$ model

\begin{tabular}{|c|c|c|c|}
\hline $\begin{array}{l}\text { Number of } \\
\text { Elements }\end{array}$ & $\begin{array}{l}\text { Degrees of } \\
\text { Freedom }\end{array}$ & Displacement (m) & Stress S11 (Pa) \\
\hline Silver: 100 & \multirow[t]{2}{*}{7227} & \multirow[t]{2}{*}{$-2.50 \mathrm{E}-6$} & \multirow[t]{2}{*}{$2.53 \mathrm{E} 6$} \\
\hline Silicon:300 & & & \\
\hline Silver: 400 & \multirow[t]{2}{*}{27027} & \multirow[t]{2}{*}{$-2.83 E-6$} & \multirow[t]{2}{*}{ 3.53E6 } \\
\hline Silicon:1200 & & & \\
\hline Silver: 900 & \multirow[t]{2}{*}{59427} & \multirow[t]{2}{*}{$-2.85 E-6$} & \multirow[t]{2}{*}{ 3.80E6 } \\
\hline Silicon:2700 & & & \\
\hline Silver: 1600 & \multirow[t]{2}{*}{124353} & \multirow[t]{2}{*}{$-2.86 E-6$} & \multirow[t]{2}{*}{ 3.95E6 } \\
\hline Silicon:4800 & & & \\
\hline Silver: 2500 & \multirow[t]{2}{*}{192933} & \multirow[t]{2}{*}{$-2.86 \mathrm{E}-6$} & \multirow[t]{2}{*}{$4.04 \mathrm{E} 6$} \\
\hline Silicon:10000 & & & \\
\hline
\end{tabular}

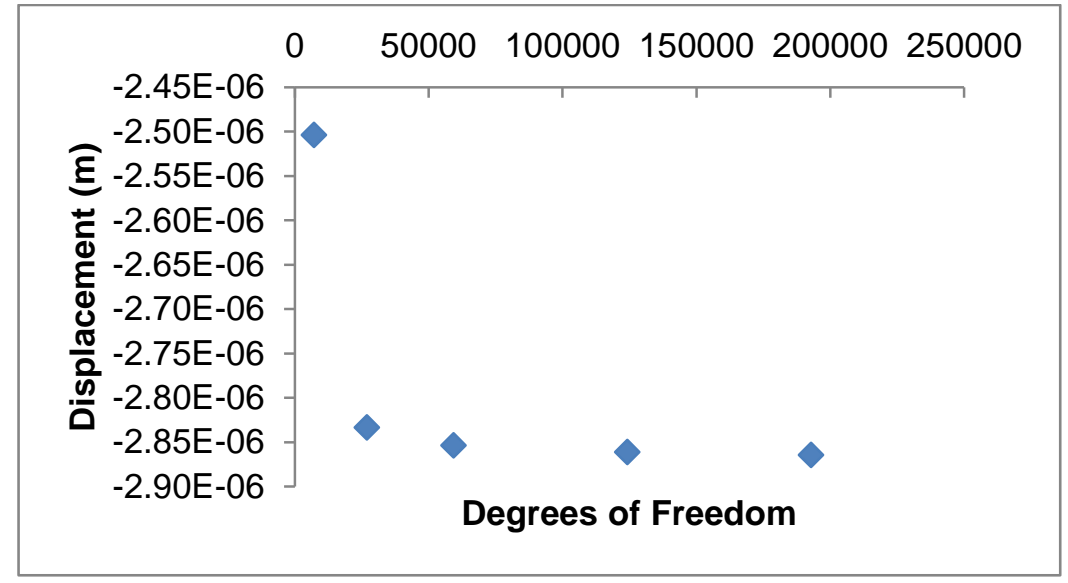

Figure 10: Displacement convergence of the $5 \mathrm{~mm} \times 5 \mathrm{~mm}$ diaphragm model.

\subsection{Results}

The final number of elements used in the full model was 12500, which corresponds to 192933 degrees of freedom, although for an approximation that minimizes computing time without sacrificing resolution, 3600 elements with 59427 degrees of freedom could be used. These mesh characteristics can be seen with their corresponding maximum principle stress and displacement results from the static analysis in Table 5 of the Mesh Convergence section. The results of the full finite 
element analysis on the quarter-model can be seen in Table 6, which covers static, constant and static, periodic pressure loading conditions as well as a dynamic analysis for a range of frequencies. For a visualization of the lower voltage, quarter-model maximum stress results for the static, $261 \mathrm{~Hz}$ loading condition, see Figure 11. The equivalent dynamic model for loading frequency $4456 \mathrm{~Hz}$ can be found in Appendix II.

Table 6: Stress and displacement summary for abbreviated $5 \mathrm{~mm}$ side length models under 260V conditions

\begin{tabular}{|c|c|c|c|c|c|}
\hline $\begin{array}{c}\text { Analysis } \\
\text { Description }\end{array}$ & $\begin{array}{c}\text { Frequency } \\
(\mathrm{Hz})\end{array}$ & Elements & $\begin{array}{l}\text { Degrees of } \\
\text { Freedom }\end{array}$ & $\begin{array}{c}\text { Max } \\
\text { Displacement (m) }\end{array}$ & $\begin{array}{c}\text { Max Stress } \\
(\mathrm{Pa})\end{array}$ \\
\hline $\begin{array}{c}\text { Static, } \\
\text { constant load }\end{array}$ & $\mathrm{N} / \mathrm{A}$ & \multirow{2}{*}{6125} & \multirow{2}{*}{95688} & $-2.87 E-6$ & 4.14E6 \\
\hline $\begin{array}{c}\text { Static, } \\
\text { periodic load }\end{array}$ & $261 \mathrm{~Hz}$ & & & $-2.86 E-6$ & 4.13E6 \\
\hline \multirow{10}{*}{ Dynamic } & 20 & \multirow{10}{*}{6125} & \multirow{10}{*}{95688} & $-2.86 E-6$ & 4.14E6 \\
\hline & 1129 & & & $-3.01 E-6$ & $4.31 \mathrm{E} 6$ \\
\hline & 2238 & & & $-3.52 E-6$ & 4.93E6 \\
\hline & 3347 & & & $-4.88 E-6$ & $6.56 \mathrm{E} 6$ \\
\hline & 4456 & & & $-10.30 \mathrm{E}-6$ & 13.06E6 \\
\hline & 5564 & & & 27.37E-6 & $34.62 \mathrm{E} 6$ \\
\hline & 6673 & & & $5.20 \mathrm{E}-6$ & 5.89E6 \\
\hline & 7782 & & & $2.74 \mathrm{E}-6$ & 2.67E6 \\
\hline & 8891 & & & $1.82 \mathrm{E}-6$ & 1.44E6 \\
\hline & 10000 & & & $1.36 \mathrm{E}-6$ & 7.91E5 \\
\hline
\end{tabular}

Table 7: Paired resonant frequency modes for the full and quarter model

\begin{tabular}{|c|c|c|}
\hline Frequency Mode & Model & Frequency \\
\hline \multirow{2}{*}{1} & Full & 5283.3 \\
\cline { 2 - 3 } & Quarter & 5280 \\
\hline \multirow{2}{*}{2} & Full & 10782 \\
\cline { 2 - 3 } & Quarter & None \\
\hline \multirow{2}{*}{3} & Full & 10782 \\
\cline { 2 - 3 } & Quarter & None \\
\hline \multirow{2}{*}{4} & Full & 15898 \\
\hline \multirow{2}{*}{5} & Quarter & None \\
\cline { 2 - 3 } & Full & 19351 \\
\cline { 2 - 3 } & Quarter & 19320 \\
\hline \multirow{2}{*}{6} & Full & 19442 \\
\cline { 2 - 3 } & Quarter & 19412 \\
\hline
\end{tabular}




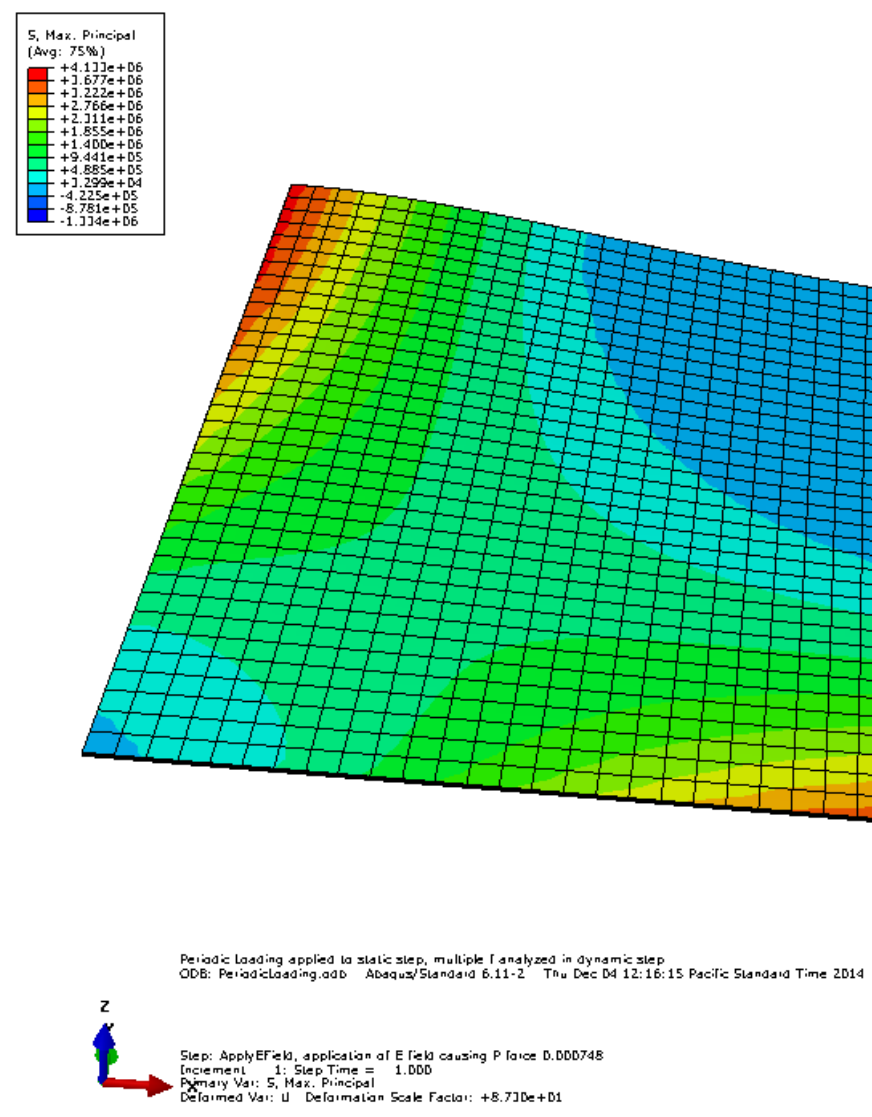

Figure 11: Static $2.5 \mathrm{~mm} \times 2.5 \mathrm{~mm}$ quarter-model stress results under periodic loading at frequency $261 \mathrm{~Hz}$.

All analyses were repeated with the higher applied pressure from a $300 \mathrm{~V}$ signal. This 81.21 Pa pressure, when applied statically, periodically, and dynamically yielded the results in Table 8. For validation of the model and assurance in the dynamic and resonant frequency results, comparisons can be made between Table 6 and Table 7's static, constant load results. For convenience, all the relevant results have been combined into Table 9 and the difference between theoretical and FEA results were calculated. 
Table 8: Results from higher pressure (81.21 Pa) application on a $5 \mathrm{~mm} \times 5 \mathrm{~mm}$ diaphragm quarter-model.

\begin{tabular}{|c|c|c|c|}
\hline $\begin{array}{c}\text { Analysis } \\
\text { Description }\end{array}$ & $\begin{array}{c}\text { Frequency } \\
(\mathrm{Hz})\end{array}$ & $\begin{array}{c}\text { Max } \\
\text { Displacement } \\
(\mathrm{m})\end{array}$ & $\begin{array}{c}\text { Max Principle } \\
\text { Stress (Pa) }\end{array}$ \\
\hline $\begin{array}{c}\text { Static, constant } \\
\text { load }\end{array}$ & $\mathrm{N} / \mathrm{A}$ & $-3.82 \mathrm{E}-6$ & $5.51 \mathrm{E} 6$ \\
\hline $\begin{array}{c}\text { Static, periodic } \\
\text { load (Frame 7, } \\
\text { step 3.5) }\end{array}$ & $261 \mathrm{~Hz}$ & $-3.84 \mathrm{E}-6$ & $5.53 \mathrm{E} 6$ \\
\hline & 20 & $-3.82 \mathrm{E}-6$ & $5.51 \mathrm{E} 6$ \\
\cline { 2 - 4 } & 1129 & $-4.01 \mathrm{E}-6$ & $5.74 \mathrm{E} 6$ \\
\cline { 2 - 4 } & 2238 & $-4.69 \mathrm{E}-6$ & $6.57 \mathrm{E} 6$ \\
\cline { 2 - 4 } & 3347 & $-6.50 \mathrm{E}-6$ & $8.74 \mathrm{E} 6$ \\
\cline { 2 - 4 } & 4456 & $-13.72 \mathrm{E}-6$ & $17.40 \mathrm{E} 6$ \\
\cline { 2 - 4 } & 5564 & $36.46 \mathrm{E}-6$ & $46.15 \mathrm{E} 6$ \\
\cline { 2 - 4 } Steady-State \\
Dynamics & 77873 & $6.93 \mathrm{E}-6$ & $7.86 \mathrm{E} 6$ \\
\cline { 2 - 4 } & 8891 & $3.65 \mathrm{E}-6$ & $3.56 \mathrm{E} 6$ \\
\cline { 2 - 4 } & 10000 & $2.43 \mathrm{E}-6$ & $1.92 \mathrm{E} 6$ \\
\hline
\end{tabular}

Table 9: Direct comparison of applicable FEA and hand calculation results.

\begin{tabular}{|c|c|c|c|c|}
\hline Analysis & Calculation Type & $\begin{array}{c}\text { Theoretical } \\
\text { Result }(\mathrm{m})\end{array}$ & $\begin{array}{c}\text { FEA Result } \\
(\mathrm{m})\end{array}$ & $\begin{array}{c}\text { Difference }(\mathrm{m}) \\
(\text { Theoretical-FEA) }\end{array}$ \\
\hline 260V Signal & Displacement $(\mathrm{m})$ & $3.10 \mathrm{E}-06$ & $2.87 \mathrm{E}-6$ & $0.232 \mathrm{E}-06$ \\
\cline { 2 - 5 } & Max Stress $(\mathrm{Pa})$ & $4.70 \mathrm{E} 6$ & $4.14 \mathrm{E} 6$ & $0.561 \mathrm{E}+06$ \\
\hline \multirow{2}{*}{ 300V Signal } & Displacement $(\mathrm{m})$ & $4.12 \mathrm{E}-06$ & $3.82 \mathrm{E}-6$ & $0.302 \mathrm{E}-06$ \\
\cline { 2 - 5 } & Max Stress $(\mathrm{Pa})$ & $6.26 \mathrm{E} 6$ & $5.51 \mathrm{E} 6$ & $0.752 \mathrm{E}+06$ \\
\hline
\end{tabular}

\subsection{Discussion}

A side by side analysis of the hand calculated (theoretical) values and the FEA values for the static, constant pressure load (seen in Table 6 of the previous section) show relatively comparable values. The discrepancies for displacements are 0.2 to 0.3 microns and the maximum stress differs by a fraction of a megapascal, with both FEA values being lower than their theoretical counterparts. These values seem close enough that the model is validated because the finite element model has a layer of silver on it 
that the hand calculated values did not incorporate. The silver layer likely absorbs some of the stresses on the silicon diaphragm and decreases the deflection capabilities very slightly. Overall, the finite element model seems accurate enough based on the static results so the dynamic and frequency response results can be referenced for diaphragm experimentation in the future. In the future, the model could be more accurately recreated using the properties of gold instead of the silver used in this model, although at that scale the mechanical properties of such a film are essentially negligible. Silver was only used in this model because it was unknown that gold would be the conductive material of choice at the time.

While the dynamic model reveals a lot about the mechanical tendencies of the device as the frequency of loading is increased, there are a multitude of FEA tests that could still be run. This includes a dynamic test at key frequencies of interest to determine exactly how the diaphragm responds throughout the sinusoidal loading from an AC driving signal. This could be done using an Abaqus standard (implicit) step with a time period that allows the device to get up to its full oscillating amplitude. The results for this analysis could reveal how long a diaphragm remains transient in its oscillatory amplitude before settling into its steady state conditions.

Above $5000 \mathrm{~Hz}$, specifically the $5280 \mathrm{~Hz}$ resonant frequency, results in the dynamic analysis begin to deviate from the expected. In Figure 12, the deformed quarter-model stress results show highly elevated stress levels when operating close to the resonant frequency. Past this frequency, there is a sharp drop in displacement and max stress. A likely cause for this occurrence is destructive interference of the sinusoidal loading rhythm with the harmonic frequency that the diaphragm attempts to oscillate at. The cause of the decreased displacement amplitudes between 5 and $10 \mathrm{kHz}$ 
could be further investigated by running the aforementioned dynamic FEA analysis at specific frequencies.

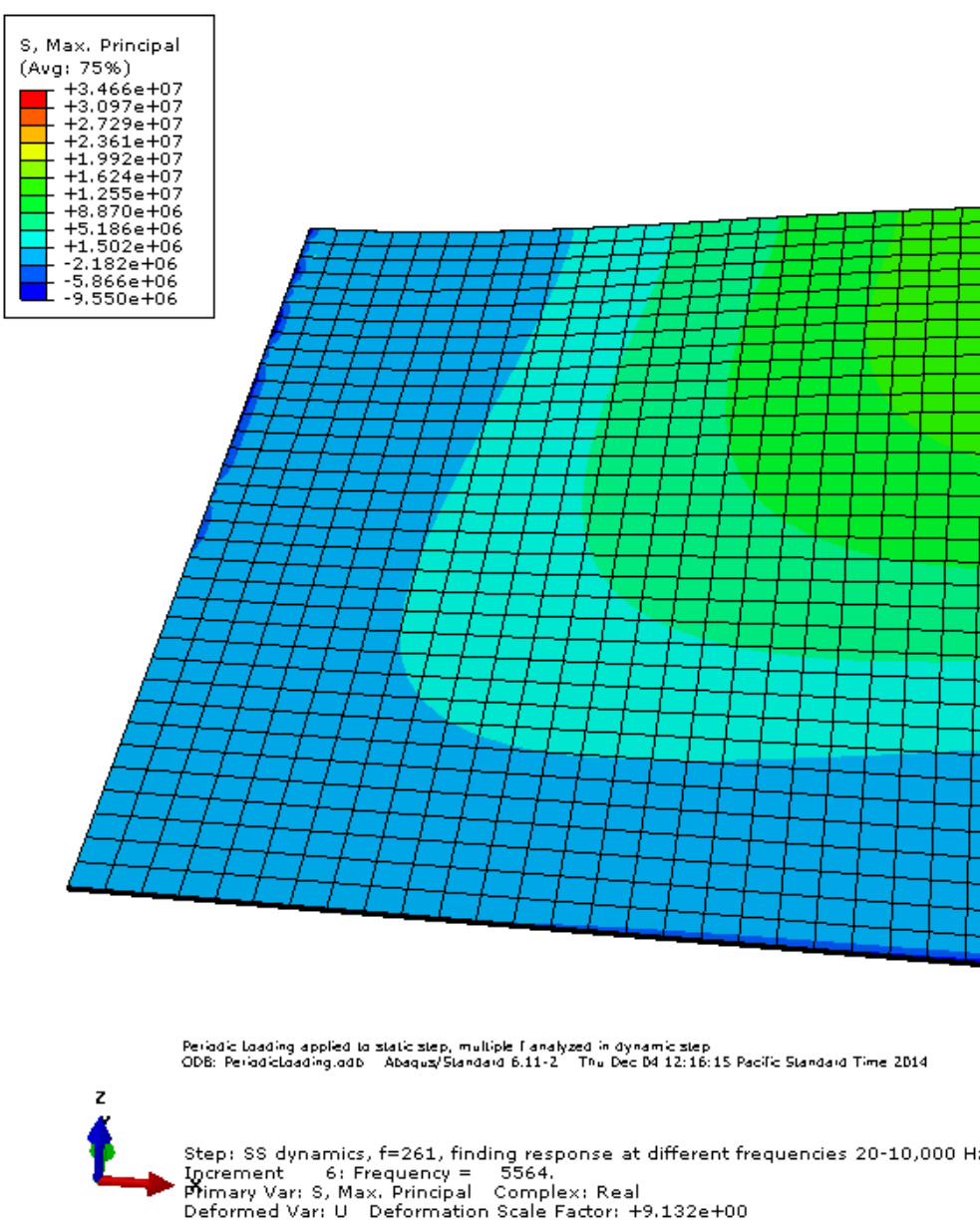

Figure 12: Dynamic quarter-model stress results at frequency $5564 \mathrm{~Hz}$. 


\subsection{Conclusion}

The primary takeaway is that the finite element model was verified by theoretical calculations so the dynamic analysis and frequency response results can be taken into account when planning future tests of these diaphragms. The first resonant frequency mode was hit at approximately $5280 \mathrm{~Hz}$ - with a slight discrepancy on the exact value between the full and quarter-model. This appears to affect the performance of the device for a few hundred hertz range less than $5.28 \mathrm{kHz}$ and for all higher frequencies. It is therefore recommended that use of these devices remain in the lower frequency range of human hearing, between $20 \mathrm{~Hz}$ and $5 \mathrm{kHz}$. Further dynamic analyses can be performed at specific frequencies to elaborate on the mechanical response of the device and solidify its optimal performance range. 


\section{SECTION 4. FABRICATION}

\subsection{Overview}

Parallel plate actuators of 3 different sizes- 4,5 , and $7 \mathrm{~mm}$ side lengths- were fabricated using 5 main steps. These included surface cleansing of the diaphragm and glass substrate, physical vapor deposition (PVD) of chromium on the glass, PVD of gold on both the glass and the diaphragm, connection of wires to the electrodes by either conductive epoxy or conductive tape, and finally, mounting of the diaphragm on the glass substrate using double-sided tape. Pairs of each size actuator were fabricated for a total of 6 devices, which were all tested for low impedance on each respective side of the insulative electrode spacers (double sided tape).

\subsection{Physical Vapor Deposition}

Starting with a $5 \mathrm{~mm}$ diaphragm, a base material and electrode material were selected. Pyrex microscope slides, composed of borosilicate glass, fit the requirements for the base material as they are insulative and sturdy. A major concern with using a glass base is the adhesion capability of gold when deposited by physical vapor deposition. Physical vapor deposition, colloquially known as sputtering, is a process involving the bombardment of a target- typically a negatively charged metal disk- by positive argon ions within a vacuum chamber. Metal ions are launched off the target by the argon ion bombardment, which directs the metal ions in the general direction of the substrate being coated. In order to remedy the adhesion issues that were experienced with gold sputtered directly onto borosilicate glass, a chromium layer was sputtered onto the glass first. 


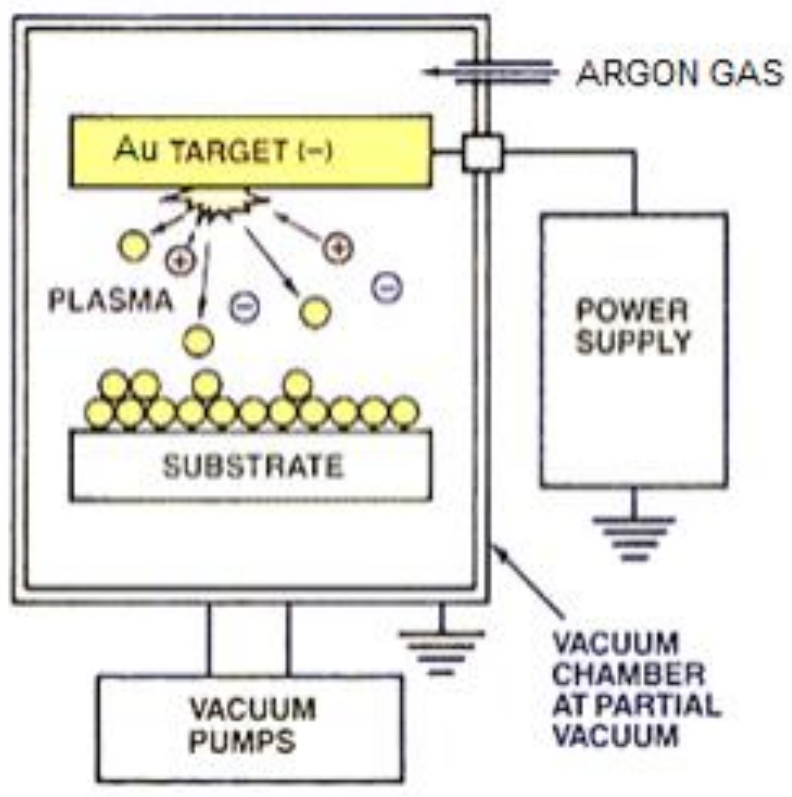

Figure 13: The sputtering process as it occurs in the Denton $V$ sputtering system in the Cal Poly microfabrication lab.

Prior to the physical vapor deposition process, the substrate must be freed of all organics and other contaminants. First, the Pyrex slides were wiped using a Kim-wipe with $70 \%$ IPA on it to remove large debris. The silicon diaphragms and Pyrex slides were then dipped in a Piranha bath, comprised of a 3:1 ratio of $\mathrm{H}_{2} \mathrm{SO}_{4}$ to $\mathrm{H}_{2} \mathrm{O}_{2}$, at $65^{\circ} \mathrm{C}$ for 10 minutes to remove all organic materials. Silicon readily grows an oxide layer at room temperature, so the previously fabricated diaphragms were then submerged in buffered oxide etchant (BOE) for 5 minutes to remove the surface oxide.

When sputtering thin films such as electrodes, there are two common approaches for patterning. High resolution patterns typically use a thin film of photoresist which is patterned using photolithography and then acts as a sputter mask. After deposition, the photoresist can be removed to reveal a fairly high resolution pattern where the sputtered metal reached the substrate. Similarly, a thin sheet of a solid material can be cut and placed on top of the substrate during the sputtering process. As 
the electrode feature being patterned does not require high feature resolution, this method is preferred due to ease of fabrication of the mask. Electrode sputtering masks, seen below in Figure 14 (a) were laser cut from 1/8" ABS plastic and 1/4" acrylic to observe the directional effects of sputtering on relatively large feature sizes. First, the Pyrex slides and masks were placed in the Torr CrC-150 sputtering system to deposit the adhesive chromium layer on the glass using the process parameters outlined in Table 10. The slides and masks were then transferred to the Denton $\mathrm{V}$ sputtering machine to deposit a gold layer on top of the chromium. Profilometer measurements of these electrodes were taken, but the variability of the measurement system is fairly large for this application. It was established that the total electrode thickness is between 100 and 300 nanometers, which is small enough to be negligible with respect to changes in electrostatic force generation.

Table 10: Torr CrC-150 and Denton V physical vapor deposition parameters.

\begin{tabular}{|c|c|c|c|c|c|}
\hline Machine & $\begin{array}{c}\text { Sputtered } \\
\text { Material }\end{array}$ & $\begin{array}{c}\text { Pump- } \\
\text { down time }\end{array}$ & $\begin{array}{c}\text { Base } \\
\text { Pressure }\end{array}$ & $\begin{array}{c}\text { Power } \\
\text { Setting }\end{array}$ & Sputter Time \\
\hline $\begin{array}{c}\text { Torr CrC- } \\
150\end{array}$ & Chromium & $30 \mathrm{~min}$ & $4 \mathrm{mT}$ & $99 \mathrm{~W}$ & $\begin{array}{c}30 \mathrm{sec} \text { pre } / 1 \\
\text { min sputter }\end{array}$ \\
\hline Denton V & Gold & $120 \mathrm{~min}$ & $1.9 \mu \mathrm{T}$ & $48 \mathrm{~mA}$ & $5 \mathrm{~min}$ \\
\hline
\end{tabular}




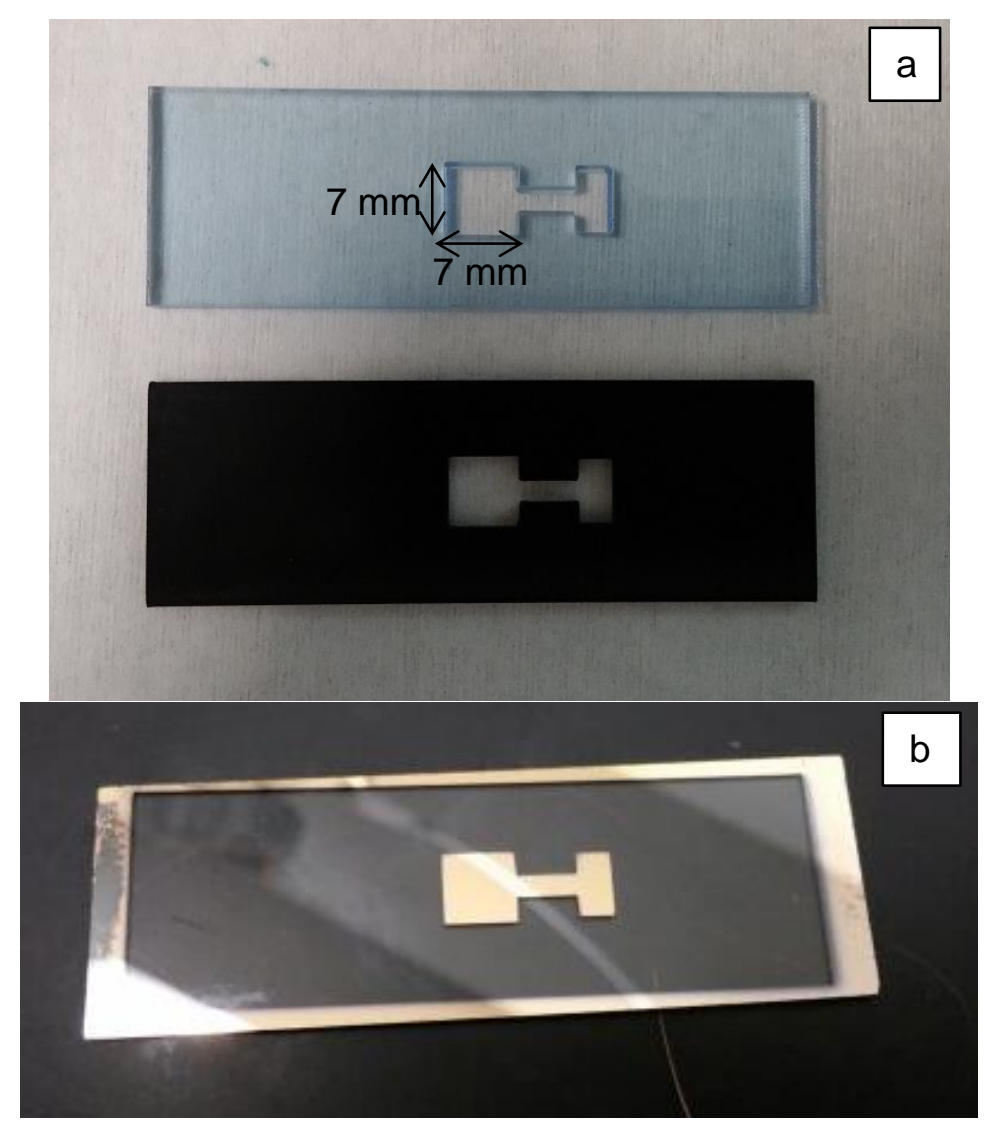

Figure 14 (a): Laser cut sputtering masks made from 1/8" ABS and 1/4" acrylic. (b) Pyrex slide with a $\mathrm{Cr}$ then Au layer deposited as an electrode.

Knowing that the next fabrication step would be adhesion of a wire or other conductor to connect the electrode to the MEMS driver, the durability of the metal layer was tested. This involved performing a peel-off test in which a piece of tape was applied to the sputtered surface, pressed down evenly, and removed. Success was qualitatively assessed, with the goal being little to no loss of gold from the glass slide. Complete peeloff was observed on glass slides coated solely with gold, while little to no peel-off was observed when chromium was deposited as an adhesive layer between the gold and glass. These results are displayed in Figure 15. 


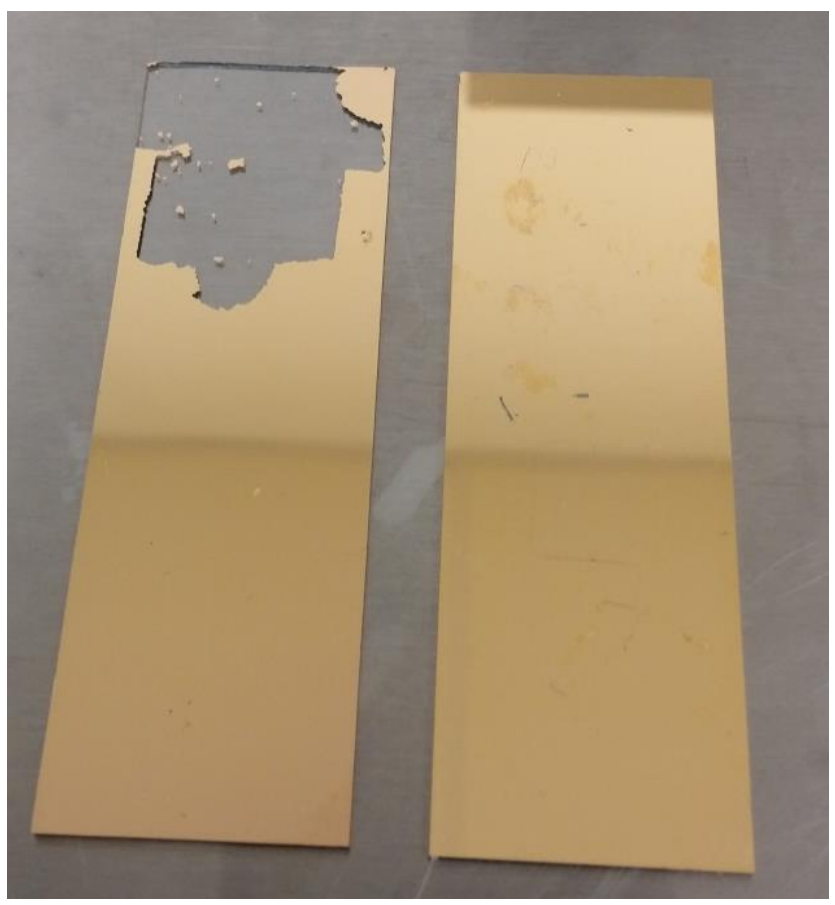

Figure 15: One gold sputtered and one chromium then gold sputtered Pyrex slide which have both undergone identical peel-off testing. The gold on chromium layer (right) displays good adhesion.

\subsection{Wire Connection}

Continuity was ensured across the length of the electrode and trace, including the connection to the MEMS driver, whether that was a conductive copper tape strip or a silver epoxied wire. This was done by measuring the resistance across the electrode and trace using a Fluke ohmmeter to verify low resistances, which typically ranged from 2-4 $\Omega$. Conductive tape had the advantage of being quickly and easily applied as well as allowing reapplication or adjustment. Silver epoxy, on the other hand, provided a rigid attachment that could be well adhered by covering both the end of the electrode trace and some of the surrounding glass. This ensured structural rigidity due to the strong connection between silver epoxy and glass absorbing any loads placed on the wire so as to not peel off the thin gold film. In the case of the conductive tape needing to be reapplied onto the electrode, new tape would need to be adhered to a new gold covered location on the diaphragm to continue to achieve low resistances measurements. 


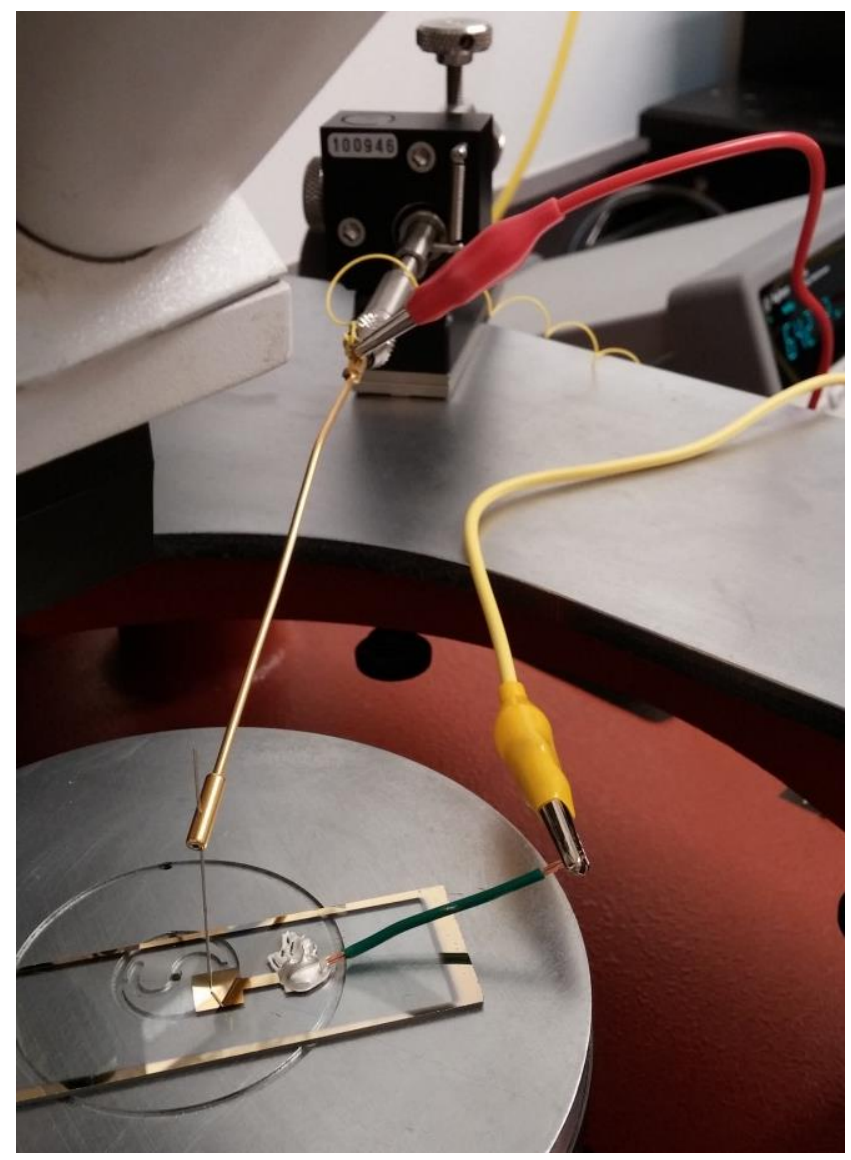

Figure 16: Continuity was established by taking resistance measurements between the base electrode and end of the epoxied wire.

The fixation of the wire to the base electrode and/or the diaphragm was done using H22 EPO-TEK Silver Conductive Epoxy. This was applied by first mixing the 2 part solution in a 100:4.5 ratio of part A to part B measured by weight. A short, approximately 2 inch wire was then inserted into the epoxy where it was applied on the diaphragm or slide, and then the sub-assembly was placed in the oven to cure for 10 minutes at $120^{\circ} \mathrm{C}$. The resultant connection was more than robust enough for the minimal forces encountered during component transit and device assembly, except the epoxy would peel off the gold layer from the diaphragm if bumped with much force. In order to bolster that connection's peel-off strength, the wire was silver epoxied to the silicon diaphragm 
before a gold layer was deposited on top of that in order to provide conductivity between the thin film of the diaphragm and the structural silicon supports surrounding the film.

In order to calculate the capacitive time constant of each electrode, the exact resistance measurements were recorded from one end of the diaphragm to the end of its attached wire or copper tape. The greater of these two measurements was then used in Equation 2.5 to determine the worst-case capacitive time constant for each device, which in turn dictates its cutoff frequency $f_{c}$ according to Equation 2.7. As explained in section 2.5 , the time constant is multiplied by 5 before being used to determine the cutoff frequency in order to achieve full device charging and discharging. These resistance test results and corresponding time constants can be seen in Table 11 .

Table 11: Resistance measurements used for diaphragm $R C$ time constant calculations

\begin{tabular}{|c|c|c|c|c|c|}
\hline $\begin{array}{c}\text { Device } \\
\text { Description }\end{array}$ & Lead Type & $\mathrm{R}_{1}(\Omega)$ & $\mathrm{R}_{2}(\Omega)$ & $5^{*} \mathrm{~T}(\mathrm{~ns})$ & $\mathrm{f}_{\mathrm{c}}(\mathrm{GHz})$ \\
\hline 4mm Device 1 & Silver Epoxy & 1.4 & 2.3 & 0.0175 & 9.09 \\
\hline 4mm Device 2 & Copper Tape & 1.8 & 2.1 & 0.0160 & 9.95 \\
\hline 5mm Device 1 & Copper Tape & 12.5 & 12.7 & 0.1525 & 1.04 \\
\hline 5mm Device 2 & Silver Epoxy & 1.2 & 1.0 & 0.0145 & 1.10 \\
\hline 7mm Device 1 & Copper Tape & 7.5 & 4.5 & 0.1767 & 0.90 \\
\hline 7mm Device 2 & Silver Epoxy & 2.1 & 1.5 & 0.0495 & 3.22 \\
\hline
\end{tabular}

Based on these sub-nanosecond capacitive charging times and cutoff frequencies in the gigahertz range, the electrical response time of the device will not be a concern when operating within the human hearing frequency band.

\subsection{Device spacer}

A critical feature of the electrostatically actuating diaphragm system is the electrode gap. This feature requires an electrically insulative material capable of providing a consistent distance between electrodes, which in turn allows the desired electrostatic force to be applied. In the past, use of SU-8 was attempted as a photo- 
definable, patterned spacer and the thickness could be tailored to match the specified electrode gap. In many instances, the diaphragm did not adhere completely to the SU-8, which was built up from the base Pyrex slide. For both cost effectiveness and ease of fabrication, double sided tape was the primary candidate in this project as a method for fixing the diaphragms to the Pyrex slide base at the desired electrode gap distance. Kapton Tape manufactures double sided polyimide tapes that suit the application of spacing an electrostatic actuator due to being electrically insulating. The tape structure is a 1 mil polyimide film with 1.5 mil of silicone adhesive coating on each side, which totals 4 mils $(101.6 \mu \mathrm{m})$ thickness when uncompressed.

A series of measurements were performed using a profilometer to establish the compressed thickness of the double sided Kapton Tape. Initially, the double sided tape was stuck to a glass slide, the adhesive cover was removed, and the tape was directly probed with a $0.20 \mathrm{mg}$ force by the profilometer stylus. This resulted in measurements of 72.2, 73.2, and $74.9 \mu \mathrm{m}$ for the tape thickness, which was considered an adequate verification of the $70 \mu \mathrm{m}$ electron gap used in FEA. It was noticed that the probe tip deflected into the silicone due to its viscoelastic properties even when the minimum stylus force of $0.20 \mathrm{mg}$ was applied, so in order to attain a more accurate compressed tape thickness, an improved measurement technique was developed. The adhesive coating on one side of the tape was first exposed and pressed onto a Pyrex slide. With the other adhesive side of the tape still covered, the profilometer was run over the tape to attain the thickness at that point. The cover that remained on the tape for the first measurement was then removed and its thickness was measured with the profilometer. By subtracting the thickness of the adhesive coating cover from the thickness of the tape with the cover on, the thickness of the compressed tape alone was determined. Table 12 displays each thickness measurement and the calculated compressed tape thickness. 
These thicknesses were averaged to find $92.0 \mu \mathrm{m}$ is the approximate working electrode gap of the electrostatic actuators.

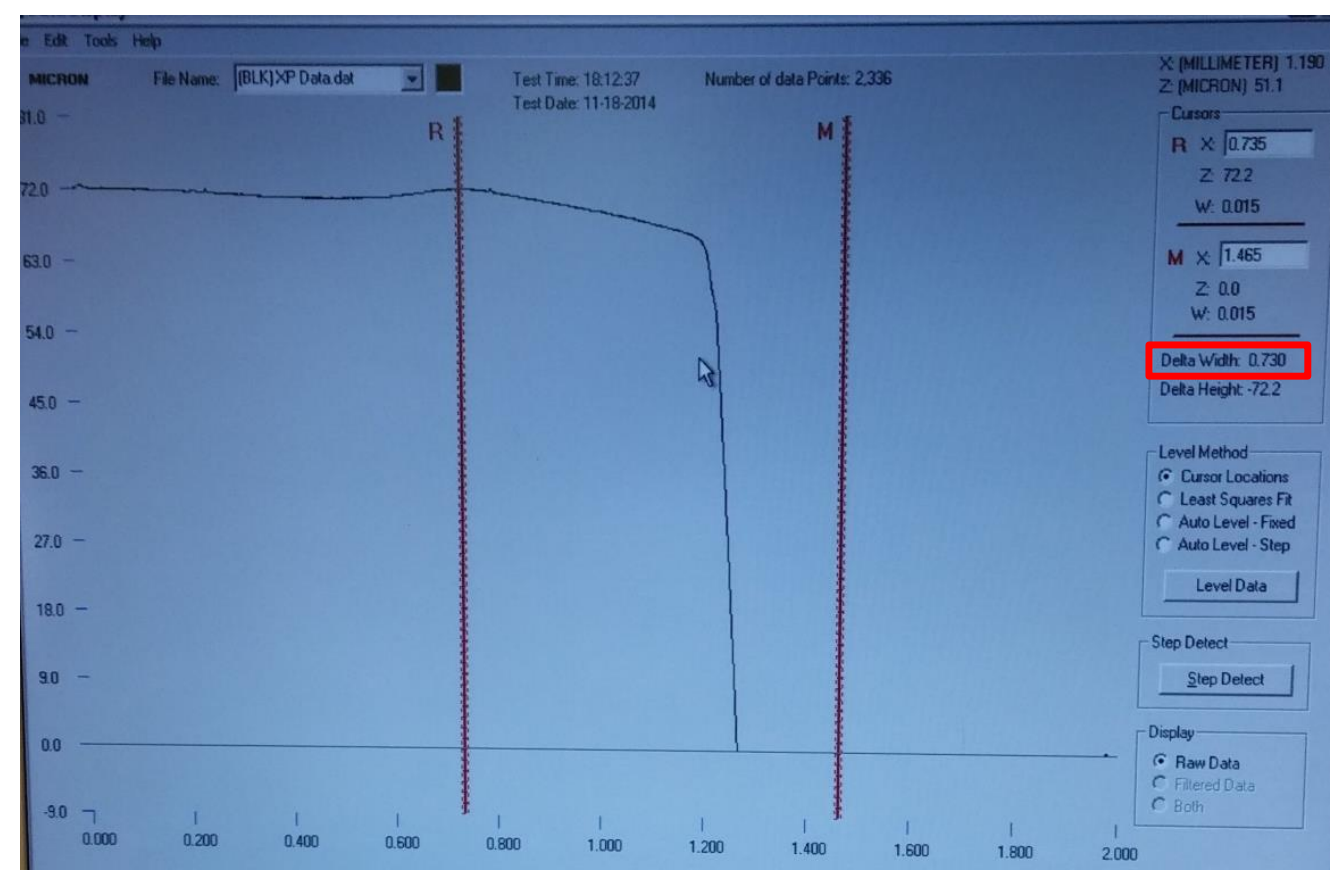

Figure 17: Profilometer output when directly measuring thickness of double sided tape

Table 12: Thickness values for double sided Kapton Tape obtained by 2 part profilometry method.

\begin{tabular}{|c|c|c|}
\hline $\begin{array}{c}\text { Thickness of Tape }+ \\
\text { Adhesive cover }(\mu \mathrm{m})\end{array}$ & $\begin{array}{c}\text { Thickness Adhesive } \\
\text { Cover }(\mu \mathrm{m})\end{array}$ & Tape Thickness $(\mu \mathrm{m})$ \\
\hline 179.9 & 87.4 & 92.5 \\
\hline 179.8 & 87.1 & 92.7 \\
\hline 177.5 & 86.8 & 90.7 \\
\hline
\end{tabular}

Acoustic advantages can also be conveyed through a flexible support structure such as double sided tape. The silicone supports can mitigate the standing waves that would be reflected from a rigid speaker frame. Research has determined that a flexural and soft device due to non-rigid supports can have an enhanced sound pressure level and reduced distortion. ${ }^{18}$ 


\subsection{Final Device Assembly}

The electrostatic actuator assembly was ultimately comprised of one diaphragm, a Pyrex slide, 4 mil thick double-sided tape, and conductive tape or wire leads attached to each electrode. This was entirely hand assembled once the physical vapor deposition processes had been performed. The first $5 \mathrm{~mm}$ device that was fabricated and tested can be seen in Figure 18.



Figure 18: $5 \mathrm{~mm}$ device 1 seen post-fabrication.

As was done throughout the fabrication process, resistance measurements were taken across the entire device. In this instance, the desired ohmmeter output was infinite resistance when measuring from one wire lead across the device to the wire attached to the opposite electrode. This is due to the insulative gap between the electrodes which causes only a tiny capacitive current (also known as leakage current) to flow through the system. The associated resistance through the system is out of range of the ohmmeter used for this measurement. If a non-infinite resistance measurement were picked up across the system, it would mean a short is present between the device and the base electrode and the voltage differential between the parallel plates is compromised. 


\section{SECTION 5. DEVICE CHARACTERIZATION}

\subsection{Overview}

The goal of this project past fabrication of a parallel plate actuator was to devise a means of characterization for such a device. In past projects, a MEMS driver has been used to drive various sized actuators while they were characterized by a mechanical contact method- either a profilometer or a customized MFDS that uses the same principles. Alternatively, this was an attempt to utilize optical and acoustic modes of characterizing similar devices. A laser was directed at the diaphragm which had a voltage applied to it, and the reflective surface of the diaphragm redirected the light to a PSD. Based on the angle of incidence of the laser on the diaphragm, the diaphragm deflection when a voltage is applied could be calculated from the PSD output. Previously, the mechanical nature of the characterization techniques limited device testing to the initial application of a DC voltage source followed by quasistatic behavior analysis. The nonphysical approach of this project opens up the possibility of dynamic analyses using the AC capability of the MEMS driver. Further attempts were made to characterize the actuators by acoustic means as well due to the potential of the actuator to generate a detectible sound pressure level. A simple microphone and data logging program were used to collect changes in the SPL created by the actuating diaphragm.

\subsection{MEMS Driver}

The MEMS driver consists of a combination of software and hardware developed by Ross Gregoriev in a past thesis project. This driver hardware can be turned on by flipping the power switch on the rear of the unit as well as the one on the front, and then by switching on all the front switches of the driver the device will be ready to generate a signal. A LabView graphical user interface (GUI) was designed to run the driver, which can apply both $A C$ and $D C$ voltages from 0 to $300 \mathrm{~V}$. As seen in Figure 19, the GUI 
provides the option of adjusting voltage amplitude, frequency, offset, and duty cycle for AC mode and DC voltage for DC mode. Testing was performed using the square wave function generator to elicit the greatest responsiveness of the diaphragms at any operating voltage. A square wave applies an impulse load to the device which gives potential for increased deflection compared to gradual sinusoidal loading. In order to configure the MEMS driver to output a square wave, the previously mentioned AC modifiers must be set, the square wave button must be clicked, and the enable output button must be clicked. For safety purposes, the applied voltage can be stopped by 3 methods: deselecting the enable output button, turning off the enable output switch on the hardware, or clicking the stop button, which shuts the whole program down. 




Figure 19: GUI of the LabView program that controls the MEMS driver.

\subsection{PSD Calibration}

The PSD used in this project tracks position by changing voltage where photons hit its surface. With light incident on its center, it registers a OV reading from each of the channels it has been connected to on the DAQ. Position changes can then trigger $+/-$ $10 \mathrm{~V}$ readings from each channel, which corresponds to movement along the horizontal and vertical axes. It is supposed to come calibrated to output a $1 \mathrm{~V}$ change for every 
millimeter the incident light moves, so a test was performed to verify this. The test setup, seen in Figure 20, reflected a laser off a diaphragm and onto the PSD. The laser, mounted on a Thor Labs high precision linear stage, was then translated $5 \mathrm{~mm}$ using the fine adjustment knob on the stage. These results, which have been plotted in Figure 21, were used to calculate the actual change in voltage for a $5 \mathrm{~mm}$ translation along the PSD surface. In Figure 21, Channels 301 and 302 correspond to the $X$ and $Y$ direction on the PSD surface, respectively. By dividing the distance traveled by the change in PSD voltage output, the following correction factor was determined:

$$
\frac{5 \mathrm{~mm}}{5.1336 \mathrm{~V}}=\mathbf{0 . 9 7 3 4 0} \frac{\mathrm{mm}}{\mathrm{V}}
$$

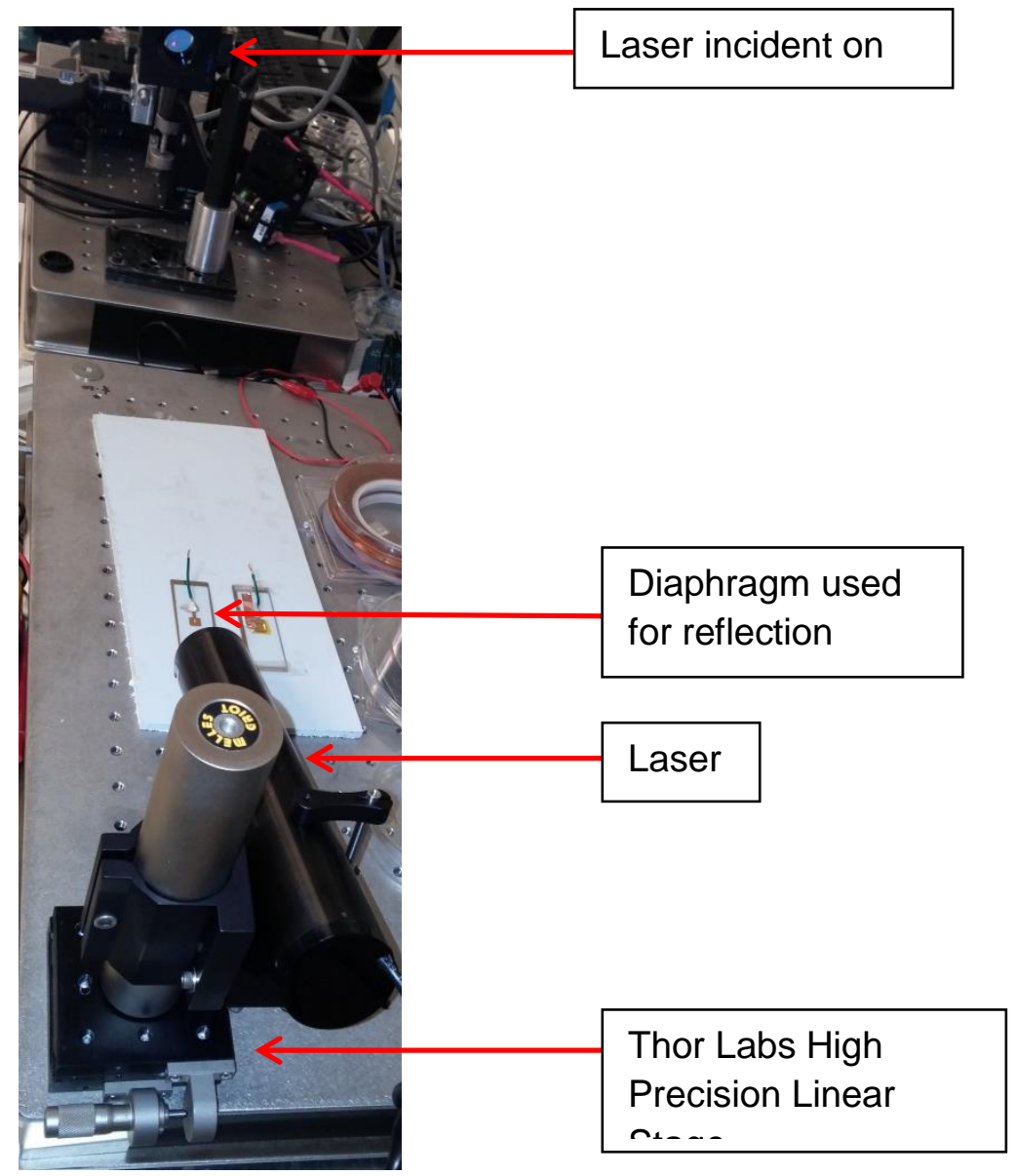

Figure 20: PSD Calibration test setup using a laser mounted on a precision linear stage to translate a laser across the PSD surface. 


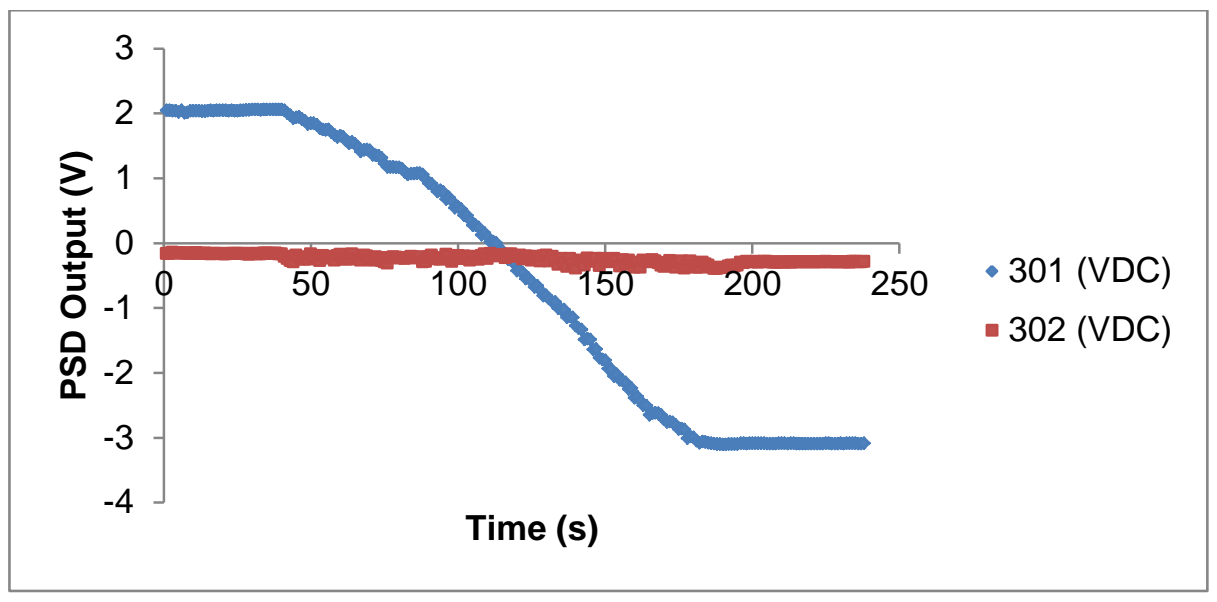

Figure 21: Channel 301 displays Voltage changes associated with horizontal translation of the laser across the PSD surface.

This correction factor can then be multiplied by the total voltage differential for a given actuation cycle of the device to determine a more accurate laser translation distance. The corresponding error associated with this result compared to the specifications of the PSD is:

$\frac{\frac{1 m m}{V}-\frac{0.97340 \mathrm{~mm}}{V}}{0.97340 \frac{\mathrm{mm}}{V}} * 100=\mathbf{2 . 7 3} \%$

\subsection{Optical Characterization Test Bed}

In order to assess the electrostatic actuation capability of the silicon diaphragms, a test setup was devised. The setup acquires data on the displacement of the diaphragm by capturing the relative change in position of the laser that is reflected off the diaphragm onto a PSD. The system is comprised of 8 components in total: a MEMS driver, a position sensitive detector, an amplifier for the PSD, a DAQ, a laser, a control box for the laser, the device under testing, and an optical breadboard. The laser is mounted on a precision angle adjustment stage, while the device under testing (DUT) and PSD are mounted on linear adjustment stages. All of these stages are mounted on 
an optical breadboard to allow for precise position control. Figure 22 shows the testing system on its workbench in the microfabrication lab.

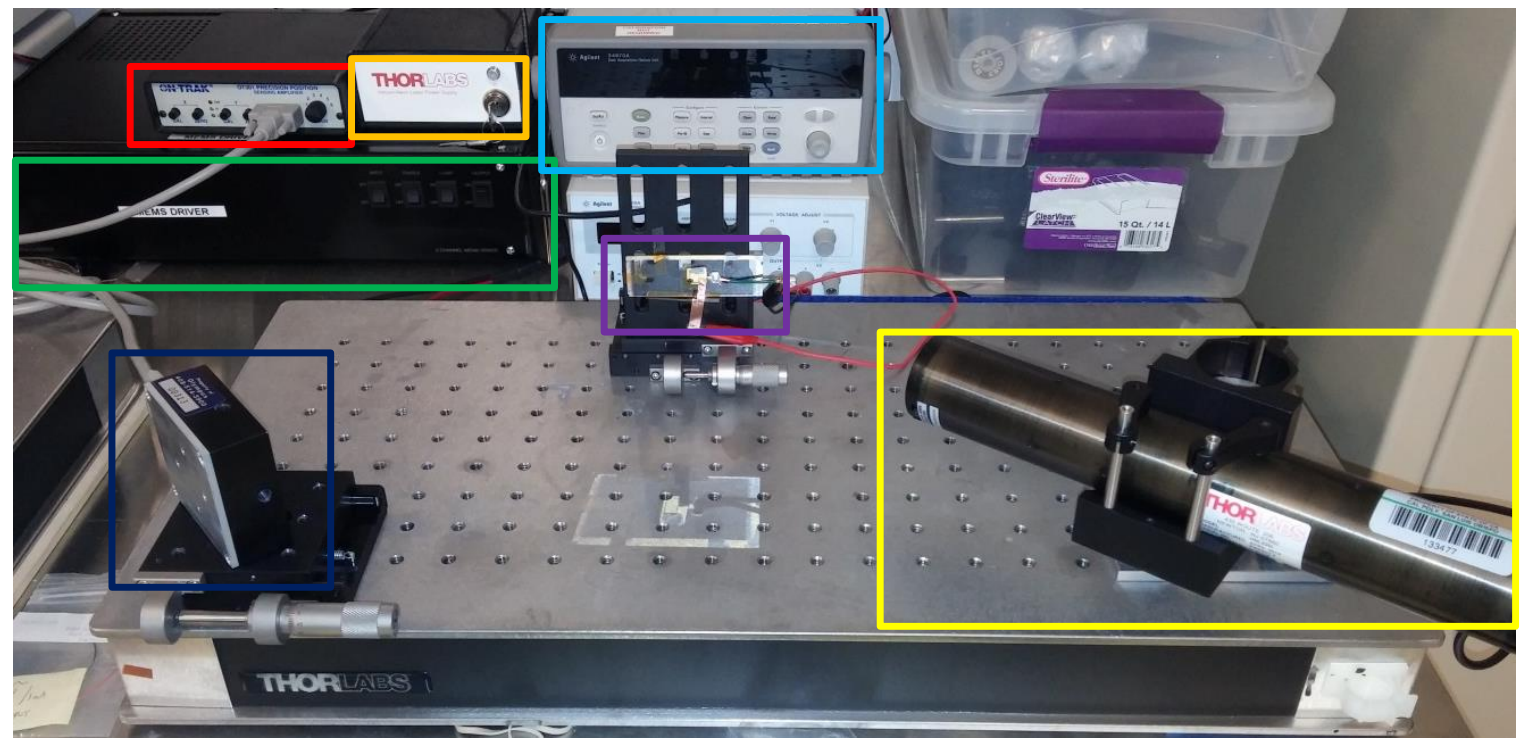

\begin{tabular}{|c|l|l|l|}
\hline \multirow{2}{*}{ KEY } & Position Sensitive & HeNe Laser & MEMS \\
\hline On-Trak PSD & Laser Power Switch & Agilent 34970 & DUT \\
\hline
\end{tabular}

Figure 22: Complete testing setup for collection of PSD output during diaphragm actuation.

The angle of incidence (AOI) of the laser on the diaphragm and the horizontal beam deflection picked up by the PSD were used in some simple trigonometry to calculate the deflection of the device. These values can be seen in the CAD assembly in Figure 23. 


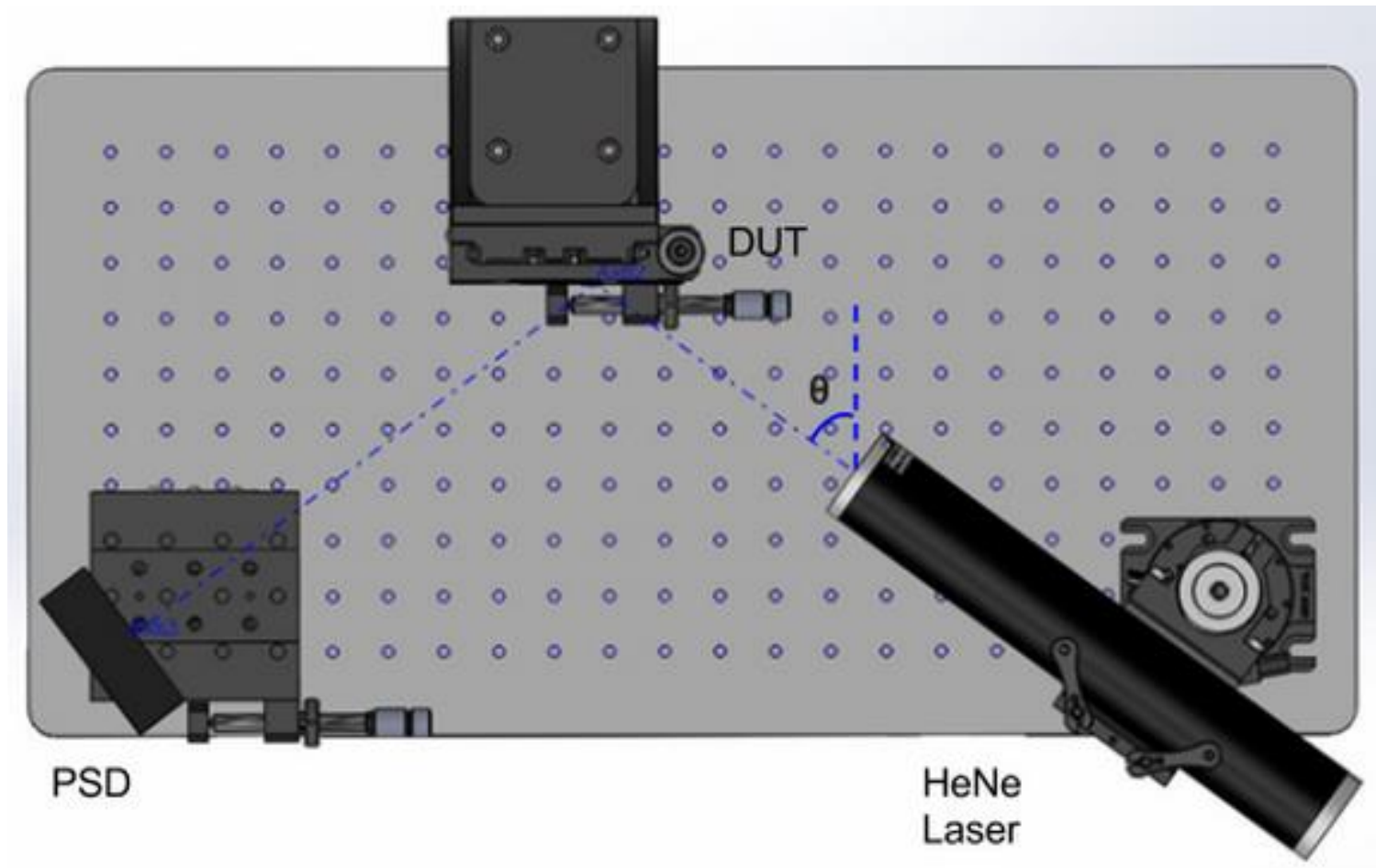

Figure 23: SolidWorks assembly of the testing setup with the AOI $\theta$ referring to the angle between the vertical and the HeNe laser beam.

Three major assumptions were made in order to calculate the diaphragm deflection based on PSD output:

1. the laser was centered on the diaphragm both vertically and horizontally

2. the deflected diaphragm surface on which the laser is incident lies on a plane parallel to its initial position

3. the diaphragm provides a smooth, uniformly reflective surface.

Figure 24 shows the simplified test station parameters based on the aforementioned assumptions. Operating under these assumptions, a rough value for the deflection of the diaphragm at the point of incidence can be calculated using Equation 4.1. 


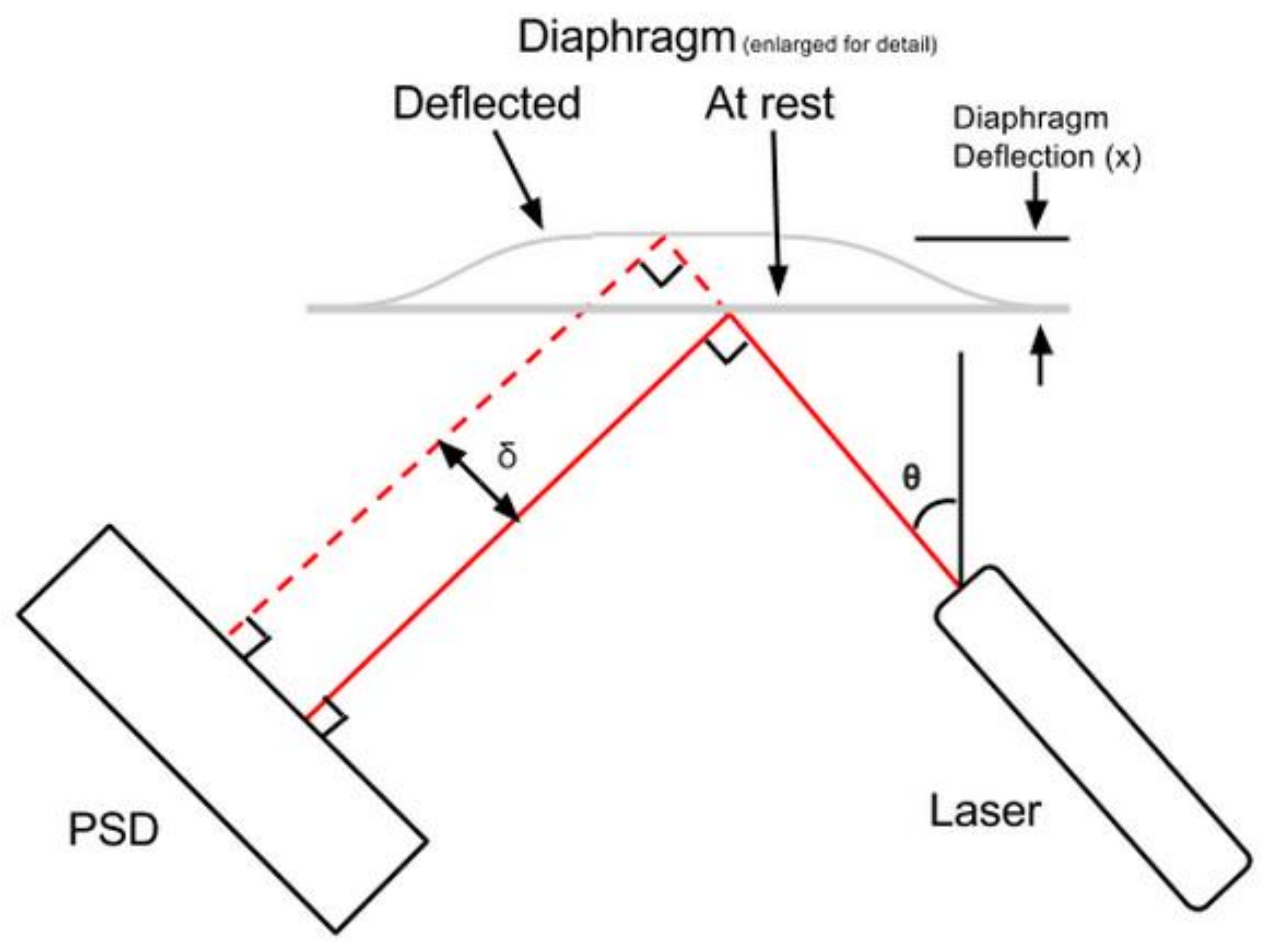

Figure 24: Simplified figure used for calculating diaphragm deflection based on $\mathrm{AOI}$ and laser translation along PSD surface.

$x_{\text {diaphragm }}=\delta * \cos (\theta)$

The angle of incidence $\theta$ was 49 degrees for this device characterization and system testing, simplifying the deflection of the diaphragm to:

$x_{\text {diaphragm }}=\delta * \cos (49) \cong 0.656 * \delta$

Because maximum deflection is the value of interest and it occurs at the center of the diaphragm, assumption 1 is critical to device characterization. Assumption 2 is reasonable because as seen in the FEA deflection results, the curvature of the diaphragm at the center is minimal and the PSD is able to average out the spread created by the laser hitting a slightly rounded surface. There is an extremely high aspect ratio between the diaphragm deflection distance and the side length, which theoretically minimizes the redirecting effects from the curvature of the sides and prevents the 
actuated location of laser incidence on the diaphragm from being significantly offset from center.

The test station was set up by a combination of visual inspection of the laser on the device surface and on-the-spot analysis of the voltage output from the PSD while an AC signal was applied to the DUT. Ideally, vertical alignment could be achieved by finding the point where the voltage output is constant on the vertical PSD channel. In reality, imperfections in the equipment holding the DUT and laser in place as well as surface defects on the DUT prevent exact vertical alignment. The precision angular adjustment dial was used to find the device's horizontal midpoint by slowly scrolling the laser across the device then visually judging when the PSD voltage output associated with the horizontal asymptote shown in Figure 25 is reached. This point symbolizes the center point because when the derivative of the change in voltage output by the PSD reaches 0 , laser deflection from the angle of the deformed diaphragm has been minimized. Figure 26 helps to explain this concept further by diagramming the laser's response to device actuation along the horizontal axis.

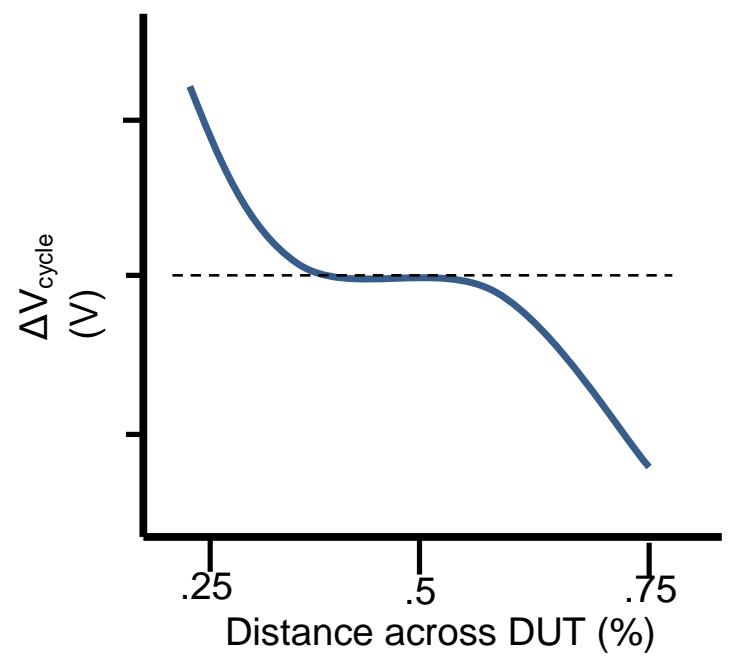

Figure 25: Idealized plot of the change in PSD voltage from non-actuated baseline values as a function of horizontal distance across the DUT during AC actuation. 




Figure 26: Diagram showing how the laser responds to device actuation based on the laser's point of incidence along the central horizontal axis of the diaphragm.



Figure 27: The HeNe laser is centered on the diaphragm using the horizontal and vertical fine adjustment knobs of the mounting assembly. 
While this approach to finding a vertical center point first then analyzing the oscillating device data output in real time seemed feasible, excessive system noise and human error prevented this from being effectively implemented in testing. Ultimately, location of the diaphragm center points was assessed on a strictly visual basis.

\subsection{Sampling Rate Limitations}

A number of issues arose during initial testing of the optical measurement testing setup, primarily due to the sampling rate of the DAQ. The Agilent 34970 DAQ operates using mechanical relays that seemed to be the limiting factor of sampling rate in the system. The PSD has a $15 \mathrm{kHz}$ sampling limit and while the DAQ software allows it to be set to a 1 millisecond sampling interval $(1 \mathrm{kHz})$, data collection was actually limited to an 89 millisecond sampling interval. An 89 millisecond sampling interval is an $11.2 \mathrm{~Hz}$ collection rate, which in itself eliminated the possibility of testing the diaphragms anywhere near their resonant frequencies, which fell between 1-5 kHz.

According to the Nyquist Theorem, the sampling rate must be at least twice as fast as the bandwidth of the signal in order to prevent aliasing in the analog to digital conversion process. ${ }^{19}$ Aliasing is the phenomenon of collecting a false lower frequency component due to data acquisition being too slow.

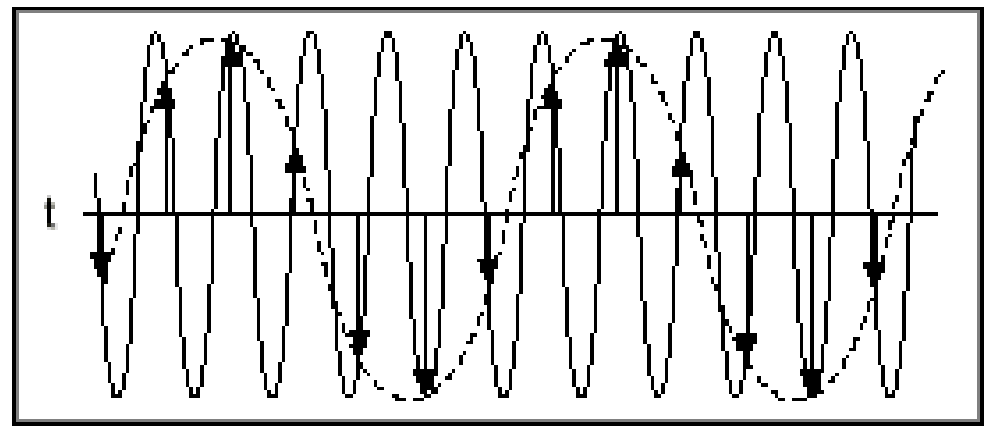

Figure 28: Demonstration of aliasing where the dashed line is the false lower frequency component being reconstructed from the solid line signal. ${ }^{19}$ 
In order to operate in adherence with the Nyquist Theorem, device testing must occur at $5 \mathrm{~Hz}$ or below in order to accurately reconstruct the correct frequency response of the device. The greater the multiplier relating the sampling frequency to the device signal the less likely the signal will be attenuated. This means $5 \mathrm{~Hz}$ testing may experience some attenuation depending on when actuation is triggered with respect to when the next sample is taken by the DAQ, so $2 \mathrm{~Hz}$ testing was also performed to ensure full resolution of device deflection. With a square wave signal powering the device, aliasing is less likely as there are two discrete voltages, $0 \mathrm{~V}$ and the testing voltage (260 or $300 \mathrm{~V}$ ), and there is additional time to perform capacitive charging so the full electrostatic potential is realized.

\subsection{Optical Testing Schema}

This section aims to congregate all previous mention of the modes of optical testing in a single location. It has been mentioned that the diaphragms will be characterized in both static and dynamic loading. This means both DC and AC signals will be applied using the MEMS driver to assess deflection patterns, frequency response, repeatability and reproducibility. Reliability, referring to the system's capability of achieving the same results twice, is greatly affected by imprecise setup procedure, which in turn affects the ability to accurately assess the repeatability of an actuator. A gage $R \& R$ study can be used to analyze the variation in a measuring system between 3 primary sources: the device under testing, the appraiser, and the equipment. ${ }^{20}$ In this situation, a single operator was used so the appraiser variability could not be analyzed and there was not time to perform a fully randomized testing process by the time all the devices had been fabricated. For these reasons, a simplified design of experiments was 
used to characterize the properties and capabilities of the diaphragms and the measurement system.

Each of the devices tested underwent 3 tests at each frequency and voltage combination for a total of $12 \mathrm{AC}$ tests. 2 different devices of each side length were used in hopes of establishing how consistent the performance of nearly identical devices is. The AC testing plan can be seen in Table 13, for which each of the stated tests lasts 1 minute and 10 seconds and is performed 3 times. The first 10 seconds of each test are taken with no power to the device in order to set a baseline PSD reading and to quantify the noise. All data collection was done at 89 millisecond intervals, which is the maximum frequency allowed by the DAQ.

Table 13: The testing plan for all devices under dynamic loading

\begin{tabular}{|c|c|c|c|}
\hline $\begin{array}{l}\text { Device Side } \\
\text { Length }(\mathrm{mm})\end{array}$ & Device Number & Voltage (V) & Frequency $(\mathrm{Hz})$ \\
\hline 4 & 1 & 260 & 2 \\
\hline 4 & 1 & 300 & 2 \\
\hline 4 & 1 & 260 & 5 \\
\hline 4 & 1 & 300 & 5 \\
\hline 4 & 2 & 260 & 2 \\
\hline 4 & 2 & 300 & 2 \\
\hline 4 & 2 & 260 & 5 \\
\hline 4 & 2 & 300 & 5 \\
\hline 5 & 1 & 260 & 2 \\
\hline 5 & 1 & 300 & 2 \\
\hline 5 & 1 & 260 & 5 \\
\hline 5 & 1 & 300 & 5 \\
\hline 5 & 2 & 260 & 2 \\
\hline 5 & 2 & 300 & 2 \\
\hline 5 & 2 & 260 & 5 \\
\hline 5 & 2 & 300 & 5 \\
\hline 7 & 1 & 260 & 2 \\
\hline 7 & 1 & 300 & 2 \\
\hline 7 & 1 & 260 & 5 \\
\hline 7 & 1 & 300 & 5 \\
\hline 7 & 2 & 260 & 2 \\
\hline 7 & 2 & 300 & 2 \\
\hline 7 & 2 & 260 & 5 \\
\hline 7 & 2 & 300 & 5 \\
\hline
\end{tabular}


After dynamic testing, static testing was performed at $300 \mathrm{~V}$ for each of the $5 \mathrm{~mm}$ and $7 \mathrm{~mm}$ side length devices used for the previous tests. Due to the time constraints of the project and the length of time required for each static test, each device was only tested once. $4 \mathrm{~mm}$ side length devices were excluded from static testing due to their poor results in preliminary testing which showed a very large noise to signal ratio. A total of 4 tests were performed at 300V DC for an hour each in order to maximize device deflection and stresses, which should result in greater resolution of device stability over time. This works out to 1 test performed on each of the $25 \mathrm{~mm}$ and $7 \mathrm{~mm}$ devices. Should the electrostatic force slowly taper off or waver over time, the mechanical restoring force would cause a more noticeable change in deflection when the initial deflection amplitude is greater. The DC testing plan can be seen in Table 14, with each test being performed only 1 time. Over the course of the 1 hour test period, 1 minute collections were taken as the DC voltage was initially applied then again every 15 minutes.

Table 14: The testing plan for all devices under static loading conditions

\begin{tabular}{|c|c|c|}
\hline Device Side Length $(\mathrm{mm})$ & Device Number & Voltage $(\mathrm{V})$ \\
\hline 5 & 1 & 300 \\
\hline 5 & 2 & 300 \\
\hline 5 & 1 & 300 \\
\hline 5 & 2 & 300 \\
\hline 7 & 1 & 300 \\
\hline 7 & 2 & 300 \\
\hline 7 & 1 & 300 \\
\hline 7 & 2 & 300 \\
\hline
\end{tabular}




\subsection{Optical Testing Results}

Due to the massive amount of data collected, representative samples were taken from each test. The key parameters of the $\mathrm{AC}$ device deflection that required collection were the frequency, the amplitude of the oscillations, and the noise. The frequency at which devices were actuating was assessed by visual inspection of the PSD output, which can be plotted over a short time period to verify adherence to the expected output. This can be seen on the next page in Figure 29, which plots PSD output from a test of 7 mm device 1 with a $260 \mathrm{~V} \mathrm{AC}$ square wave signal running at $2 \mathrm{~Hz}$. By counting the local maxima and minima in a set period, the mechanical frequency response of the diaphragm can be compared to the output frequency of the MEMS driver. Figure 30 displays the actuator response of $7 \mathrm{~mm}$ device 2 driven at $5 \mathrm{~Hz}$ and $260 \mathrm{~V}$. 




Figure 29 (a): Full minute and 10 seconds of data collected for $7 \mathrm{~mm}$ device 2 at $300 \mathrm{~V}$ $2 \mathrm{~Hz}$. (b) Expanded view of first 20 seconds of data collection. (c) Expanded view of initial actuation data with a square outlining 4 oscillations in a 2 second period, which validates the $2 \mathrm{~Hz}$ driving frequency was achieved mechanically. 


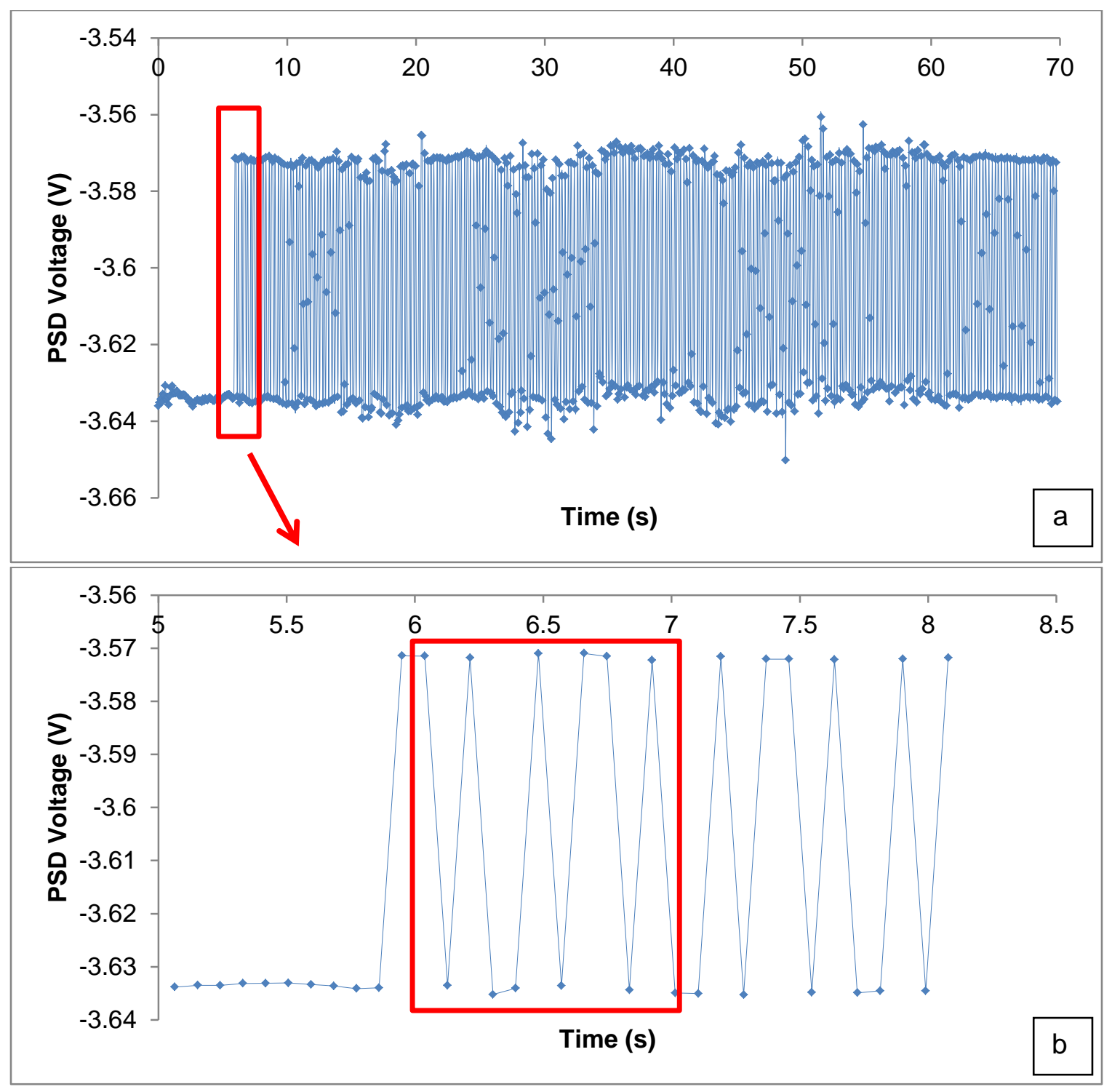

Figure 30 (a): $7 \mathrm{~mm}$ device 2 data from testing at $260 \mathrm{~V} \mathrm{AC} 5 \mathrm{~Hz}$. (b) Expanded view of the data from (a) showing 5 peaks and troughs in the first second of actuation, validating that $5 \mathrm{~Hz}$ was achieved mechanically.

Due to the oscillating patterns of the PSD voltage output, each data set had to be post-processed to find the local oscillation amplitudes and total deflections relative to a baseline value. In the following tables, the post-processed data is broken down by device being tested, the testing parameters, and the immediate deflection and oscillation amplitude. Additional data can be found for all devices at both AC frequencies and voltages in Appendix III. One important consideration for this data is that while it has 
been converted into a distance metric, it is the distance the laser translated along the horizontal axis of the PSD surface and not the distance the diaphragm deflected. The distance the center of the diaphragm has physically deflected, which is roughly 0.656 times the distance the laser traveled across the PSD, can be estimated using Equation 4.1. The immediate oscillation amplitude values are simply a calculation of the local minima subtracted from the local maxima at the beginning of device actuation. To find the immediate PSD deflection, the local maxima were subtracted from the PSD baseline voltage collected at the beginning of each test prior to device actuation. As was determined in the PSD calibration section, the laser travels $0.9734 \mathrm{~mm}$ on the surface of the PSD per volt change in output, so the voltage output was multiplied by 973 to convert it to a micron distance value. In all subsequent plots, collection point 1 refers to immediately after powering the actuator, point 2 is 30 seconds after, and point 3 is 1 minute after.

Table 15: Oscillation results immediately, 30 seconds, and 60 seconds after powering of $4 \mathrm{~mm}$ devices tested at 2 and $5 \mathrm{~Hz}, 260 \mathrm{~V}$.

\begin{tabular}{|c|c|c|c|c|c|c|}
\hline $\begin{array}{c}\text { Device } \\
\text { Size }(\mathrm{mm})\end{array}$ & Device \# & Rep & $\begin{array}{c}\text { Frequency } \\
(\mathrm{Hz})\end{array}$ & $\begin{array}{c}\text { Immediate } \\
\text { Oscillation } \\
\text { Amp (um) }\end{array}$ & $\begin{array}{c}30 \mathrm{Sec} \\
\text { Oscillation } \\
\text { Amp (um) }\end{array}$ & $\begin{array}{c}60 \text { Sec } \\
\text { Oscillation } \\
\text { Amp (um) }\end{array}$ \\
\hline 4 & 1 & 1 & 2 & 9.1621 & 9.584 & 10.52 \\
\hline 4 & 1 & 2 & 2 & 10.1377 & 8.7007 & 7.3297 \\
\hline 4 & 1 & 3 & 2 & 7.277 & 7.4611 & 6.9075 \\
\hline 4 & 2 & 1 & 2 & 13.1961 & 12.3392 & 12.9588 \\
\hline 4 & 2 & 2 & 2 & 14.0794 & 11.5878 & 10.955 \\
\hline 4 & 2 & 3 & 2 & 12.0228 & 13.2225 & 10.7178 \\
\hline 4 & 1 & 1 & 5 & 7.5406 & 11.1392 & 5.4446 \\
\hline 4 & 1 & 2 & 5 & 6.3937 & 6.2091 & 2.518 \\
\hline 4 & 1 & 3 & 5 & 7.8702 & 10.5727 & 4.1394 \\
\hline 4 & 2 & 1 & 5 & 10.5727 & 10.164 & 8.8194 \\
\hline 4 & 2 & 2 & 5 & 9.7159 & 8.8326 & 1.0282 \\
\hline 4 & 2 & 3 & 5 & 13.8949 & 8.3579 & 8.5426 \\
\hline
\end{tabular}




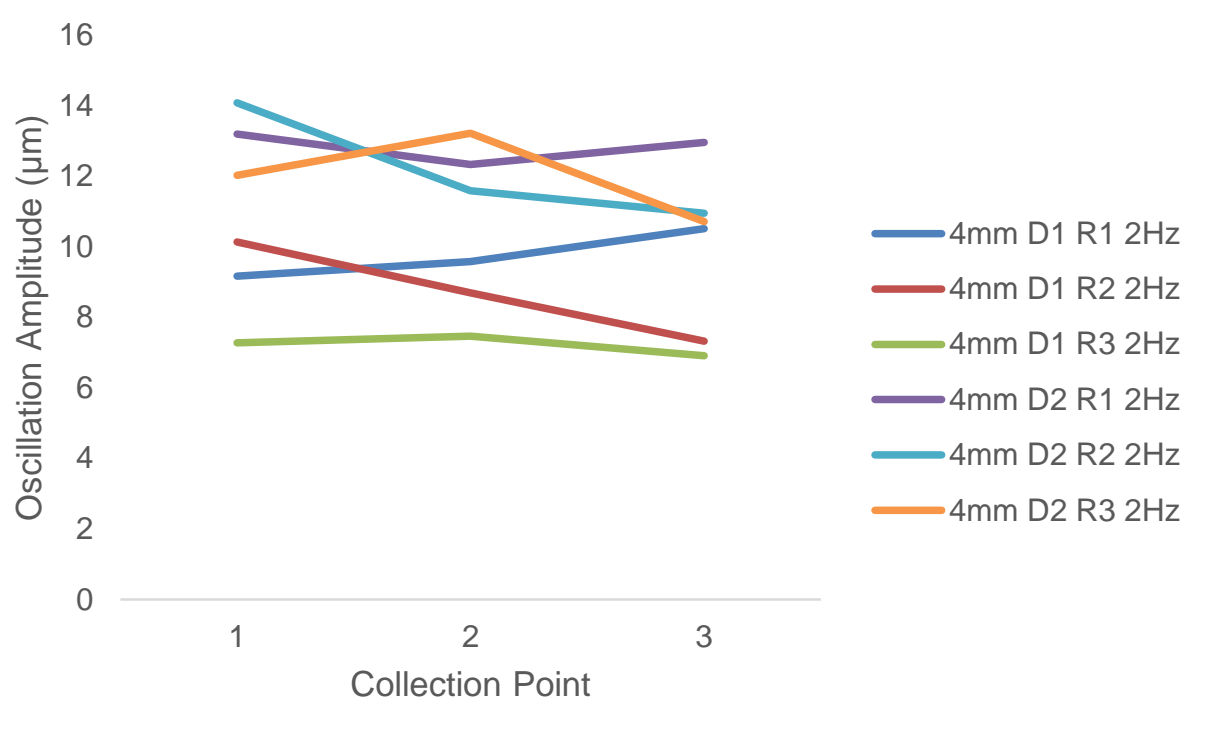

Figure 31: Oscillation amplitudes over time for $4 \mathrm{~mm}$ devices tested at $260 \mathrm{~V}$ for 1 minute (device number is denoted by $\mathrm{D} \#$ and replicate by $\mathrm{R} \#$ ).

Table 16: Oscillation results immediately, 30 seconds, and 60 seconds after powering of $5 \mathrm{~mm}$ devices tested at 2 and $5 \mathrm{~Hz}, 260 \mathrm{~V}$.

\begin{tabular}{|c|c|c|c|c|c|c|}
\hline $\begin{array}{c}\text { Device } \\
\text { Size }(\mathrm{mm})\end{array}$ & Device \# & Rep & $\begin{array}{c}\text { Frequency } \\
(\mathrm{Hz})\end{array}$ & $\begin{array}{c}\text { Immediate } \\
\text { Oscillation } \\
\text { Amplitude (um) }\end{array}$ & $\begin{array}{c}30 \mathrm{Sec} \\
\text { Oscillation } \\
\text { Amp (um) }\end{array}$ & $\begin{array}{c}60 \text { Sec } \\
\text { Oscillation } \\
\text { Amp (um) }\end{array}$ \\
\hline 5 & 1 & 1 & 2 & 8.8194 & 5.8533 & 2.0434 \\
\hline 5 & 1 & 2 & 2 & 5.6555 & 8.5557 & 9.7949 \\
\hline 5 & 1 & 3 & 2 & 24.5469 & 22.7803 & 21.8575 \\
\hline 5 & 2 & 1 & 2 & 14.9495 & 15.0022 & 12.6161 \\
\hline 5 & 2 & 2 & 2 & 16.1887 & 14.844 & 13.6839 \\
\hline 5 & 2 & 3 & 2 & 12.7083 & 14.0794 & 12.6028 \\
\hline 5 & 1 & 1 & 5 & 8.7271 & 8.5162 & 10.6254 \\
\hline 5 & 1 & 2 & 5 & 8.9644 & 6.1696 & 2.8607 \\
\hline 5 & 1 & 3 & 5 & 1.7533 & 2.5443 & 1.371 \\
\hline 5 & 2 & 1 & 5 & 13.8421 & 18.1397 & 15.4109 \\
\hline 5 & 2 & 2 & 5 & 12.8007 & 11.746 & 0.066 \\
\hline 5 & 2 & 3 & 5 & 12.6556 & 23.5447 & 13.2752 \\
\hline
\end{tabular}






Figure 32: Oscillation amplitudes over time for $5 \mathrm{~mm}$ devices tested at $260 \mathrm{~V}$ for 1 minute (device number is denoted by $\mathrm{D} \#$ and replicate by $\mathrm{R} \#$ ).

Table 17: Oscillation results immediately after powering the $7 \mathrm{~mm}$ devices at 2 and $5 \mathrm{~Hz}$, $260 \mathrm{~V}$

\begin{tabular}{|c|c|c|c|c|c|c|}
\hline $\begin{array}{c}\text { Device } \\
\text { Size } \\
(\mathrm{mm})\end{array}$ & $\begin{array}{c}\text { Device } \\
\#\end{array}$ & Rep & $\begin{array}{c}\text { Frequency } \\
(\mathrm{Hz})\end{array}$ & $\begin{array}{c}\text { Immediate } \\
\text { Oscillation } \\
\text { Amplitude } \\
\text { (um) }\end{array}$ & $\begin{array}{c}30 \text { Sec } \\
\text { Oscillation } \\
\text { Amp (um) }\end{array}$ & $\begin{array}{c}60 \mathrm{Sec} \\
\text { Oscillation } \\
\text { Amp (um) }\end{array}$ \\
\hline 7 & 1 & 1 & 2 & 552.1934 & 549.9259 & 547.1311 \\
\hline 7 & 1 & 2 & 2 & 570.4781 & 569.5948 & 567.5251 \\
\hline 7 & 1 & 3 & 2 & 116.3659 & 114.8499 & 122.1268 \\
\hline 7 & 2 & 1 & 2 & 71.3329 & 67.9976 & 67.9844 \\
\hline 7 & 2 & 2 & 2 & 66.1915 & 65.6114 & 64.0427 \\
\hline 7 & 2 & 3 & 2 & 60.9184 & 63.5945 & 65.1369 \\
\hline 7 & 1 & 1 & 5 & 570.8604 & 567.3142 & 563.9919 \\
\hline 7 & 1 & 2 & 5 & 569.1993 & 563.9655 & 562.1463 \\
\hline 7 & 1 & 3 & 5 & 115.9441 & 120.4262 & 26.6163 \\
\hline 7 & 2 & 1 & 5 & 64.0032 & 67.2067 & 62.8562 \\
\hline 7 & 2 & 2 & 5 & 63.054 & 62.5399 & 51.4266 \\
\hline 7 & 2 & 3 & 5 & 69.2632 & 67.4703 & 63.5418 \\
\hline
\end{tabular}

Another useful means by which the data can be visualized is by the boxplot in

Figure 33. Side by side comparisons can be made between each device size, applied voltage, and their respective deflections. Results from $7 \mathrm{~mm}$ device 1 were excluded due to the extraordinarily large deflection measurements. It was apparent during post- 
processing that the point of laser incidence on the diaphragm was on an angled portion of the diaphragm during its deflection, which as demonstrated in Figure 26 causes a greatly exaggerated translation of the laser on the PSD.

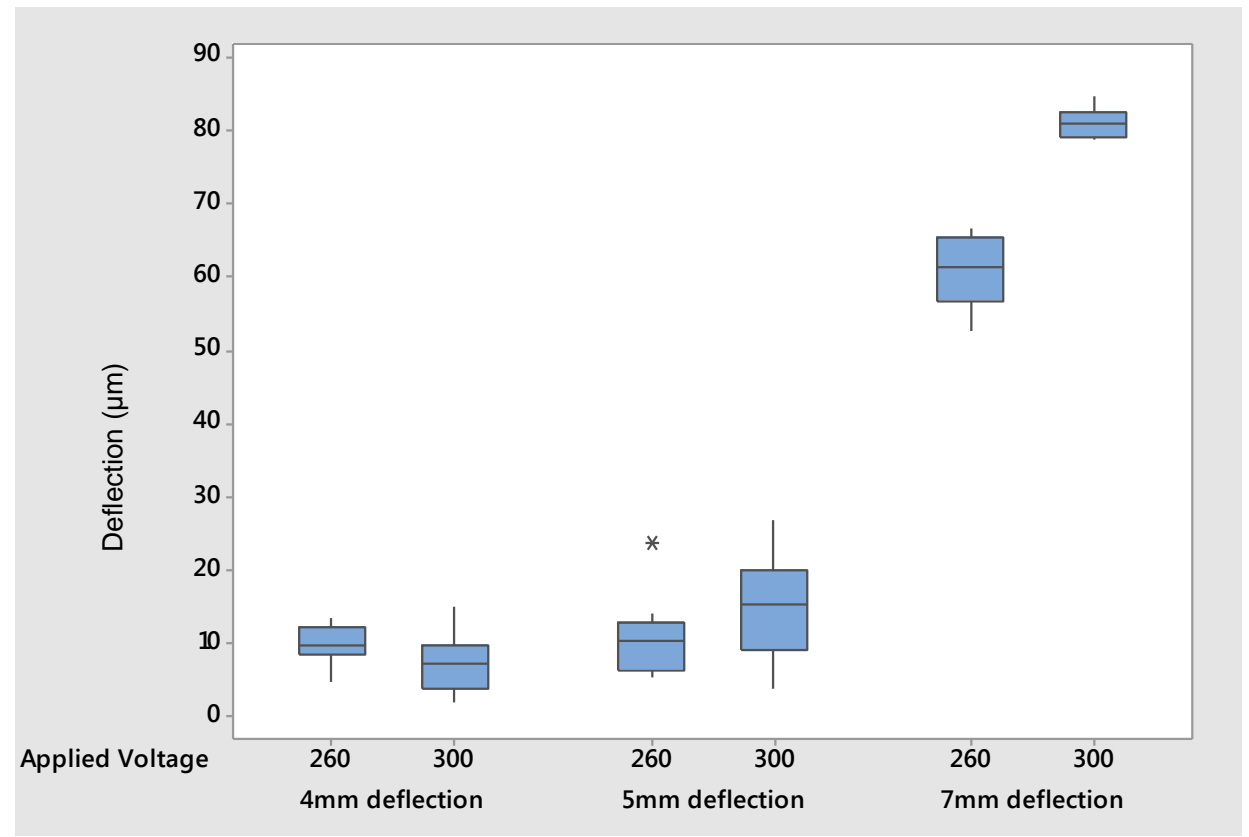

Figure 33: Boxplot of distances traveled by the laser on the PSD as a result of oscillating diaphragm deflections. Data is broken up by applied voltage and device side length, including $24 \mathrm{~mm}, 25 \mathrm{~mm}$, and $17 \mathrm{~mm}$ devices.

The DC testing can best be summarized by magnitude of initial deflection and the plots seen in the following figures. Table 18 displays the initial diaphragm deflection from each of the 5 and $7 \mathrm{~mm}$ devices at the $300 \mathrm{~V} \mathrm{DC}$ output used for all hour-long stability tests. Figures 34 and 35 exemplify the difficulties that were encountered with discontinuous, lengthy stability testing with the current test setup.

Table 18: Calculated initial diaphragm deflection during DC testing at $300 \mathrm{~V}$.

\begin{tabular}{|c|c|c|c|}
\hline Device & PSD Output $(\mathrm{V})$ & Laser Travel on PSD $(\mu \mathrm{m})$ & $\begin{array}{c}\text { Calculated Diaphragm } \\
\text { Deflection }(\mu \mathrm{m})\end{array}$ \\
\hline $5 \mathrm{~mm}$ Device 1 & 0.033 & 31.73 & 20.82 \\
\hline $5 \mathrm{~mm}$ Device 2 & 0.063 & 61.34 & 40.24 \\
\hline $7 \mathrm{~mm}$ Device 1 & 0.278 & 269.98 & 177.11 \\
\hline $7 \mathrm{~mm}$ Device 2 & 0.117 & 113.38 & 74.38 \\
\hline
\end{tabular}




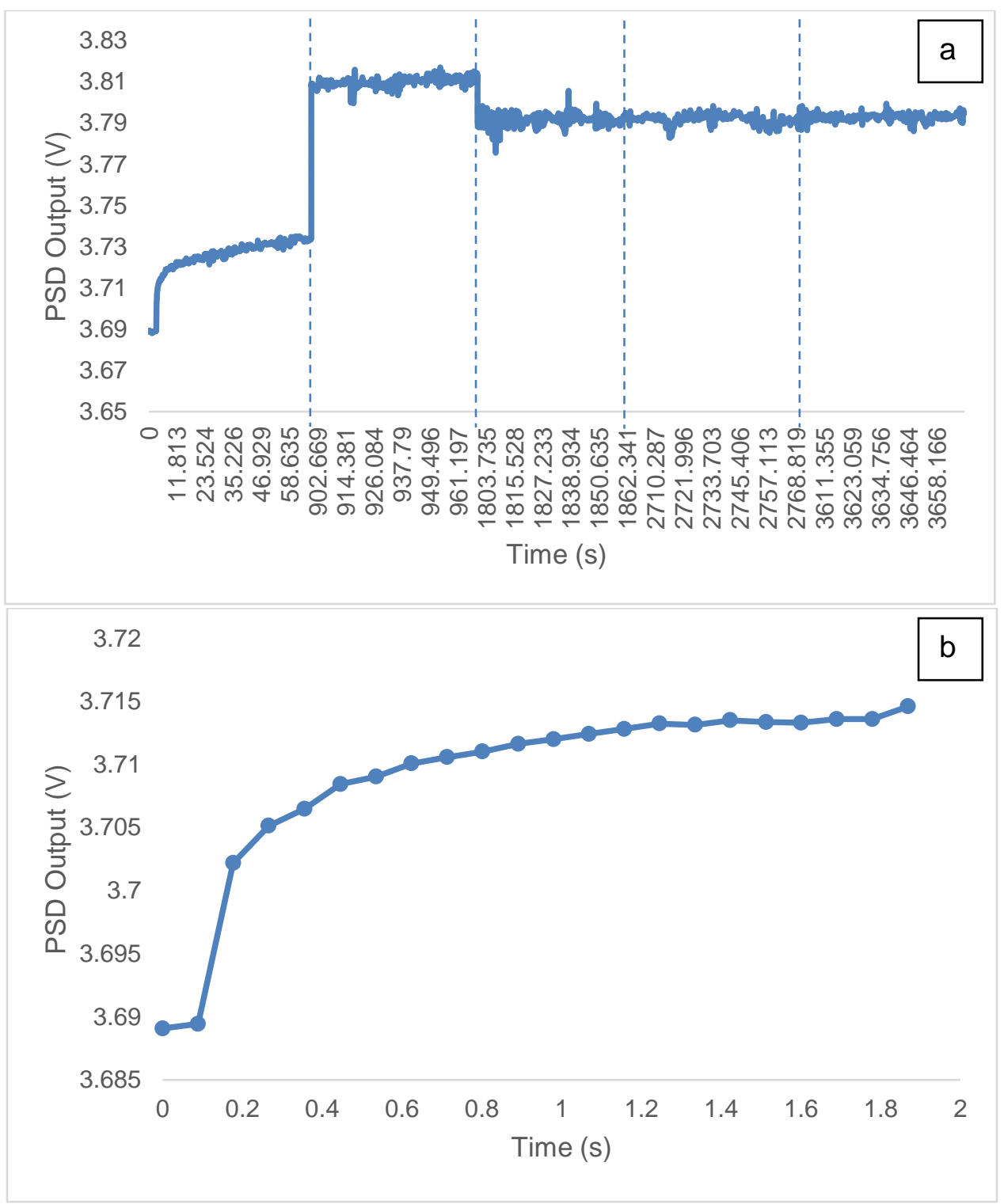

Figure 34 (a): DC stability testing of $5 \mathrm{~mm}$ device 1 at $300 \mathrm{~V}$ with split lines between each 1 minute test segment, which were each 15 minutes apart. (b) Expanded view of the first 2 seconds of deflection demonstrating a gradual mechanical response. 


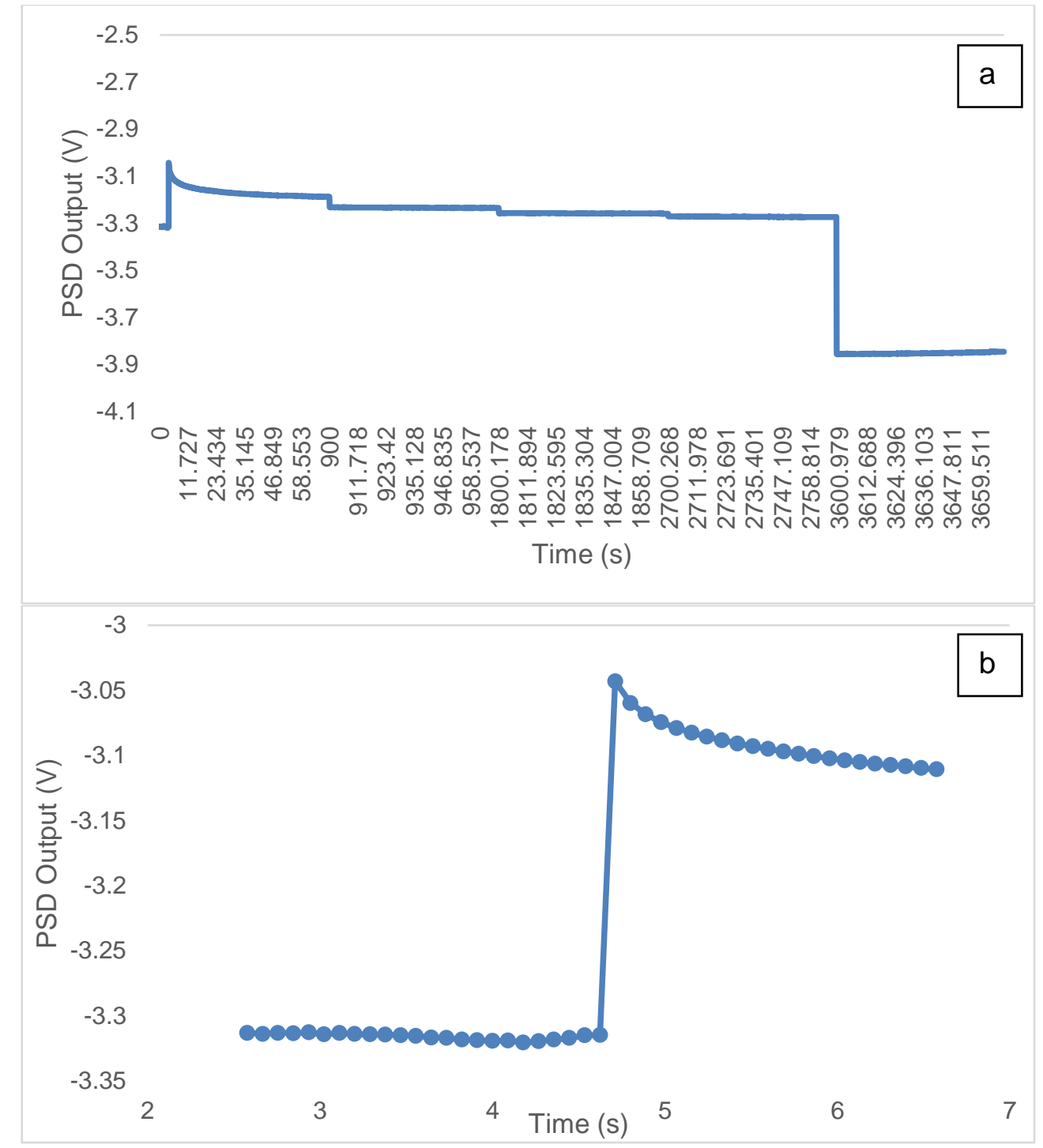

Figure 35 (a): DC stability testing of $7 \mathrm{~mm}$ device 1 at $300 \mathrm{~V}$. (b) Expanded view of the diaphragm response at the time of actuation.

It is key to note that the deflection of the 4 and $5 \mathrm{~mm}$ devices were too small to visualize with the naked eye, but with the $7 \mathrm{~mm}$ devices the deflections could be seen at both 260 and $300 \mathrm{~V}$. Additionally, the $7 \mathrm{~mm}$ devices responded so much more efficiently than 4 or $7 \mathrm{~mm}$ that the deflections could be detected over the system noise down to approximately $15-20 \mathrm{~V}$ applied. A differentiable signal could not be attained below approximately $220 \mathrm{~V}$ for a $4 \mathrm{~mm}$ device and $180 \mathrm{~V}$ for a $5 \mathrm{~mm}$ device. 


\subsection{Analysis of Optical Test Results}

In device characterization, noise contributed to a high degree of variability in PSD output whether the tests were a minute or an hour long. For $260 \mathrm{~V}$ AC testing, the standard deviations of the pre-test noise ranged from 0.428 to $5.98 \mu \mathrm{m}$ and averaged $1.988 \mu \mathrm{m}$. These numbers were then compared to the average and standard deviation of the change in oscillation amplitudes for all devices over the 1 minute AC testing period, which are 3.797 and $3.093 \mu \mathrm{m}$, respectively. The overlap in the standard deviation of the pre-test noise and the change in oscillation amplitude values suggest the two could be too similar to draw any conclusions as to whether noise or an actual change in device oscillation amplitude is causing the observed results. Also supporting the claim that the noise is causing the majority of instability in AC oscillation is the fact that oscillation amplitudes do not follow a consistently increasing or decreasing trend over time as seen by Figures 31, 32, and multiple figures in Appendix III. In order to validate this belief, a 1 sample t-test was performed in which the standard deviation of the noise was used as the hypothesized mean $\left(\mu_{0}\right)$ and the following criteria was tested:

$\mu_{\Delta \mathrm{O} \text { scillation Amp }}>\mu_{0}$

where $\mu_{\Delta O \text { oscillation Amp }}$ is the mean oscillation amplitude. A t-value of 3.41 and $p$-value of 0.001 were obtained, which suggests that within a $95 \%$ confidence interval, we can reject the null hypothesis. These results suggest the noise during testing is too great to resolve changes in electrostatic effects over the course of the tests performed. In other words, it can be said with $95 \%$ confidence that the variability in oscillation magnitude is less than or equal to the standard deviation of the noise, proving a reasonable degree of device actuation repeatability. 
An ANOVA test was performed to verify that PSD output could be differentiated based on device size, device number, and voltage applied. In this ANOVA test, the data was blocked by replicate and interaction terms were included for the three other factors, as seen in Figure 36. Two interaction terms- interaction between applied voltage and device size and interaction between applied voltage and device number- accounted for the vast majority of variability in the data.

\begin{tabular}{|c|c|c|c|c|c|c|c|}
\hline Factor & Type & Levels & \multicolumn{5}{|c|}{ Values } \\
\hline Device Size (mm) & Fixed & 3 & \multicolumn{5}{|c|}{$4,5,7$} \\
\hline Device Number & Fixed & 2 & \multicolumn{5}{|c|}{1,2} \\
\hline Vapplied (V) & Fixed & 2 & \multicolumn{5}{|c|}{260,300} \\
\hline Replicate & Fixed & 3 & \multicolumn{5}{|c|}{$1,2,3$} \\
\hline \multicolumn{8}{|c|}{ Analysis of Variance } \\
\hline \multicolumn{3}{|l|}{ Source } & $\mathrm{DF}$ & Adj $S S$ & Adj MS & F-Value & P-Value \\
\hline \multicolumn{3}{|l|}{ Device Size (mm) } & 2 & 464744 & 232372 & 42.44 & 0.000 \\
\hline \multicolumn{3}{|l|}{ Device Number } & 1 & 166959 & 166959 & 30.49 & 0.000 \\
\hline \multicolumn{3}{|l|}{ Vapplied (V) } & 1 & 500 & 500 & 0.09 & 0.764 \\
\hline \multicolumn{3}{|l|}{ Replicate } & 2 & 28635 & 14317 & 2.61 & 0.082 \\
\hline \multicolumn{3}{|c|}{ Device Size (mm)*Device Number } & 2 & 266549 & 133274 & 24.34 & 0.000 \\
\hline \multicolumn{3}{|c|}{ Device Size (mm)*Vapplied (V) } & 2 & 704 & 352 & 0.06 & 0.938 \\
\hline \multicolumn{3}{|c|}{ Device Number*Vapplied (V) } & 1 & 83 & 83 & 0.02 & 0.902 \\
\hline \multicolumn{3}{|l|}{ Error } & 54 & 295679 & 5476 & & \\
\hline \multicolumn{3}{|l|}{ Lack-of-Fit } & 21 & 294770 & 14037 & 509.73 & 0.000 \\
\hline \multicolumn{3}{|l|}{ Pure Error } & 33 & 909 & 28 & & \\
\hline \multicolumn{3}{|l|}{ Total } & 65 & 1242791 & & & \\
\hline
\end{tabular}

Model Summary

$\begin{array}{rrrr}\text { S } & \text { R-sq } & \text { R-sq(adj) } & \text { R-sq (pred) } \\ 73.9968 & 76.21 \% & 71.36 \% & 63.24 \%\end{array}$

Figure 36: ANOVA readout from Minitab for analysis of $A C$ characterization results.

Due to the complications of such a multifaceted ANOVA, comparisons were simplified into a few direct comparison t-tests. Based on the results seen in Figure 33, the $7 \mathrm{~mm}$ devices outperform the others in terms of achievable deflection under the same power limitations. Paired t-tests were performed between the $260 \mathrm{~V}$ and $300 \mathrm{~V}$ deflections of each sized device to determine which sized devices provide a significant 
enough difference in responses for the system to resolve. For $4 \mathrm{~mm}$ devices, this test gives a t-value of 3.01 and a p-value of 0.012 as seen in the Minitab results in Figure 37. This low p-value means the null hypothesis of equivalence can be rejected with $95 \%$ confidence and one of the displacement means is greater than the other. It is apparent from Figure 33 that the mean for $4 \mathrm{~mm}$ devices powered at $300 \mathrm{~V}$ is lower than the same devices powered at $260 \mathrm{~V}$, which defies the principles of electrostatics. This means the quantity of error in the current optics-based measurement system is likely too large to draw conclusions between $4 \mathrm{~mm}$ device deflections.

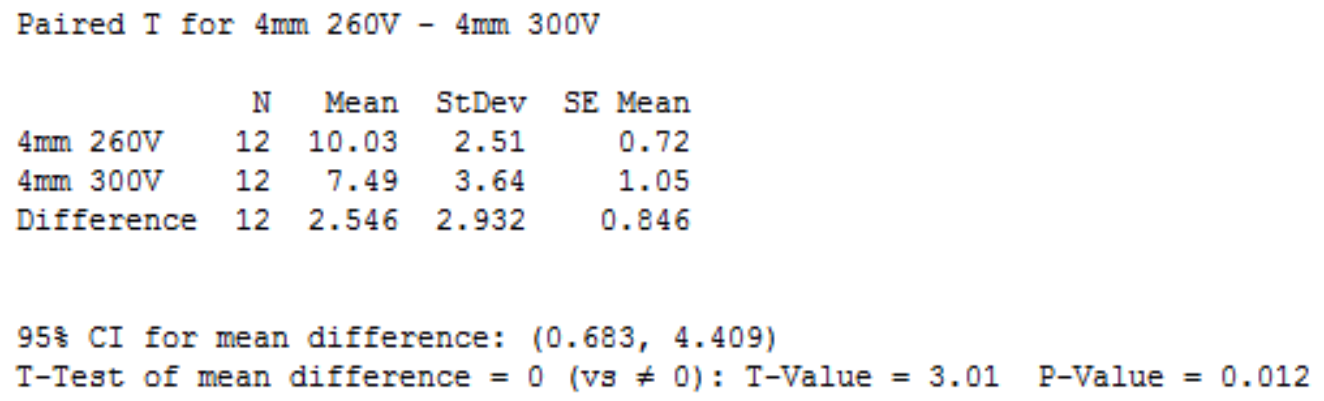

Figure 37: Minitab output for a paired t-test comparing laser deflection from $4 \mathrm{~mm}$ diaphragms operated at both 260 and $300 \mathrm{~V}$.

Additional paired t-tests were performed to compare the deflections at $260 \mathrm{~V}$ and $300 \mathrm{~V}$ for 5 and $7 \mathrm{~mm}$ devices. Table 19 summarizes this information, in which the null hypothesis is always equivalence of means and a rejection of that hypothesis can be interpreted to mean the sample population with the larger mean is significantly different than the lesser mean within a 95\% confidence interval.

Table 19: Paired t-tests were performed for both 5 and $7 \mathrm{~mm}$ devices to compare deflections at 260 and $300 \mathrm{~V}$ for each.

\begin{tabular}{|c|c|c|c|}
\hline Devices compared & T-Value & P-Value & Conclusion \\
\hline $5 \mathrm{~mm}$ & -1.49 & 0.165 & Fail to Reject $\mathrm{H}_{0}$ \\
\hline $7 \mathrm{~mm}$ & -7.66 & 0.001 & Reject $\mathrm{H}_{0}$ \\
\hline
\end{tabular}


As can be seen from Table 19, the $7 \mathrm{~mm}$ devices were the only ones capable of deflecting at statistically different amplitudes while complying with the expected results based on electrostatic principles.

Due to noise being one of the main issues with the current system, it was closer observed to see if a root cause could be determined. The AC test results were reordered from least to greatest noise during testing so that device size, device number, time of test, and frequency could be observed for patterns. Unfortunately, the reordered data in all the aforementioned fields was highly randomized and no conclusions could be drawn. Non-tested factors must therefore be playing a role in the inaccuracy of the test setup. Speculated factors include the consistency of the HeNe laser intensity and uniformity throughout its $2 \mathrm{~mm}$ beam diameter and the stability of the second story location of the microfabrication lab. Changes in ambient lighting that reach the PSD could occur on some scale due to people walking by outside the microfabrication lab because the test bed is located next to a window. Vibrations can often be felt when standing in the microfabrication lab, so some degree of these vibrations undoubtedly are introduced into the system. The long-term positional drift of the PSD is also a factor in the reliability of optical testing.

As can be seen in the DC testing results in Table 18, diaphragm deflections were calculated that surpass the electrode gap. There is clearly a large amount of inaccuracy with the alignment of the laser in the exact center of the diaphragm. Additionally, assumption 2 made in Section 5.1 that a circular section of the deflected diaphragm reaches an essentially flat point of peak deflection is likely incorrect. A safe assumption is the actual deflections of all devices are less than those recorded in the data section of this report, although this could very well not be the case if the test setup mimicked that of the yellow line in Figure 26. 
The data from Figures 34 (b) and 35 (b) shows two opposing trends upon powering of each respective device. Figure 34 (b) displays a gradually increasing trend towards an equilibrium displacement for the $5 \mathrm{~mm}$ device at $300 \mathrm{~V} \mathrm{DC}$, whereas Figure 35 (b) shows an immediate spike upon powering of the $7 \mathrm{~mm}$ device under the same conditions before it tapers off to a seemingly less-actuated equilibrium state. It is believed that the observed discrepancy stems from the difficulty in locating the device center. Referencing Figure 26 again, the $5 \mathrm{~mm}$ device was most likely directed at the diaphragm in the same fashion as either the red or blue lines. The $7 \mathrm{~mm}$ device results of Figure 35 (b) can then be explained by hitting the device at the same location as the yellow line of Figure 26. For convenience, Figure 38 includes all 3 previously mentioned figures. Under these assumptions, it can be stated that the diaphragms take multiple seconds to realize their full actuation potential, which is far beyond the nanoseconds of delay predicted by capacitive charging and milliseconds predicted for mechanical response to the parallel plate capacitance. 


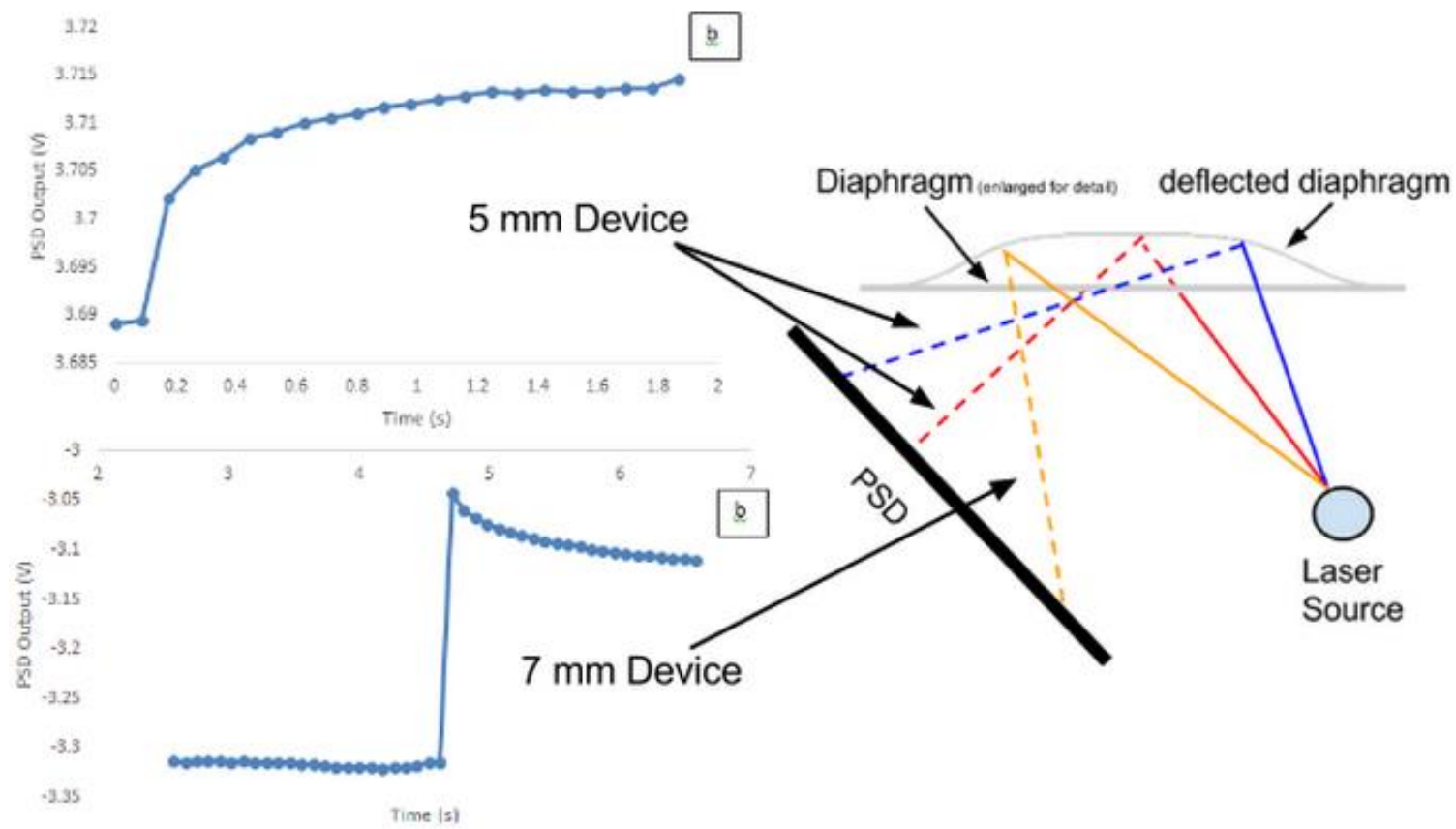

Figure 38: DC testing results plotted and shown with the figure demonstrating laser redirection based on point of incidence on a deflected diaphragm.

\subsection{Acoustic Response Testing}

Acoustic response testing of the actuators was performed using a Vernier microphone connected to the computer using a LabQuest Mini interface and Logger Lite software. Baseline testing was performed using the Vernier microphone to gather data from a piezoelectric actuator with low voltage, $2000 \mathrm{~Hz}$ signals generated by a Keithley 2400 SourceMeter. This test helped establish the acoustic threshold at which it could register variations in sound pressure level (SPL). Based on the calculated acoustic output of the diaphragms, a very quiet response should have been audible at a 1 inch distance from the device surface. The microphone was fixtured at this distance from the device while a range of frequencies around the calculated resonant frequency were applied using the MEMS driver in hopes of triggering the harmonic frequency of the 5 $\mathrm{mm}$ diaphragm. In the microfabrication lab there is a great deal of ambient noise from 
the machinery in the room, so the microphone was not capable of picking up any change in actuation response.

A fixture was then used to hold the microphone 1 inch from the DUT's surface using convoluted foam to provide acoustic insulation. The inside of this acoustically insulating fixture can be seen in Figure 39, which shows the Vernier microphone tip protruding towards the end of the foam that is placed on the testing surface. The full acoustic testing setup including the foam fixture, microphone, and DUT can be seen in Figure 40.

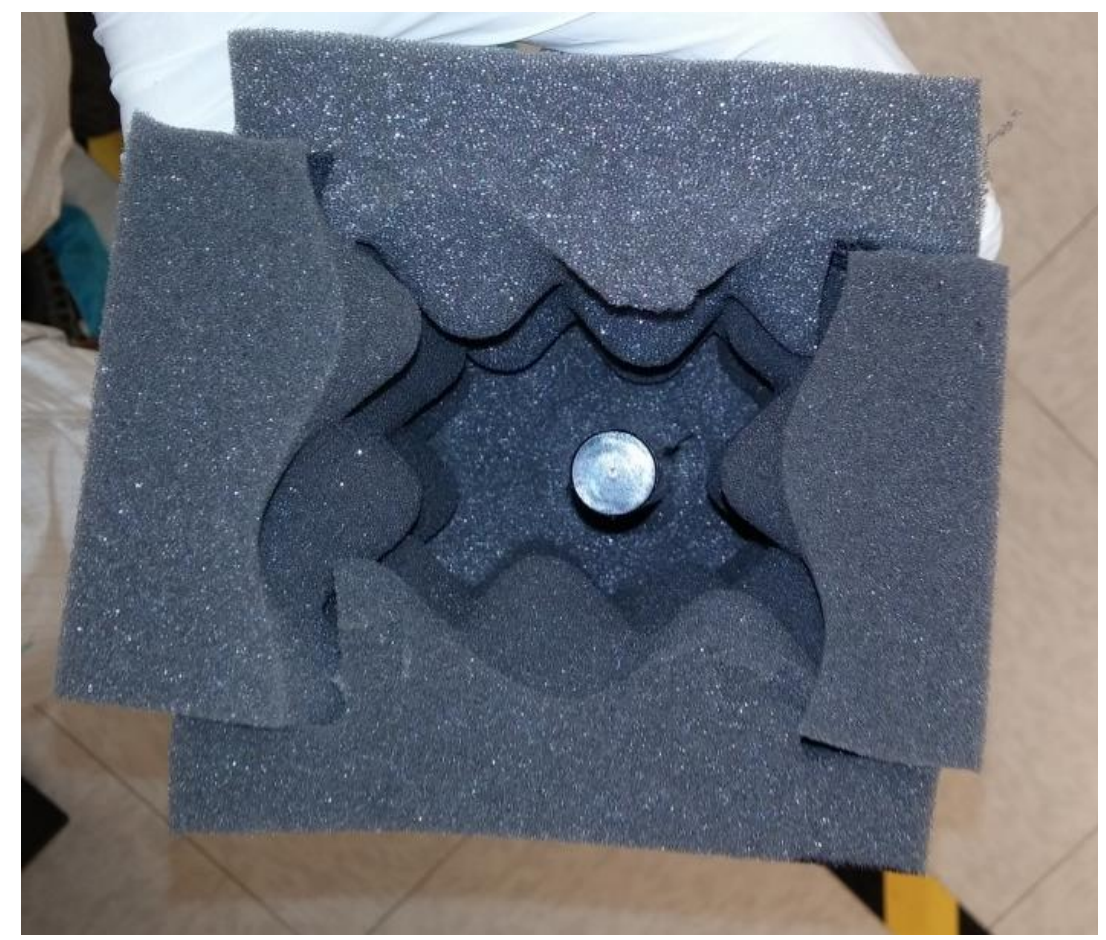

Figure 39: The inside of the acoustic foam fixture with the Vernier microphone inserted. 


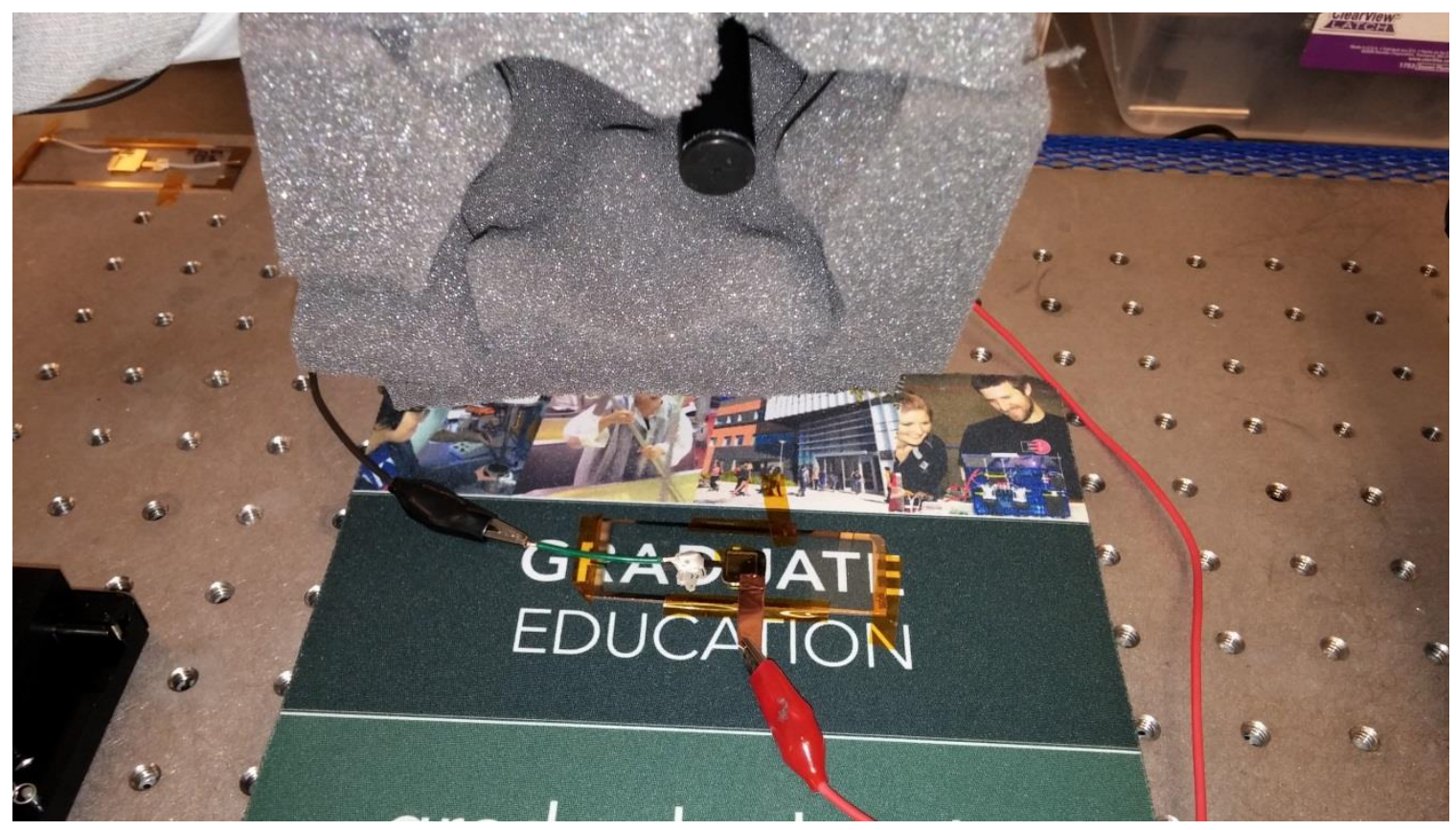

Figure 40: Acoustic testing setup including the DUT connected to the MEMS driver and the acoustic foam fixture lifted from where it sits over the DUT.

Figure 41 plots the offset pressure seen in the acoustic foam fixture without the device being run. This gives a sense of the ambient SPL noise picked up by the Vernier microphone, which sampled at $10 \mathrm{kHz}$. Testing was then performed using the piezoelectric actuating disc at a variety of voltages at $2 \mathrm{kHz}$ to observe the ability of the Vernier microphone to capture fluctuations in SPL. The results of this test can be seen in Figure 42. Note the LoggerPro program output a baseline SPL of 25 , and the data plotted is the offset from said SPL. 


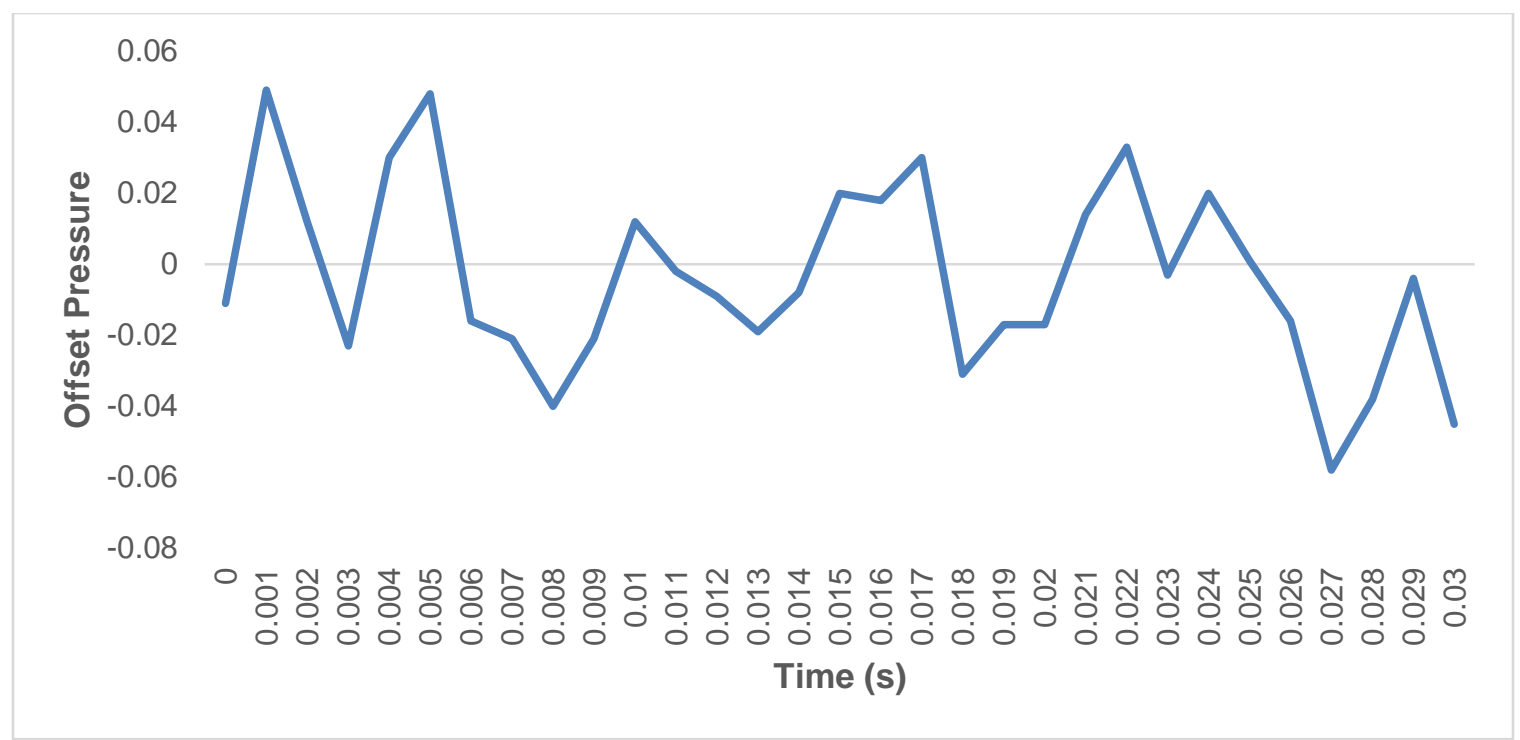

Figure 41: Plot of ambient noise in the acoustic foam fixture.

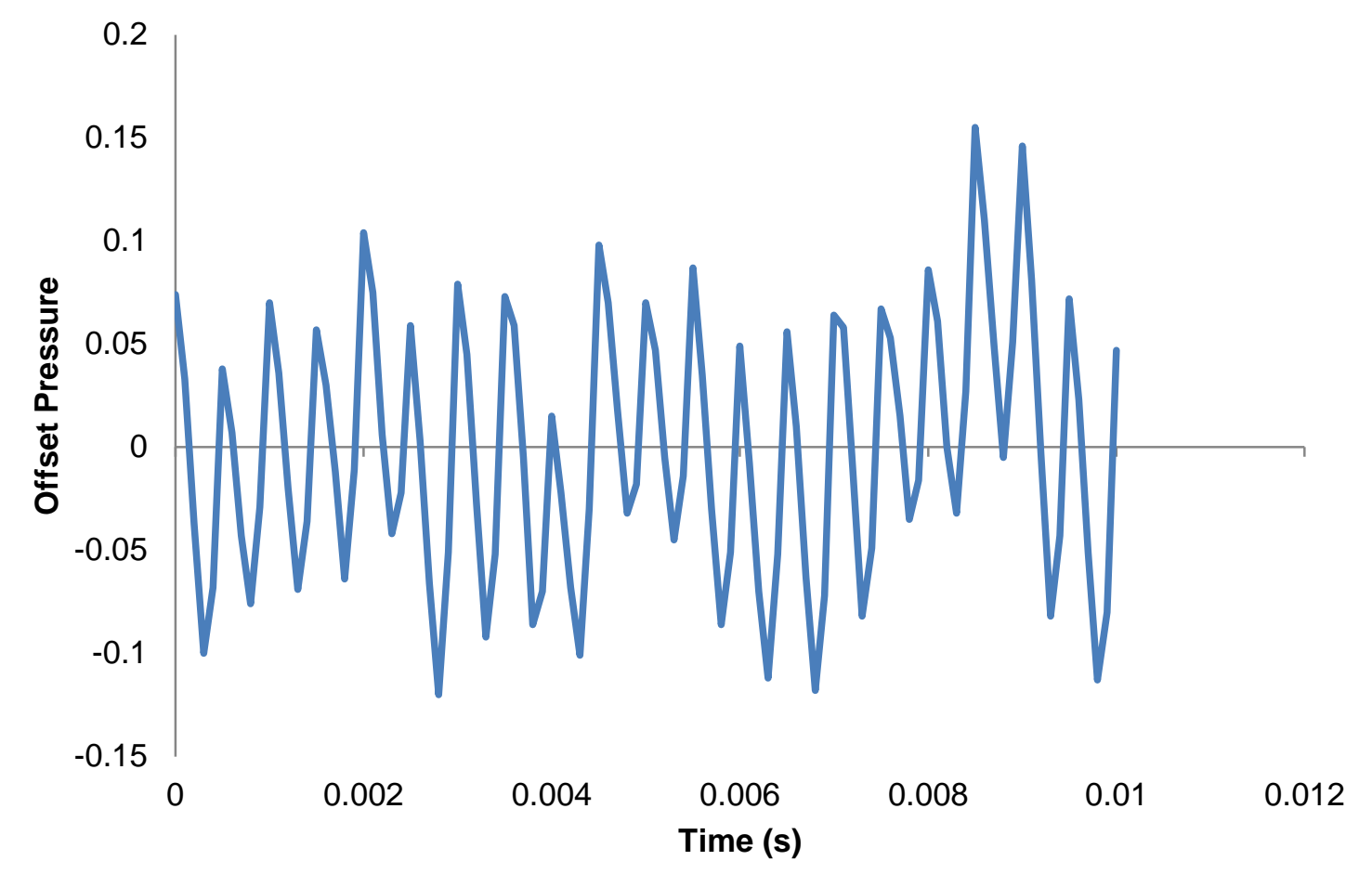

Figure 42: Offset pressure generated by PZT disc operating at 1 VPP and $2 \mathrm{kHz}$ with a $10 \mathrm{kHz}$ sampling rate.

Figure 42 demonstrates a strong signal from the actuating device, with noticeable oscillation of the minima and maxima from the noise of the system. With knowledge of what an audible acoustic response looks like in terms of SPL response, device testing 
was performed using 5 and $7 \mathrm{~mm}$ devices. The $5 \mathrm{~mm}$ devices did not create an audible sound at any frequency tested, but the $7 \mathrm{~mm}$ devices were capable of producing an audible noise when operating between approximately 800 and $3000 \mathrm{~Hz}$ and the observer was within approximately 6 inches of the device. This gave hope of registering an acoustic output using the microphone, although such results were not attained. Tests were performed on $7 \mathrm{~mm}$ devices 1 and 2 at $300 \mathrm{~V}$ and frequencies of 2 and $5 \mathrm{~Hz}$ as well as a sweep from $700-2000 \mathrm{~Hz}$. Figure 43 shows the data from a test of $7 \mathrm{~mm}$ device 2 actuating at $2000 \mathrm{~Hz}$ with a $300 \mathrm{~V}$ potential applied using the MEMS driver. The amplitude of the SPL offset oscillations during diaphragm testing is equivalent to the noise in Figure 41, suggesting that the pressure waves from the diaphragm were not detected by the microphone.

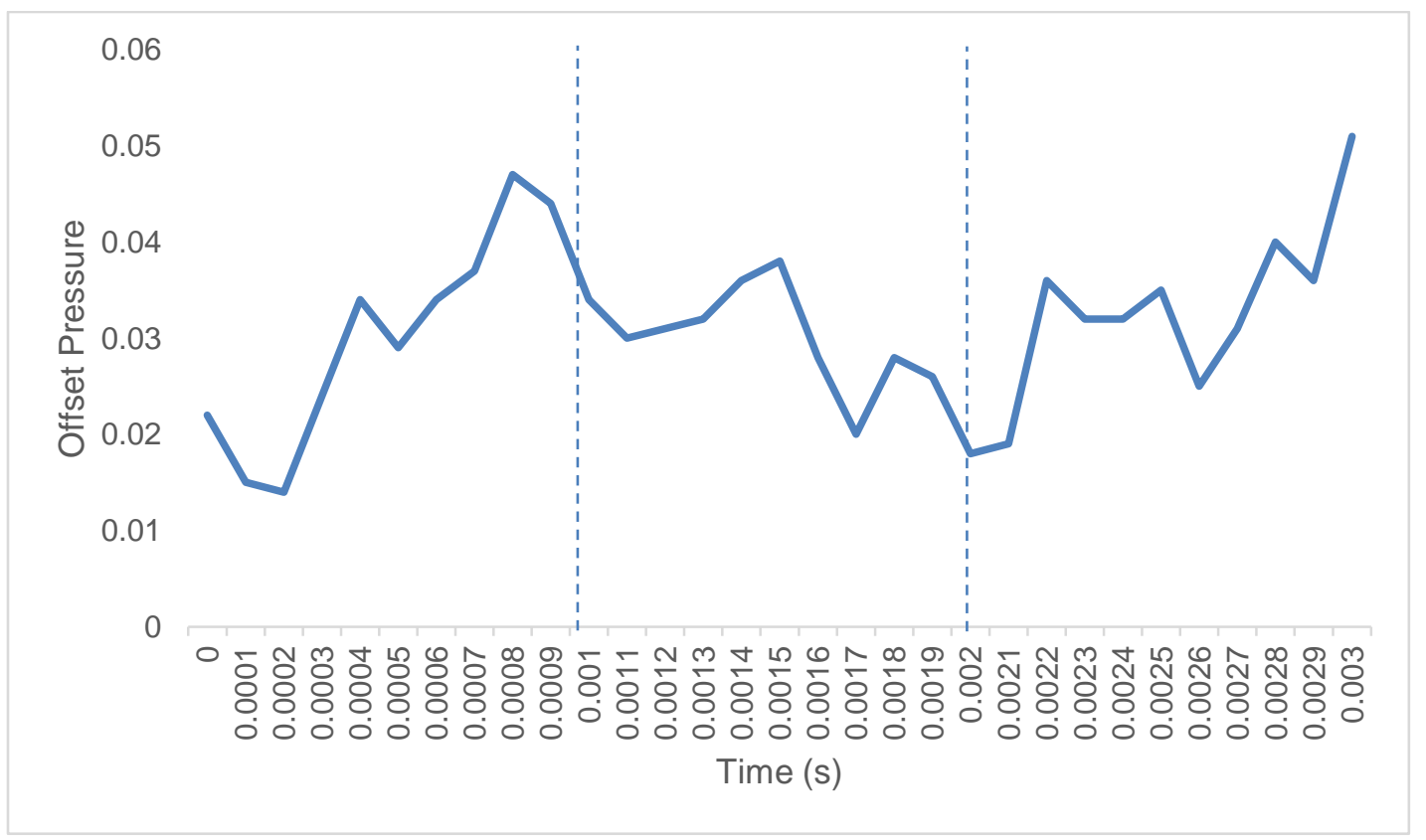

Figure 43: Plot of $7 \mathrm{~mm}$ device 2 actuating at $2000 \mathrm{~Hz}$ with $300 \mathrm{~V}$ applied. 


\subsection{Conclusions}

While actuation and detection of said actuation was achieved using all 3 diaphragm sizes and this optical test bed, there remains much room for improvement in the test setup. Reliability and repeatability are critical factors in an electrostatic actuator, whether the end goal is for hearing aids or microfluidics. One major repeatability issue lies in the failure to locate the laser on the exact center of the diaphragm. Real time tracking of the laser as it scans across the DUT surface while simultaneously seeking a local, non-zero plateau in the change of voltage during deflection is practically impossible. The ability to achieve this feat would vary greatly on a run-by-run and appraiser-by-appraiser basis, meaning the issue lies in the testing setup itself.

The fact that the change oscillation amplitude during $\mathrm{AC}$ testing was proven to be indistinguishable from the system noise suggests the devices themselves can actuate with a reasonable degree of reliability. PSD's used in past optical test beds have been known to suffer from the same drift tendencies seen in this testing, so even though the PSD has a high resolution, the reliability issues that stem from its drift tendencies are significant enough to void any analyses performed on hour-long DC tests. This was seen by the large spikes between each collection point in Figures 34 (a) and 35 (a).

The helium-neon laser used for the test was likely sufficient for this form of analysis if its beam diameter were condensed to a fraction of its current size. The circular laser beam has a high angle of incidence which means on the PSD and diaphragm surfaces, an elliptic shape is formed. For this reason, it is very likely the antipodal points of the major axis are incident on an angled diaphragm surface and assumption 2 of section 5.4 is inadequate for accurate deflection calculations. 
Overall, $7 \mathrm{~mm}$ devices outperformed the smaller ones by far due to the greatly increased electrostatic force generated from the larger area. These were the only devices that successfully achieved both visible and audible actuation at various frequencies. All devices were actuated thousands of times with no sign of damage, so no definitive conclusions can be made on their lifespans. The theoretical deflection of 7 $\mathrm{mm}$ devices is only double that of $5 \mathrm{~mm}$ devices, but the testing results yielded drastically different deflections between the two sizes. 


\section{SECTION 6. RECOMMENDATIONS FOR FUTURE WORK}

\subsection{Diaphragms}

As was established in the optical testing analysis, the $4 \mathrm{~mm}$ and $5 \mathrm{~mm}$ deflections were statistically identical. Neither of those devices produced audible acoustic output, so in the case of researching electrostatic actuation for a micro-speaker application the devices are inadequate as they are currently fabricated. An analysis of which factors effect diaphragm displacement most was performed by Elizabeth Brooks when she was fabricating the first batch of diaphragms from SOI wafers. The results of this analysis, which was performed by differentiating displacement with respect to each factor independently in the critical design parameter equation below, where $d$ is the deflection distance. ${ }^{11}$

$\frac{8}{27} * d_{0}^{2}=0.01303 * \varepsilon * \varepsilon_{0} * V^{2} * \frac{a^{4}}{E * h^{3}}$

The results of this analysis yielded diaphragm thickness to be the critical design factor of utmost significant to determining potential deflection, followed by side length. ${ }^{11}$ In future diaphragm fabrication attempts, creation of a thinner diaphragm is paramount to achieving an acoustic response from a $5 \mathrm{~mm}$ device with the other electrostatic actuation limitations present. Silicon is most understood and experimented with in the Cal Poly Microfabrication Lab and aiming for an $8 \mu \mathrm{m}$ thick by $5 \mathrm{~mm}$ side length silicon diaphragm would deflect approximately the same as the $10 \mu \mathrm{m}$ thick by $7 \mathrm{~mm}$ side length diaphragms that saw the most success in this project. Alternately, experimentation of diaphragm actuation for acoustic purposes has been performed in other labs that saw success using graphene with a thickness of a few hundred nanometers. ${ }^{22}$ 


\subsection{DAQ}

Amplifiers such as the MEMS driver can have a slew rate that causes measurable losses in the efficiency of high frequencies devices such as a microspeaker. Within the scope of this project, there was no such concern because the response time of the Agilent DAQ was so significantly slower than the driver slew rate. Upgrading the DAQ used for optical testing to one capable of at least $6 \mathrm{kHz}$ sampling rate is a requirement for future characterization endeavors. Assuming future characterization of diaphragms will be done using at least $5 \mathrm{~mm}$ diaphragms, a minimum $6 \mathrm{kHz}$ sampling frequency would provide adequate leeway when determining resonant frequency to avoid aliasing based on theoretical calculations. Three potential routes can be taken when upgrading the data collection device: a different type of DAQ such as a DT9839 USB powered sound and vibration DAQ, a signal analyzer, or a digitizing oscilloscope. Using a digitizing oscilloscope is by far the most cost effective means of achieving data collection rates in the gigahertz range so frequency response would no longer be a concern.

\subsection{Test Bed}

Optical characterization has resulted in very poor reliability and repeatability on the part of the test bed itself. A number of steps can be taken to mitigate these issues, the most important of which being to consistently target the center of the diaphragm with a relatively small diameter laser. The most likely means of achieving this is with a beam condenser that can focus the laser down to the smallest point possible on the diaphragm surface. Beam divergence and wavelength are the primary factors determining the laser's minimum spot size, but for future testing a $.5 \mathrm{~mm}(50 \mu \mathrm{m})$ diameter spot size should suffice based on the size of the smallest diaphragm tested and the low deflection angle at its center. This condensed laser point can then be centered with the aid of a 
camera feed that could display a greatly enlarged image of the diaphragm on a computer screen. The fine adjustment stages used to position the DUT in the current system can then be used to their full potential.

Vibrational isolation is another critical component of improved characterization capability for an optics based test setup. There is no reason moving forward with the project that the testing equipment needs to remain in the microfabrication lab, so the option of relocating all equipment to a ground-floor room with more vibrational and acoustic isolation. This has the potential to increase system reliability and repeatability to levels that make long term DC reliability testing viable. In a location with significantly less ambient noise than the microfabrication lab, the pressure waves generated by diaphragms have a much better chance of being detected as well.

A number of additional components can be added to the test bed in order to utilize vibrometry, which has the capability of directly measuring frequency and displacement of small, high frequency devices. Laser-doppler Vibrometry takes advantage of the principles of optical interferometry by using two coherent helium-neon laser beams with overlapping intensities to determine the difference in path length between beams and allow the Doppler effect to be analyzed. ${ }^{21}$ The Doppler effect is based on the frequency shift of a wave coming off a vibrating surface, which is described by the following equation:

$f_{D}=2 * v / \lambda$

where $\mathrm{v}$ is the object velocity and $\lambda$ is the emitted (known) wavelength. With overlapping light sources, an interference factor is created which relates to the path length difference between beams. The light intensity equation behind this theory is as follows: 


$$
I_{\text {tot }}=I_{1}+I_{2}+2 * \sqrt{I_{1} * I_{2} * \cos \left(2 * p i * \frac{r_{1}-r_{2}}{\lambda}\right)}
$$

where $I$ is the intensity of a given light source and $r$ is the path length. In order to use laser-doppler vibrometry, the additional components include 3 beam splitters, a mirror, a Bragg cell (also known as an acoustic-optic modulator), and an optical condensing lens. An example setup of such a system is seen in Figure 44.

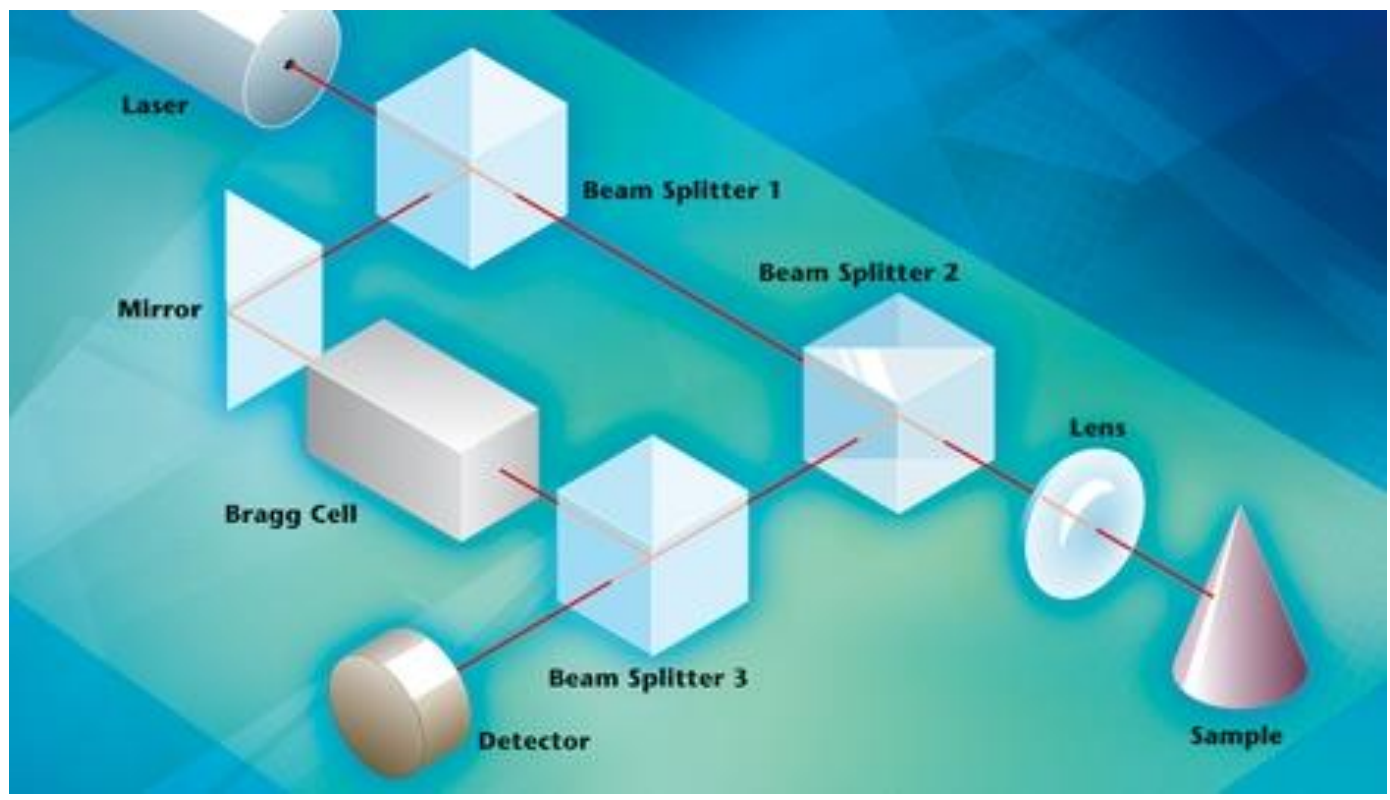

Figure 44: An example setup that can be used in laser-Doppler vibrometry. ${ }^{21}$

Such a system is considerably more complex than the current characterization setup, but with it comes a well-established means of characterizing high frequency actuators with vastly greater accuracy.

\subsection{MEMS Driver Program}

The LabView program that controls the MEMS driver can be modified to allow the capability of a voltage sweep test. This would allow for an automated means of covering a large range of frequencies at small voltage intervals to locate the resonant frequency of the device. A simple loop could be implemented in the program to allow voltage to be 
incremented until an amplitude spike is registered by the DAQ or a maximum frequency has been reached.

\subsection{Data Filtering}

The data analysis process was excessively time consuming for this project due to the large quantity of data that frequently had too great of a noise to signal ratio. Steps can be taken to ease this analysis in the future by applying a low pass filter that can eliminate some of the high frequency distortion caused by the noise of the measurement system. This on top of general noise dampening from relocating the test environment could be the factors that improve system resolution capabilities to the level of individual microns.

\subsection{Finite Element Modelling}

In the future, larger devices (e.g. $7 \mathrm{~mm}$ ) should be modeled and analyzed using a finite element approach assuming they will continue to be fabricated due to their documented acoustic capabilities. FEA of such a device could provide insight as to why its physical response was so different from the 4 and $5 \mathrm{~mm}$ devices. Future analyses should use the built-in electrostatic effects analysis features of Abaqus/CAE rather than the physical pressure loading approach taken in this study. By applying a calculated equivalent pressure load on the diaphragm, a small margin of error is introduced from an early stage of the analysis. If a non-physical approach to measuring the electrode gap is taken, additional accuracy could also be implemented into that parameter for all calculations and modelling. An electrostatic analysis in Abaqus could also be performed on a $5 \mathrm{~mm}$ device to compare the results to those of this physical loading analysis. This would help validate future work done using the equivalent pressure load to calculate electrostatic effects. 


\section{REFERENCES}

1. Gordon E. Moore, "Cramming More Components onto Integrated Circuits,"

Electronics. April 19, 1965: 114-117. Web. 12 March 2015.

2. Halbo, Leif, and Ohlckers, Per. "Micro Structure Technology and Micromachined

Devices." Electronics Components, Packaging and Production. Oslo: Strandberg \& Nilsen Grafisk A.s, 1993. Print.

3. Zhang W-M, Meng G, and Chen D. "Stability, Nonlinearity and Reliability of

Electrostatically Actuated MEMS Devices." Sensors. 2007; 7(5):760-796.

4. C. Liu, Foundations of Mems. Prentice Hall, 2005.

5. Stiff Structures, Compliant Mechanisms, and MEMS: A short course offered at IISc, Bangalore, India. Aug.-Sep., 2003. G. K. Ananthasuresh

6. Tipler, Paul A. Physics for Scientists and Engineers. New York: W.H. Freeman/Worth Publishers, 1999. Print. 22 April 2015.

7. Elie LEFEUVRE, Iman Shahosseini, Johan Moulin, Marion Woytasik, Emile Martincic, et al.. Potential of MEMS technologies for manufacturing of high-fidelity microspeakers. Soci'et'e Francaise d'Acoustique. Acoustics 2012, Apr 2012, Nantes, France. <hal-00811084>

8. Fletcher, Harvey, and W. A. Munson. "Loudness, Its Definition, Measurement and Calculation. The Journal of the Acoustical Society of America 12.4 (1933): 377430.Wiley Online Library. Web. 5 April 2015.

9. "Sound in Air." Help Wiki. The Evergreen State College, 22 Oct. 2013. Web. 01 Apr. 2015

10. E. Cate, M.S. thesis, Design, Implementation, and Test of a Micro Force Displacement System, California Polytechnic State University- San Luis Obispo, 2014 
11. E. Brooks. M.S. Thesis, The Design and Fabrication of an Electrostatically Actuated Diaphragm with a Silicon-on-Insulator Wafer. California Polytechnic State University- San Luis Obispo. 2013.

12. Je, San-Soo, Fernando Rivas, Rodolfo E. Diaz, Juik Kwon, and Joenghwan Kim. "A Compact and Low-Cost MEMS Loudspeaker for Digital Hearing Aids." IEEE Explore, Oct. 2009. Web.

13. Chapter 4 Engineering mechanics for microsystems design. (2008). Informally published manuscript, Retrieved from http://www.engr.sjsu.edu/trhsu/ME189_Chapter 4.pdf.

14. T. Hsu, MEMS \& Microsystems Design and Manufacture. McGraw-Hill. New York, 2002: 96-162.

15. J. Yoon, M.S. thesis, Aluminum/Aluminum Oxide (Yoon, 2010) Structured Microplasma Devices: Paschen's Law and Applications. University of Illinois at Urbana-Champaign, 2010.

16. B. Huigens. M.S. Thesis, Mechanical Reliability of Micro Electrostatic Actuation for MEMS Applications. California Polytechnic State University- San Luis Obispo. 2007.

17. Sputtering Vacuum Deposition Process [Print Graphic]. Retrieved from http://www.tcbonding.com/images/sput_diagram.gif. 2015.

18. Hye Jin Kim, Kunmo Koo, Sung Q Lee, Kang-Ho Park, and Jongdae Kim, "High Performance Piezoelectric Microspeakers and Thin Speaker Array System," ETRI Journal, vol. 31, no. 6, Dec. 2009: 680-687.

19. "Nyquist Theorem - Sampling Rate Versus Bandwidth." National Instruments. N.p., 6 Sept. 2006. Web. 26 Apr. 2015.

20. Sloop, Rick. "Understand Gage R\&R." Qualitymag.com. N.p., 1 Sept. 2009. Web. 12 May 2015. 
21. "Basic Principles of Vibrometry." Polytec GmbH Waldbronn, 2015. Web. 27 Mar. 2015.

22. Zhou, Qin, and A. Zettl. "Electrostatic Graphene Loudspeaker." University of California at Berkeley. Web. 8 June 2015. Retrieved from http://arxiv.org/ftp/arxiv/papers/1303/1303.2391.pdf. 


\section{APPENDICES}

\section{Appendix I. Theoretical Electrostatics Calculations}

Electrostatic actuation calculations for each diaphragm size

\begin{tabular}{|c|c|c|c|c|}
\hline $\begin{array}{c}\text { Diaphragm } \\
\text { Side Length } \\
(\mathrm{mm})\end{array}$ & $\begin{array}{c}\text { Electrode } \\
\text { gap }(\mathrm{m})\end{array}$ & $\begin{array}{c}\text { Force with } \\
300 \mathrm{~V} \\
\text { applied }\end{array}$ & Stress $(\mathrm{Pa})$ & $\begin{array}{c}\text { Displacement } \\
(\mathrm{m})\end{array}$ \\
\hline 4 & 0.00007 & $0.00130 \mathrm{~N}$ & $4.01 \mathrm{E} 6$ & $1.69 \mathrm{E}-6$ \\
\hline 5 & 0.00007 & $0.00203 \mathrm{~N}$ & $6.26 \mathrm{E} 6$ & $4.12 \mathrm{E}-6$ \\
\hline 7 & 0.00007 & $0.00398 \mathrm{~N}$ & $12.27 \mathrm{E} 6$ & $8.08 \mathrm{E}-6$ \\
\hline
\end{tabular}

Theoretical electrostatic force applied by the stated voltage on a $5 \mathrm{~mm}$ diaphragm

\begin{tabular}{|c|c|c|c|c|c|c|}
\hline & \multicolumn{7}{|c|}{ Applied Voltage (V) } \\
\hline Electrode Gap & 200 & 220 & 240 & 260 & 280 & 300 \\
\hline 0.0001 & 0.00044 & 0.00054 & 0.00064 & 0.00075 & 0.00087 & 0.00100 \\
\hline 0.00009 & 0.00055 & 0.00066 & 0.00079 & 0.00092 & 0.00107 & 0.00123 \\
\hline 0.00008 & 0.00069 & 0.00084 & 0.00100 & 0.00117 & 0.00136 & 0.00156 \\
\hline 0.00007 & 0.00090 & 0.00109 & 0.00130 & 0.00153 & 0.00177 & 0.00203 \\
\hline 0.00006 & 0.00123 & 0.00149 & 0.00177 & 0.00208 & 0.00241 & 0.00277 \\
\hline 0.00005 & 0.00177 & 0.00214 & 0.00255 & 0.00299 & 0.00347 & 0.00398 \\
\hline
\end{tabular}

Theoretical deflection in meters due to the electrostatic force on a $5 \mathrm{~mm}$ diaphragm

\begin{tabular}{|c|c|c|c|c|c|c|}
\hline & \multicolumn{7}{|c|}{ Applied Voltage (V) } \\
\hline $\begin{array}{c}\text { Electrode } \\
\text { Gap }(\mathrm{m})\end{array}$ & 200 & 220 & 240 & 260 & 280 & 300 \\
\hline 0.0001 & $8.98 \mathrm{E}-07$ & $1.09 \mathrm{E}-06$ & $1.29 \mathrm{E}-06$ & $1.52 \mathrm{E}-06$ & $1.76 \mathrm{E}-06$ & $2.02 \mathrm{E}-06$ \\
\hline 0.00009 & $1.11 \mathrm{E}-06$ & $1.34 \mathrm{E}-06$ & $1.60 \mathrm{E}-06$ & $1.87 \mathrm{E}-06$ & $2.17 \mathrm{E}-06$ & $2.49 \mathrm{E}-06$ \\
\hline 0.00008 & $1.40 \mathrm{E}-06$ & $1.70 \mathrm{E}-06$ & $2.02 \mathrm{E}-06$ & $2.37 \mathrm{E}-06$ & $2.75 \mathrm{E}-06$ & $3.16 \mathrm{E}-06$ \\
\hline 0.00007 & $1.83 \mathrm{E}-06$ & $2.22 \mathrm{E}-06$ & $2.64 \mathrm{E}-06$ & $3.10 \mathrm{E}-06$ & $3.59 \mathrm{E}-06$ & $4.12 \mathrm{E}-06$ \\
\hline 0.00006 & $2.49 \mathrm{E}-06$ & $3.02 \mathrm{E}-06$ & $3.59 \mathrm{E}-06$ & $4.22 \mathrm{E}-06$ & $4.89 \mathrm{E}-06$ & $5.61 \mathrm{E}-06$ \\
\hline 0.00005 & $3.59 \mathrm{E}-06$ & $4.35 \mathrm{E}-06$ & $5.17 \mathrm{E}-06$ & $6.07 \mathrm{E}-06$ & $7.04 \mathrm{E}-06$ & $8.08 \mathrm{E}-06$ \\
\hline
\end{tabular}




\section{Appendix II. Finite Element Modelling}

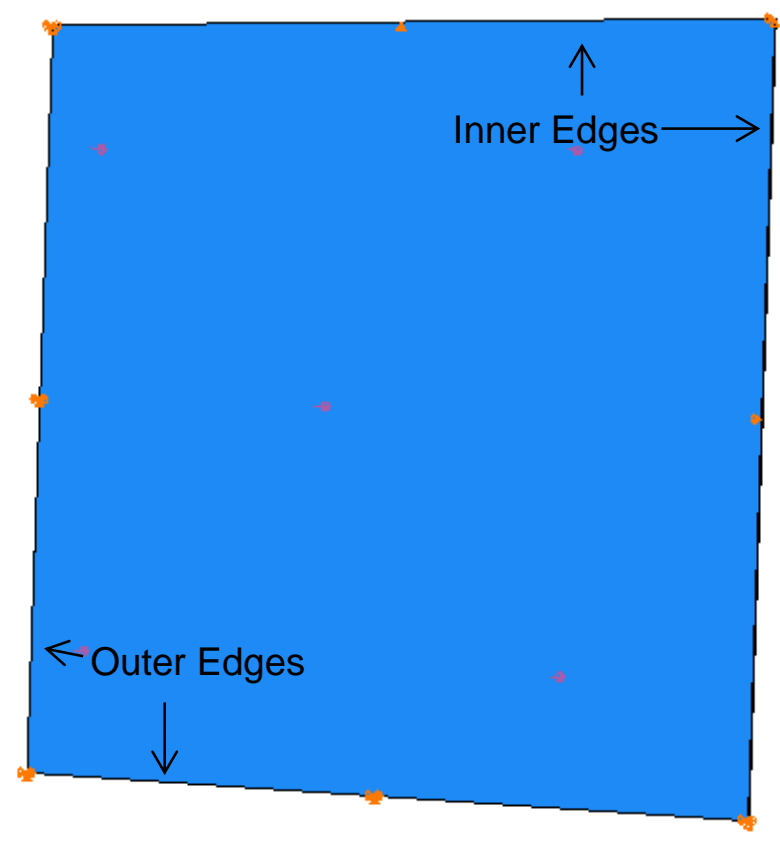

Quarter-model utilizing symmetry of boundary and loading conditions

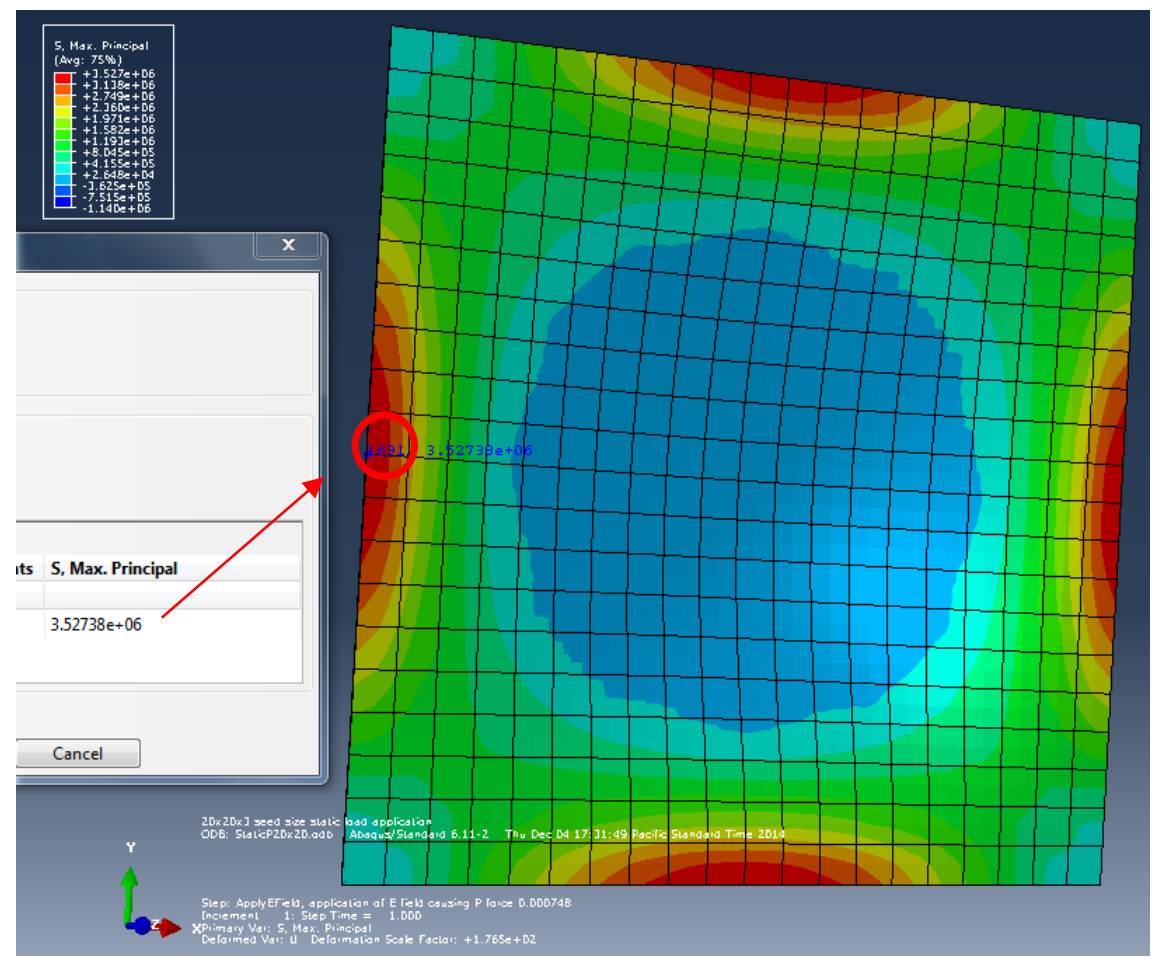

High stress node at middle of silicon edge selected for stress based mesh convergence study 


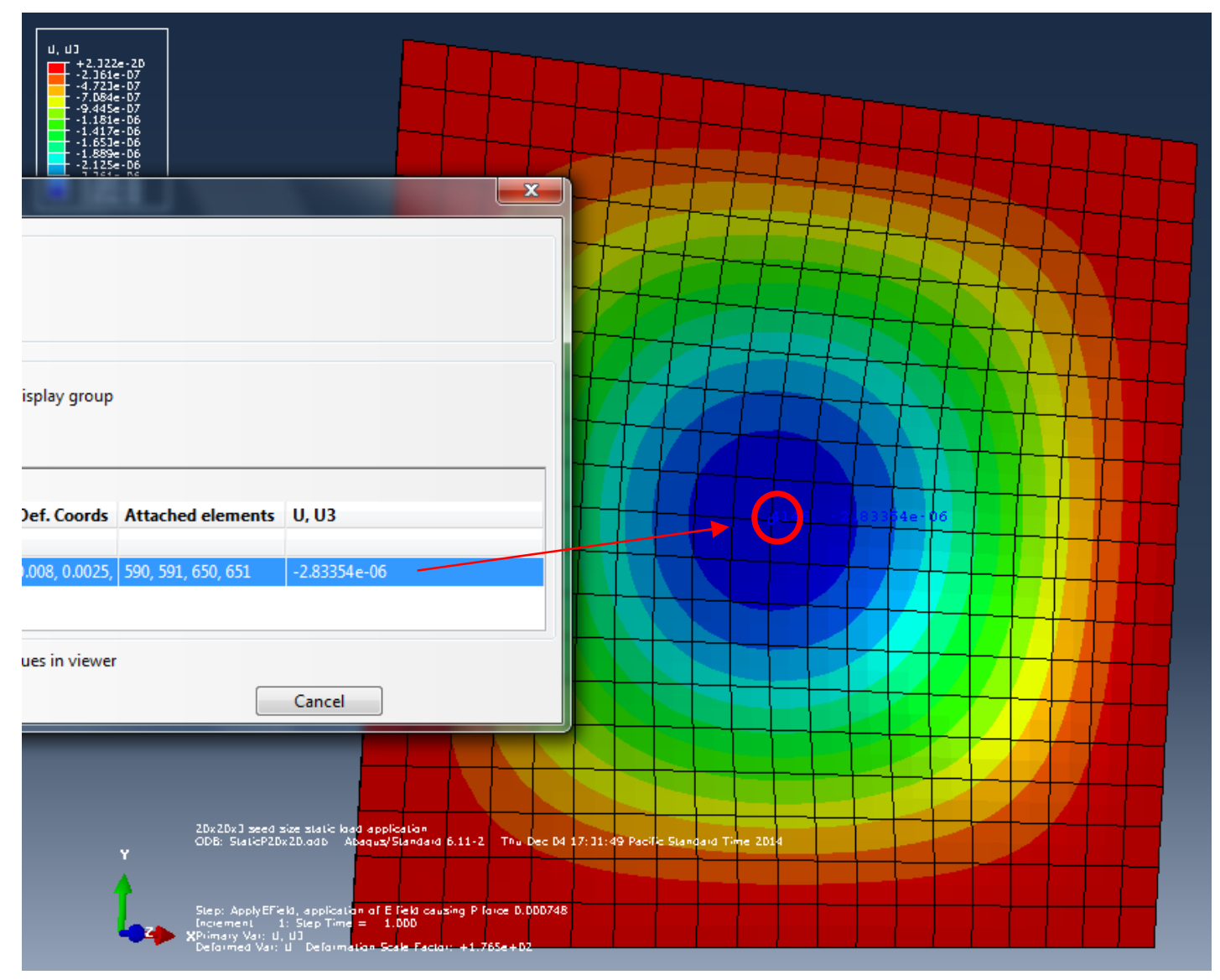

Max displacement node at center of diaphragm selected for mesh convergence check

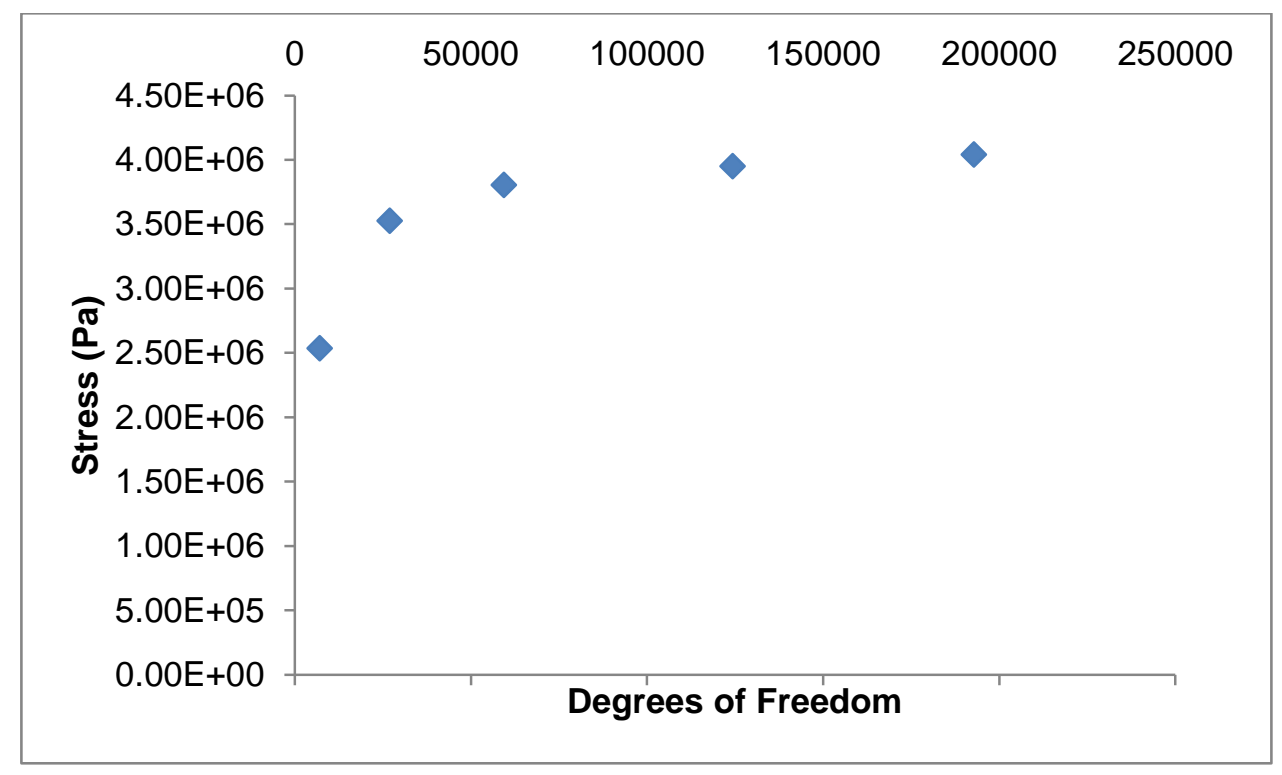

$5 \mathrm{~mm} \times 5 \mathrm{~mm}$ stress based mesh convergence study plot 




Dynamic $2.5 \mathrm{~mm} \times 2.5 \mathrm{~mm}$ quarter-model stress results at frequency $4456 \mathrm{~Hz}$ 


\section{Appendix III. Optical Testing Data}

Deflection from baseline 30 and 60 seconds after powering the $4 \mathrm{~mm}$ devices tested at 2 and $5 \mathrm{~Hz}, 260 \mathrm{~V}$

\begin{tabular}{|c|c|c|c|r|r|r|}
\hline $\begin{array}{c}\text { Device } \\
\text { Size }(\mathrm{mm})\end{array}$ & $\begin{array}{c}\text { Device } \\
\#\end{array}$ & Rep & $\begin{array}{c}\text { Frequency } \\
(\mathrm{Hz})\end{array}$ & $\begin{array}{l}\text { Immediate PSD } \\
\text { Deflection (um) }\end{array}$ & $\begin{array}{l}\text { 30 Sec PSD } \\
\text { Deflection (um) }\end{array}$ & $\begin{array}{l}\text { 60 Sec PSD } \\
\text { Deflection (um) }\end{array}$ \\
\hline 4 & 1 & 1 & 2 & 9.326915217 & 10.40791522 & 11.35711522 \\
\hline 4 & 1 & 2 & 2 & 9.422106522 & 10.33170652 & 9.343006522 \\
\hline 4 & 1 & 3 & 2 & 7.518045652 & 10.61554565 & 14.74184565 \\
\hline 4 & 2 & 1 & 2 & 13.54228913 & 14.33328913 & 16.00748913 \\
\hline 4 & 2 & 2 & 2 & 13.13970652 & 13.33740652 & 16.05310652 \\
\hline 4 & 2 & 3 & 2 & 12.78172174 & 14.65372174 & 16.59162174 \\
\hline 4 & 1 & 1 & 5 & 8.406523913 & 9.540323913 & 7.523323913 \\
\hline 4 & 1 & 2 & 5 & 4.876791304 & 3.479391304 & 4.230891304 \\
\hline 4 & 1 & 3 & 5 & 8.900169565 & 10.12616957 & 6.645869565 \\
\hline 4 & 2 & 1 & 5 & 10.60881522 & 10.62201522 & 12.41491522 \\
\hline 4 & 2 & 2 & 5 & 10.84012391 & 11.90792391 & 6.226023913 \\
\hline 4 & 2 & 3 & 5 & 11.01867826 & 9.172978261 & 11.55917826 \\
\hline
\end{tabular}

Deflection from baseline 30 and 60 seconds after powering the $5 \mathrm{~mm}$ devices at 2 and $5 \mathrm{~Hz}, 260 \mathrm{~V}$

\begin{tabular}{|c|c|c|c|r|r|r|}
\hline $\begin{array}{c}\text { Device } \\
\text { Size }(\mathrm{mm})\end{array}$ & $\begin{array}{c}\text { Device } \\
\#\end{array}$ & Rep & $\begin{array}{c}\text { Frequency } \\
(\mathrm{Hz})\end{array}$ & $\begin{array}{r}\text { Immediate PSD } \\
\text { Deflection (um) }\end{array}$ & $\begin{array}{l}\text { 30 Sec PSD } \\
\text { Deflection (um) }\end{array}$ & $\begin{array}{l}\text { 60 Sec PSD } \\
\text { Deflection (um) }\end{array}$ \\
\hline 5 & 1 & 1 & 2 & 10.54236087 & 7.07526087 & 4.68916087 \\
\hline 5 & 1 & 2 & 2 & 6.271395652 & 7.932395652 & 5.849495652 \\
\hline 5 & 1 & 3 & 2 & 24.01639783 & 21.97299783 & 21.43249783 \\
\hline 5 & 2 & 1 & 2 & 5.490130435 & 3.235830435 & 0.297169565 \\
\hline 5 & 2 & 2 & 2 & 14.38518043 & 10.72028043 & 7.833280435 \\
\hline 5 & 2 & 3 & 2 & 13.58726957 & 11.10896957 & 9.803769565 \\
\hline 5 & 1 & 1 & 5 & 11.5207 & 12.3513 & 19.3382 \\
\hline 5 & 1 & 2 & 5 & 11.29693043 & 11.96923043 & 11.99563043 \\
\hline 5 & 1 & 3 & 5 & 5.973567391 & 9.467067391 & 8.834267391 \\
\hline 5 & 2 & 1 & 5 & 10.32998696 & 11.71418696 & 0.983286957 \\
\hline 5 & 2 & 2 & 5 & 8.604776087 & 4.030276087 & 7.307023913 \\
\hline 5 & 2 & 3 & 5 & 6.976317391 & 4.352917391 & 3.219217391 \\
\hline
\end{tabular}


Deflection from baseline 30 and 60 seconds after powering the $7 \mathrm{~mm}$ devices at 2 and $5 \mathrm{~Hz}, 260 \mathrm{~V}$

\begin{tabular}{|c|c|c|c|c|c|c|}
\hline $\begin{array}{c}\text { Device } \\
\text { Size }(\mathrm{mm})\end{array}$ & $\begin{array}{c}\text { Device } \\
\#\end{array}$ & Rep & $\begin{array}{c}\text { Frequency } \\
(\mathrm{Hz})\end{array}$ & $\begin{array}{c}\text { Immediate PSD } \\
\text { Deflection (um) }\end{array}$ & $\begin{array}{c}30 \text { Sec PSD } \\
\text { Deflection (um) }\end{array}$ & $\begin{array}{c}60 \text { Sec PSD } \\
\text { Deflection (um) }\end{array}$ \\
\hline 7 & 1 & 1 & 2 & 574.72275 & 588.18255 & 595.06405 \\
\hline 7 & 1 & 2 & 2 & 593.0275935 & 606.1445935 & 611.0618935 \\
\hline 7 & 1 & 3 & 2 & 96.18276522 & 87.28426522 & 81.89236522 \\
\hline 7 & 2 & 1 & 2 & 52.75642174 & 52.36092174 & 51.75452174 \\
\hline 7 & 2 & 2 & 2 & 65.01535652 & 65.00215652 & 65.38445652 \\
\hline 7 & 2 & 3 & 2 & 58.27691739 & 60.50481739 & 59.88521739 \\
\hline 7 & 1 & 1 & 5 & 595.9322891 & 604.1584891 & 607.1112891 \\
\hline 7 & 1 & 2 & 5 & 592.4104783 & 599.5158783 & 602.6006783 \\
\hline 7 & 1 & 3 & 5 & 97.31543261 & 92.78043261 & 83.27553261 \\
\hline 7 & 2 & 1 & 5 & 61.47575 & 66.77535 & 62.38535 \\
\hline 7 & 2 & 2 & 5 & 61.57523478 & 60.96883478 & 48.39223478 \\
\hline 7 & 2 & 3 & 5 & 66.7535413 & 63.5105413 & 61.5726413 \\
\hline
\end{tabular}

Deflection from baseline 30 and 60 seconds after powering the $4 \mathrm{~mm}$ devices tested at 2 and $5 \mathrm{~Hz}, 300 \mathrm{~V}$

\begin{tabular}{|c|c|c|c|c|c|c|}
\hline $\begin{array}{c}\text { Device } \\
\text { Size }(\mathrm{mm})\end{array}$ & $\begin{array}{c}\text { Device } \\
\#\end{array}$ & Rep & $\begin{array}{c}\text { Frequency } \\
(\mathrm{Hz})\end{array}$ & $\begin{array}{c}\text { Immediate PSD } \\
\text { Deflection (um) }\end{array}$ & $\begin{array}{c}30 \text { Sec PSD } \\
\text { Deflection (um) }\end{array}$ & $\begin{array}{c}60 \text { Sec PSD } \\
\text { Deflection (um) }\end{array}$ \\
\hline 4 & 1 & 1 & 2 & 3.562006522 & 5.117606522 & 3.601506522 \\
\hline 4 & 1 & 2 & 2 & 6.8239 & 5.1233 & 5.4133 \\
\hline 4 & 1 & 3 & 2 & 7.04166087 & 2.16406087 & 3.46916087 \\
\hline 4 & 2 & 1 & 2 & 10.36211087 & 13.34141087 & 11.95721087 \\
\hline 4 & 2 & 2 & 2 & 9.5496 & 9.9978 & 11.2766 \\
\hline 4 & 2 & 3 & 2 & 7.908273913 & 7.578773913 & 7.117373913 \\
\hline 4 & 1 & 1 & 5 & 4.77193913 & 4.61373913 & 3.42723913 \\
\hline 4 & 1 & 2 & 5 & 3.844508696 & 3.567708696 & 3.778608696 \\
\hline 4 & 1 & 3 & 5 & 2.092397826 & 6.363597826 & 0.932297826 \\
\hline 4 & 2 & 1 & 5 & 9.985708696 & 8.904708696 & 11.8445087 \\
\hline 4 & 2 & 2 & 5 & 15.19564348 & 7.892243478 & 6.165343478 \\
\hline 4 & 2 & 3 & 5 & 8.694719565 & 5.952619565 & 6.427219565 \\
\hline
\end{tabular}


Oscillation amplitudes immediately, 30 seconds, and 60 seconds after powering of $4 \mathrm{~mm}$ devices tested at 2 and $5 \mathrm{~Hz}, 300 \mathrm{~V}$

\begin{tabular}{|c|c|c|c|c|c|c|}
\hline $\begin{array}{c}\text { Device } \\
\text { Size }(\mathrm{mm})\end{array}$ & $\begin{array}{c}\text { Device } \\
\#\end{array}$ & Rep & $\begin{array}{c}\text { Frequency } \\
(\mathrm{Hz})\end{array}$ & $\begin{array}{c}\text { Immediate } \\
\text { Oscillation } \\
\text { Amplitude (us) }\end{array}$ & $\begin{array}{c}30 \mathrm{sec} \\
\text { oscillation } \\
\text { amplitude (us) }\end{array}$ & $\begin{array}{c}60 \text { sec } \\
\text { oscillation } \\
\text { amplitude (us) }\end{array}$ \\
\hline 4 & 1 & 1 & 2 & 4.2318 & 8.2394 & 6.8683 \\
\hline 4 & 1 & 2 & 2 & 8.648 & 4.9436 & 5.1809 \\
\hline 4 & 1 & 3 & 2 & 4.4953 & 3.4012 & 5.8664 \\
\hline 4 & 2 & 1 & 2 & 9.8081 & 17.3751 & 9.5444 \\
\hline 4 & 2 & 2 & 2 & 12.3524 & 8.2789 & 13.5653 \\
\hline 4 & 2 & 3 & 2 & 10.77 & 11.4688 & 4.97 \\
\hline 4 & 1 & 1 & 5 & 7.5538 & 4.1658 & 4.904 \\
\hline 4 & 1 & 2 & 5 & 4.2712 & 4.1263 & 2.2938 \\
\hline 4 & 1 & 3 & 5 & 5.8928 & 8.5161 & 3.5067 \\
\hline 4 & 2 & 1 & 5 & 10.0454 & 7.5538 & 7.2111 \\
\hline 4 & 2 & 2 & 5 & 18.4034 & 7.3956 & 11.2842 \\
\hline 4 & 2 & 3 & 5 & 6.3937 & 7.1979 & 11.1524 \\
\hline
\end{tabular}

Deflection from baseline 30 and 60 seconds after powering the $4 \mathrm{~mm}$ devices tested at 2 and $5 \mathrm{~Hz}, 300 \mathrm{~V}$

\begin{tabular}{|c|c|c|c|c|c|c|}
\hline $\begin{array}{c}\text { Device } \\
\text { Size }(\mathrm{mm})\end{array}$ & $\begin{array}{c}\text { Device } \\
\#\end{array}$ & Rep & $\begin{array}{c}\text { Frequency } \\
(\mathrm{Hz})\end{array}$ & $\begin{array}{c}\text { Immediate PSD } \\
\text { Deflection (um) }\end{array}$ & $\begin{array}{c}30 \text { Sec PSD } \\
\text { Deflection (um) }\end{array}$ & $\begin{array}{c}\text { 60 Sec PSD } \\
\text { Deflection } \\
\text { (um) }\end{array}$ \\
\hline 4 & 1 & 1 & 2 & 3.562006522 & 5.117606522 & 3.601506522 \\
\hline 4 & 1 & 2 & 2 & 6.8239 & 5.1233 & 5.4133 \\
\hline 4 & 1 & 3 & 2 & 7.04166087 & 2.16406087 & 3.46916087 \\
\hline 4 & 2 & 1 & 2 & 10.36211087 & 13.34141087 & 11.95721087 \\
\hline 4 & 2 & 2 & 2 & 9.5496 & 9.9978 & 11.2766 \\
\hline 4 & 2 & 3 & 2 & 7.908273913 & 7.578773913 & 7.117373913 \\
\hline 4 & 1 & 1 & 5 & 4.77193913 & 4.61373913 & 3.42723913 \\
\hline 4 & 1 & 2 & 5 & 3.844508696 & 3.567708696 & 3.778608696 \\
\hline 4 & 1 & 3 & 5 & 2.092397826 & 6.363597826 & 0.932297826 \\
\hline 4 & 2 & 1 & 5 & 9.985708696 & 8.904708696 & 11.8445087 \\
\hline 4 & 2 & 2 & 5 & 15.19564348 & 7.892243478 & 6.165343478 \\
\hline 4 & 2 & 3 & 5 & 8.694719565 & 5.952619565 & 6.427219565 \\
\hline
\end{tabular}




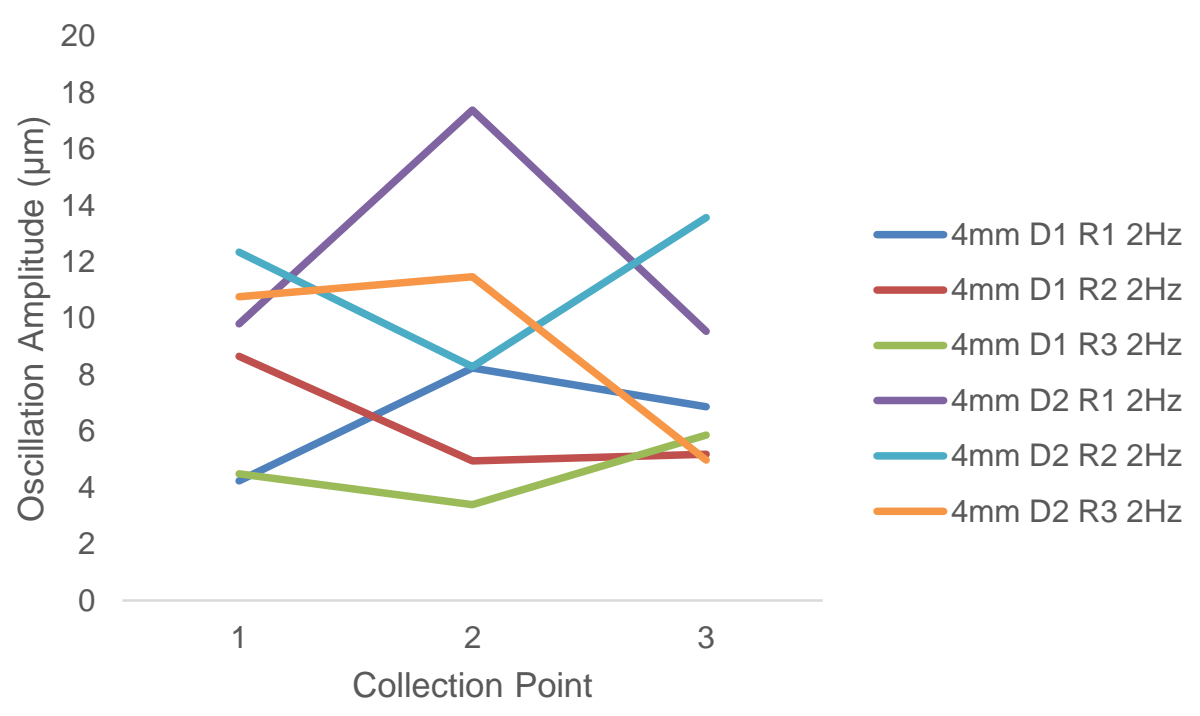

Oscillation amplitudes over time for $4 \mathrm{~mm}$ devices tested at $300 \mathrm{~V}$ for 1 minute (device number is denoted by $\mathrm{D \#}$ and replicate by $\mathrm{R \#}$ )

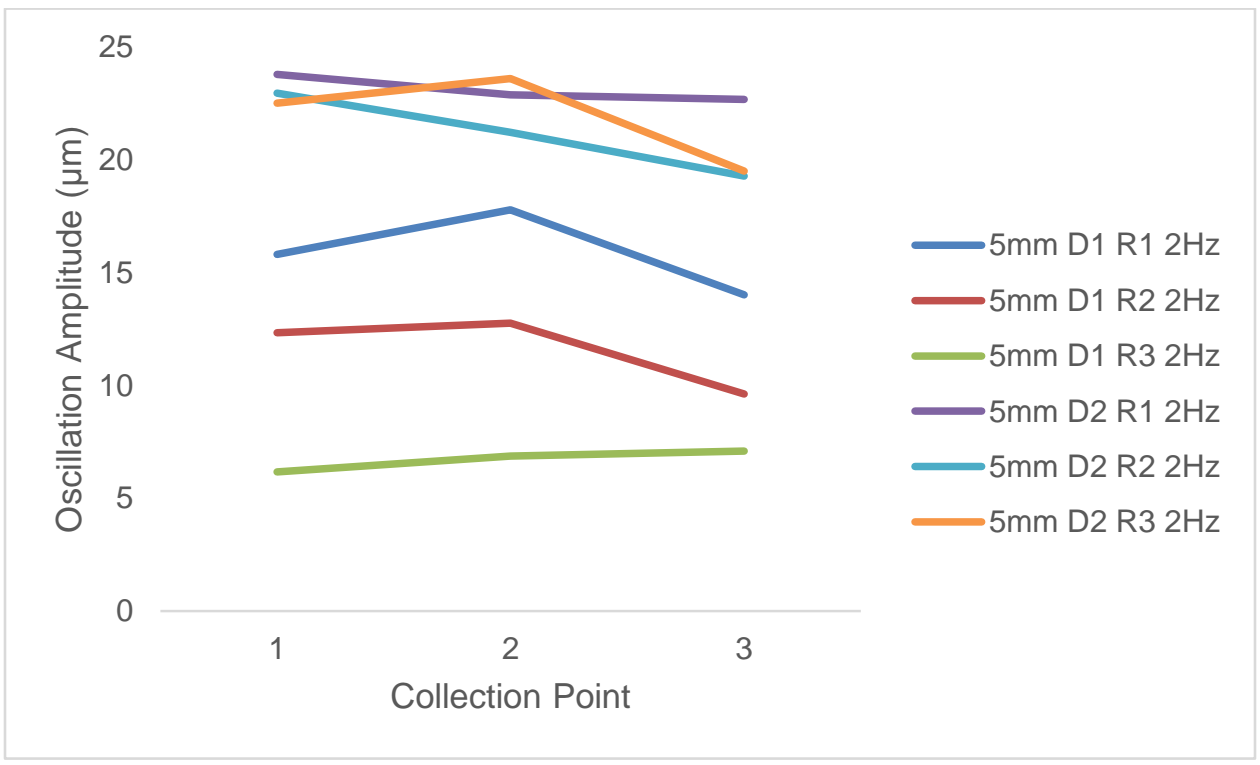

Oscillation amplitudes over time for $5 \mathrm{~mm}$ devices tested at $300 \mathrm{~V}$ for 1 minute 


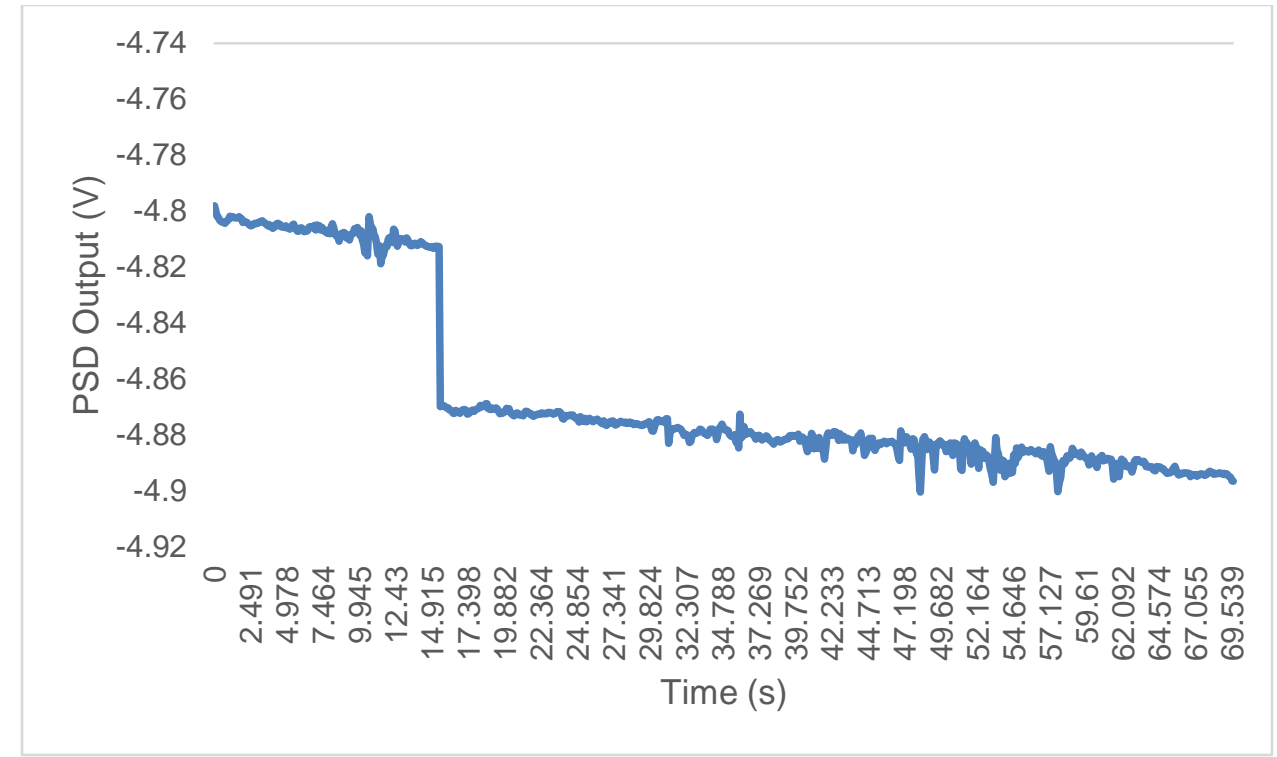

Immediate deflection on powering $5 \mathrm{~mm}$ device 2 with $300 \mathrm{~V}$ DC.

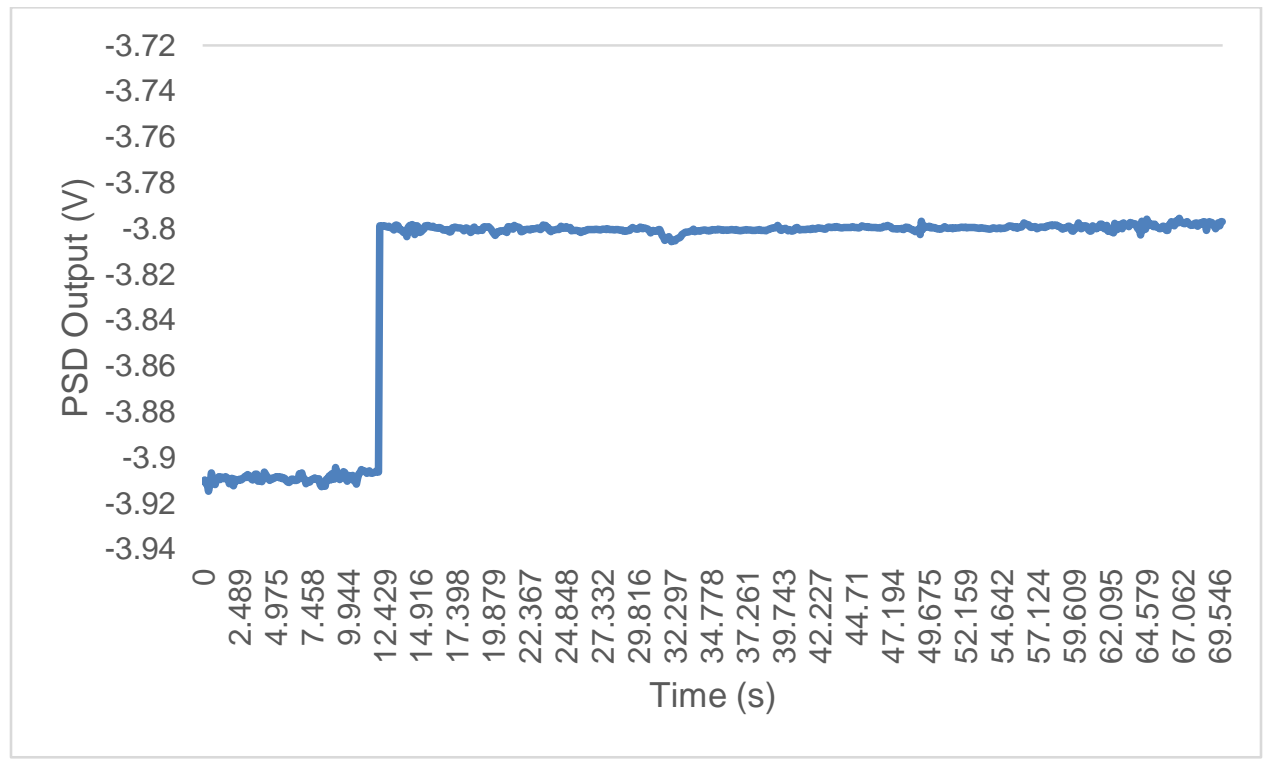

Immediate deflection on powering $7 \mathrm{~mm}$ device 2 with $300 \mathrm{~V} \mathrm{DC}$. 